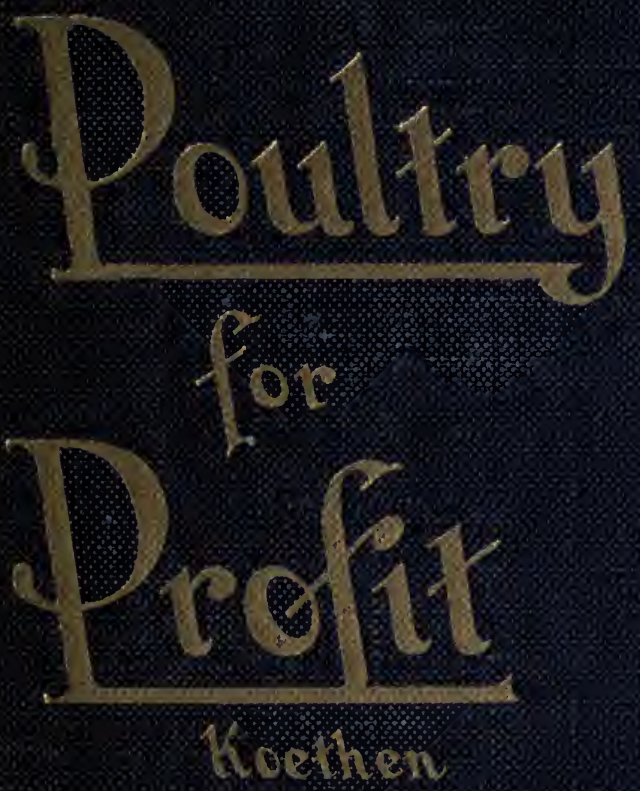



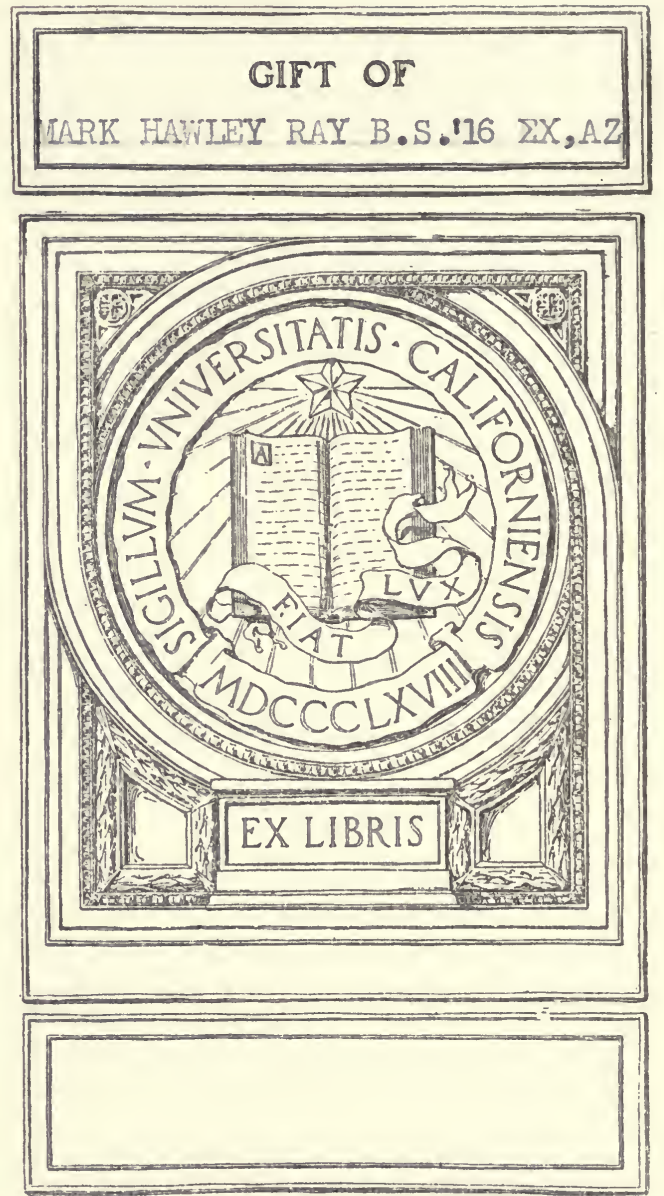




fean A. Foethen. 


\section{POULTRY FOR PROFIT}

A PRACTICAL MANUAL FOR BEGINNERS, FARMERS AND SIDE - L I NE POUL TRYMEN

B Y

JEAN A. KOETHEN

CULTIVATOR PUBLISHING CO. LOS ANGELES, CAL. 
$5 F 487$ $k 6$ Copyright 1915 by Cuitivator Pubiishing Company Gigt of Mark Hawley Ray 


\section{Acknowledgement and Explanation}

This book is designed as a simple outline of the principles of poultry culture and a resumé of the most up-to-date methods in use among practical poultrymen. There is no best method for any part of poultry work, but there are a few broad principles underlying all, which must be grasped by the learner who is seeking for best results. Naturally, such a book must be largely a compilation, and the writer acknowledges her indebtedness to the bulletins of the Missouri, Oregon, California, Iowa, Indiana, Maine and New York Experiment Stations, to Robinson's "Principles and Practice of Poultry Culture," Milo Hasting's "Dollar Hen," Brigham's "Progressive Poultry Culture," the Reliable Poultry Journal Publishing Company's Turkey and Duck Books, I. K. Felch's "Poultry Culture," and many current publications which cannot be specifically mentioned here.

Grateful acknowledgment is also made of the courtesy of the Missouri, California and Oregon Experiment Stations for the loan of valuable photographs.

Los Angeles, Cal.

JEAN A. KoETHEN.

Jan. 15, 1915. 



\section{Table of Contents}

CHAPTER

PAGE

Acknowledgment and Explanation...

I. Making a Beginning............ 9- 24

II. Housing and Yarding.......... 25- 39

III. Incubation .............. 40-63

IV. Brooding ................ 64- 81

V. Feeding ................. 82-113

VI. Breeding . . . . . . . . . . . . . 114-131

VII. Marketing . . . . . . . . . . . . . 132-141

VIII. Sanitation and Hygiene........... 142-159

IX. Fixtures and Conveniences. . . . . . . 160-169

X. Diseases and Vices.............170-196

XII. Ducks and Geese. . . . . . . . . . . . . . 213-224

XI. Turkeys ...................197-212

\section{Text Figures}

PAGE

Double Runs at Front of House (Fig. 3) ..... 26 Double Runs, Front and Rear (Fig. 4) ...... 26 Triple Yard System (Fig. 5) ............ 27 Canvas Covered Scratching Shed (Fig. 8) ..... 32 Framework for Portable Colony House (Fig. 9) 33 Floor Plan for Double House (Fig. 13) ...... 36 Housing and Yarding (Fig. 16) ........... 37 Diagram Showing Air Cells (Fig. 19) ....... 60 Toe Markings (Fig. 20)............... 62 Coop for Chicks (Fig. 23) .............. 79 Felch Line Breeding Chart (Fig. 27) . . . . . 122 Feed Hopper (Figs. 28 and 29) ........... 138 Diagram Missouri Trapnest (Fig. 39) . . . . . 167 Homemade Trapnest. ..............168, 169 


\section{Plates}

The Author .................. Frontisipece

FACING PAGE

Lady Show-You ................... 9

Scratching-Shed House (Fig. 1) ......... 25

Shed-Roof Colony House (Fig. 2) .......... 25

Colony Houses (Fig. 6) . ............... 29

Colony House with Scratching Shed (Fig. 7) .. 29

Interior of Laying House (Fig. 10) ......... 33

Front of Model Scratching-Shed House (Fig.14) 36

Rear of Model Scratching-Shed (Fig. 15) ..... 40

Hatching and Brooding Coop (Fig. 21) ...... 60

Brooder House and Runs (Fig. 22) ......... 60

Brooder House, 1200 Chick Capacity (Fig. 11) . 64

Simplest Form of Long House (Fig. 12) ...... 64

Breeding House. Adjustable Doors (Fig. 17) . 82

Portable Tarred Paper House (Fig. 18') ...... 82

First Feed for Baby Chicks (Fig. 32) ....... 99

Home Made Trough and Fountains (Fig. 33) .. 99

Typical White Leghorn (Fig. 24) .......... 114

Pullet of High Vitality (Fig. 25) ........... 114

Rose Comb White Leghorn (Fig. 26) . . . . . . 114

Movable Hopper (Fig. 30) .............. 160

Feed Hopper for Baby Chicks (Fig. 31) ..... 160

Broody Coop (Fig. 34) ................. 162

Brood Coop of Grocer's Box (Fig. 35) ....... 165

Jug Mother (Fig. 36) ................ 165

Oregon Trapnest (Fig. 37) ............ 168

Missouri Trapnest (Fig. 38) ........... 168

Most Profitable Crop (Fig. 42) ........... 197

White Diarrhea Chicks (Fig. 40) ......... 213

Aylesbury Ducks (Fig. 41)............ 213 



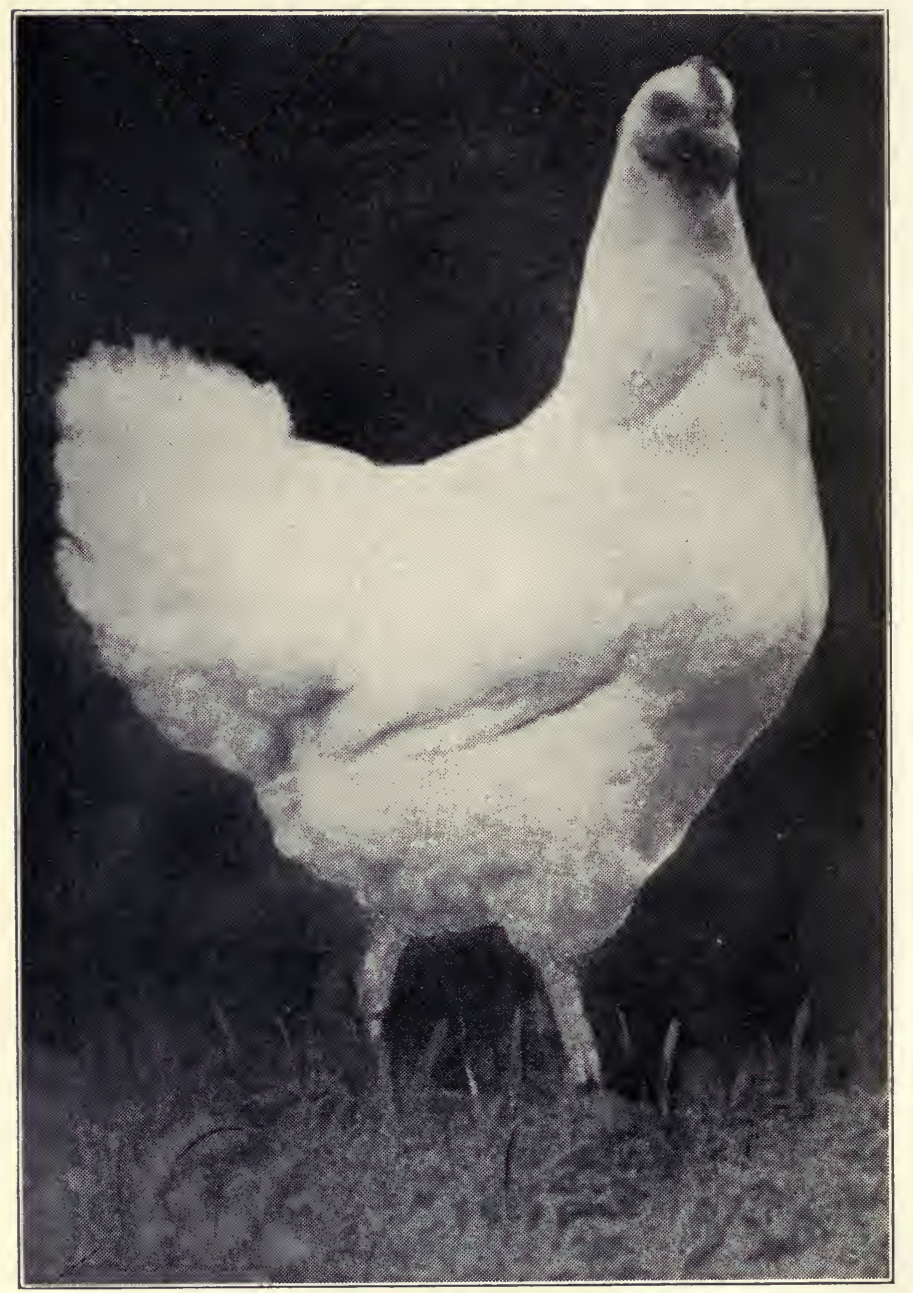

LADY SHOW-YOU

281-EGG HEN OF THE NATIONAL EGG LAYING CONTEST 


\section{Poultry for Profit}

\section{CHAPTER I. \\ Making a Beginning}

Poultry keepers, present and prospective, may be divided into five classes:

1. The man who makes poultry production a business.

2. The man (it is more often a woman) who keeps chickens in the back yard to supply the family table.

3. The farmer who keeps poultry as a necessary and profitable adjunct to the more important farm operations.

4. The back-lotter or suburbanite who raises fowls as a side line to add to the family income.

5 . The person (man or woman) who is interested in good poultry and who looks forward to some time becoming a producer.

If you belong to the first class, this book is not for you. If you belong to one of the other four, and especially to the last class, you may find in it something that will give you a clearer idea of the much misrepresented "chicken business" and of the principles which underlie successful poultry production.

\section{DOES POULTRY PAY?}

As well ask if farming or plumbing or the grocery business pays. Some people. will succeed in any business; some will fail in any.

"The fault, dear Brutus, is not in our stars,

But in ourselves, that we are underlings." 
Poultry work has paid many people; it may not pay you.

A great deal of literature has been published, chiefly by people who had something to sell, calling attention to the easy money in the chicken business. It is quite time a gullible public stopped listening to these sirens' songs. There is no easy money in the chicken business. Some men are making fortunes; many are finding a good living; and many others are adding materially to their income by raising poultry; but it is through "long days of labor and nights devoid of ease." No work is more exacting, no hours longer, no experiences at times more discouraging, no business more at the mercy of untoward tides and winds of circumstance; and yet no work has, for the right man or woman, more real pleasure and profit.

If you have a clear head and strong feet; if you love good fowls and hard work; if you have it in you to rise at five o'clock of a cold, wet morning to see that chicks and hens have their meals at regular hours, and to spend the evening going the rounds of your houses to see that crops are full and every fowl comfortable; if you can give up part of your Sundays and most of your holidays for the sake of your fowls; if you are willing to study and plan and keep accounts, then consider that you can succeed with poultry. This is "a man's job." If you are looking for something easy, let it alone.

\section{HOW TO BEGIN}

The way to begin, as a famous statesman said of the resumption of specie payments, is to begin. Right where you are is the place; right now the time; but don't make the mistake of thinking you can drop the business you are engaged in and, without experi- 
ence, make a flying leap into "the chicken business." You would not think of doing it with any other business. Why imagine that poultry culture is so mean and insignificant a thing that it needs neither knowledge nor preparation? The best way to learn the "poultry business" is to hire out to a poultryman and learn to do by doing. The second best way is to begin with a few hens in your own back yard, keep accurate account of every cent received and spent, of poultry and eggs used by the family, and of losses, and see at the end of the year what your profit is. When you have made twenty-five hens pay a profit of a dollar or more a year per hen, you are ready to increase the number, and not till then.

Some people have the knack of raising poultry; some have not. Put no more money into it than you can afford to lose till you have found out which sort of person you are.

\section{BEFORE YOU BEGIN}

Most of the people who read this book already know something about chickens, have "kept hens" after a fashion and raised chicks with hen mothers. Perhaps you have now some common stock on which you can practice. If you have not, buy or borrow a sitting hen. She will probably cost a dollar if she is large enough to be a good mother, and a setting of eggs will cost another dollar. Learn how to set a hen, how to keep her from breaking the eggs and from dying on the nest from the attacks of mites; how to save some of the chicks which do not pip the shell, how to raise every chick hatched, barring accidents, and how to keep them growing. Study Mother Biddy's ways and learn how she keeps her babies warm and at the same time hardens them. She is mistress of the art of combining warmth, 
fresh air, exercise, and that utterly indefinable something called "mothering." When you have learned something of her methods, you are ready to make a beginning with good stock.

There are three ways of beginning with poultry:

1.-BuYing BABY CHICKs.-This is the cheapest and usually the safest way to begin. Baby chicks may be had from reliable breeders for from ten to twenty cents apiece. One hundred Leghorns from bred-to-lay stock may be bought for twelve or fifteen dollars, but don't buy Leghorns if you are limited to a town lot, and do not, under any circumstances, buy more than you have hens to hover. Artificial brooders should be purchased only when you know you are going to make a success of your venture, and the fireless brooders, which can be made from soap and starch boxes, are not very satisfactory in the hands of a novice.

In planning to order chicks, you must consider not only how many chicks you can provide comfortable quarters for, but how many grown fowls you can house without overcrowding them. Leghorns require less room after they are grown than hens of the heavy breeds. If you have a house and yard of suitable size for fifty Leghorn hens, it should not be expected to house more than forty Rocks. Poultrymen usually consider it necessary to hatch three chicks for every pullet they wish to have at maturity. You will therefore need to order 150 Leghorn or 120 Rock or Red chicks if you wish to fill a house of this size.

Unless you have had some experience with incubator chicks it will be safer not to order more than fifty the first time. If you succeed with these, you can buy more later. If you do not raise a good percentage of them, you will be glad you have no more. 
If there is one rule that is of vital importance to the beginner, it is "Go slow." Better raise twenty-five chicks to a fine, sturdy maturity than have a hundred runts to get rid of. It is quality that counts, not quantity.

To care for the fifty chicks you have ordered you should have three hens. In warm weather a hen can care for twenty-five chicks, though she is quite likely to trample on some of them; but in March, when you should be raising these chicks, from fifteen to twenty are all a good-sized hen can cover.

There are two ways of providing mothers for a brood of incubator chicks. If you have a sufficient number of hens of your own, the best plan is to set as many as four three weeks before you expect your chicks. Four hens will not hatch more than thirty chicks, unless you are remarkably fortunate, and the four can easily care for the fifty you buy and the thirty they hatch. If you raise thirty vigorous pullets from this lot, you may not need to order more. If you have not hen mothers, but must buy broodies, get them at least a week before your chicks are to arrive and keep them quiet upon china eggs till your chicks are ready. If two or three chicks are slipped under a hen at night, she will think she has hatched them and take the rest of the brood without objection.

The cockerels should be separated from the pullets as soon as they show their sex and fattened for broilers. Get them off to market as soon as they weigh two pounds. The earlier your broilers go to market, the better price will they bring. This is especially true of Leghorns, which make excellent broilers but are poor fryers.

2.-BUYING BREEdING STOCK.-For the backlotter who can keep only a few fowls, and the 
side-line poultry keeper who has a taste for good birds, there is much to be said in favor of buying breeding stock to begin with. You get fewer birds for your money, but you get better ones-that is, if you pay a fair price for them. For $\$ 25$ you can buy a trio of thoroughly good birds, and the chicks you hatch the first year from these will give you a good start toward a flock of choice birds. Sometimes it is a good plan to raise your pullets and then buy a pure-bred male of good stock to mate to the best six or eight of them.

3.-BUYING HATCHING EGGS.-Many persons consider hatching eggs the very best way to get a start with first-class stock, but there are more chances to be taken than in buying either chicks or breeding stock. If you are fortunate in your hatching, you will probably get more birds for your money than in buying stock, but eggs that have traveled a long distance do not always hatch satisfactorily, and even when infertile eggs are replaced, hatching one or two with cheaper eggs is troublesome, and there is always a chance that the birds hatched will be just ordinary stock. When the eggs are purchased from near-by breeders there is a better chance of success.

\section{LOCATING THE POULTRY FARM}

Most of us have to raise poultry where we find it convenient to live, and poultry is so adaptable that it will thrive wherever human beings can live. There are, however, three essentials in the location of a profitable poultry farm.

\section{Three Essentials}

1.-WATER.-In California, especially, a good supply of water for irrigation is of prime importance. Other things may be managed without, but water is 
the sine qua non of poultry raising. Without water the poultryman cannot raise the green feed which his fowls must have if they are to be profitable, nor can he raise the fruit and vegetables which should go along with the raising of poultry or the part of his feed which it is desirable a poultryman should raise. In short, he is handicapped at every turn. Some localities, otherwise perfect for poultry growing, are entirely barred because of the scarcity or high cost of water.

2.-FerTile SoIL.-It has been the custom to recommend a light, sandy soil as best for poultry because of its capacity for carrying off droppings and disease germs, but with the new "back to the land" movement in poultry culture, i. e., the movement away from too intensive culture and toward combination of fruit and poultry, there has come a new emphasis on the importance of good soil. The day is nearly passed, I hope, when we shall see certain kinds of soil advertised as "good for chickens, but not for fruit." Land that is not good enough for fruit is not good enough for chickens, and the best fruit land is none too good. There is nothing better than a decomposed granite soil if it has water, but even adobe, bad as it is for chickens, may be made tolerable if cultivated sufficiently.

3.-TRANSPORTATION FACILITIES.-The best location for a poultry farm is within easy reach of a large city. The next best is close to a railroad within a hundred miles of that city. Indeed it is a question whether a good-sized tract of land at a distance, but with transportation, is not better than a small tract close to market. The important thing is that the producer be convenient to the railroad. If he must haul his products six or seven miles over a rough road, it is good-by to any possible profits. 


\section{Other Considerations}

Three other considerations in regard to location should be aimed for if possible, but done without if necessary. These are:

1.-Proximity to Other Poultrymen.-Association with others in the same business is always a help, and in none more than in work with poultry. Such poultry colonies as those at Gardena, San Gabriel and Arlington, not to mention Petaluma and a hundred towns in Northern California, are of great advantage to the men who compose them. Supplies are bought at wholesale prices, when otherwise they would be purchased at retail, and in many associations products are collected and marketed for the producers. On the other hand, the small producer, if he has the land, may be able to build up a profitable retail business in a suburban town where there are not many other producers-if there is such a town in California.

2.-DRAINAGE.-Some drainage for poultry runs is vital, for water standing on the ground where fowls are kept is always a source of disease, but it is usually possible on several acres of land to find one point which is sufficiently higher than the rest to insure good drainage.

3.-A SOUTHERLY EXPOSURE.-This is not necessary, but it is a very great help in maintaining health among the fowls. A gentle southerly slope is probably the best of all locations for a poultry farm or plant, for on such a slope there can never be lack of sunshine, that best of germicides. Given open-front houses, fronting south and downhill, there should be no excuse whatever for disease of any sort.

4.-Protection From Wind.-An exposed hilltop is never a good place for chickens, but a judicious arrangement of windbreaks can be made to obviate 
this difficulty. Better a too exposed situation than a hollow where the air does not circulate at all or blows through in a constant draft. Such a place is always unhealthful and should be avoided.

\section{How Much Land?}

The amount of land necessary for a poultry farm depends on the breed kept, the character of the soil and the ability of the caretaker to keep yards and houses clean and sanitary. In general a thousand hens to five acres is a safe number, but many persons succeed with less land.

I know one chicken rancher who is making a good living with 2000 hens on eight acres, another who is very successful with $\mathbf{1 5 0 0}$ hens on three and a half acres, and still another who does a nice side-line business with from 300 to 400 hens on a half acre. These men, however, are experts, and the first two keep White Leghorns, which thrive in closer confinement than heavier fowls can bear, and can often be raised intensively where Rocks or Orpingtons would be a failure.

It is very important that the poultryman raise his own green feed, and as much as possible beside, and the initial cost of the land is a small matter in comparison with the advantages that result from having room for stock and garden.

\section{How Much Capital?}

The question is often asked, "How much capital is needed for starting a poultry farm?" This depends largely upon the price of the land. In the most highly cultivated parts of the state land suitable for fruit and poultry can hardly be found for less than $\$ 300$ an acre. Close to markets and in localities where irrigating water can be bought from plants 
already developed, it will cost more than this. If the land is bare, houses and fences must be built. Stock is to be bought and feed for the first year provided. These are expenses which the prospective poultry farmer must look squarely in the face, and it is better to overestimate than to underestimate. The figures would be something like this:

5 acres of bare land.............\$1500

Housing and fencing for 1000 hens, at about $\$ 1$ per hen .............. 1000

Dwelling house (at the very least) ..... 500

2000 Leghorn chicks............. 200

$\$ 3200$

It is not necessary to pay cash for the land, but a heavy indebtedness is a most serious handicap, and a payment of at least one-third cash should be made. It is generally considered that the sale of the cockerels as broilers will pay for the raising of both cockerels and pullets, so we will assume that the pullets at six months of age have cost nothing but the $\$ 200$ that was paid for the chicks.

The beginner in the poultry business must expect to lose money the first year and to spend two years in bringing his plant to a paying basis. To be sure the hens will pay their own way if they are bred-tolay hens, but there are many other expenses, and the man who has not the money for necessary equipment and supplies has a difficult task before him. Probably more failures in poultry work are due to beginning with insufficient capital than to any other one thing.

\section{CHOOSING A BREED}

There is no best breed. This has been said so often that it is axiomatic. Nevertheless, there are best breeds for given purposes, and breeds which seem to 
be more popular or more profitable in certain localities. The beginner, if he is wise, will find out by making careful inquiries, visiting poultry ranches and shows and reading the local poultry journals, what breeds are generally kept in his neighborhood and which are most highly valued. The experienced poultryman may find it to his advantage to launch a new breed, but never the beginner. The beaten path is always safer.

\section{Breed Classification}

Without entering into a detailed classification of the various breeds, we may roughly classify them as egg breeds, meat breeds and general purpose breeds, but the term "egg breed" is a misnomer, for some general purpose fowls lay quite as many eggs as the so-called "egg breeds."

Another classification, which covers all kinds of fowls a little better than the above, considers them as well-defined types; and we have (1) the game types, represented by the different varieties of Games; (2) the laying types, represented mainly by the Mediterranean class-Leghorns, Minorcas, Anconas, etc.; (3) the meat types, represented by the Asiatics-Brahmas, Cochins and Langshans; (4) the general purpose types, to which belong our honored and beloved American fowls-Rocks, Reds and Dottes, and the English Orpingtons; (5) deformed types-Frizzles, Silkies and Rumpless, and (6) bantams.

\section{White Leghorns for Egg-Farms}

Time has proved that the White Leghorn is better adapted than any other breed for the exclusive production of eggs, and it holds the field as the universal egg-farm fowl. From time to time some enthusias- 
tic breeder comes forward with a new breed which is "just as good," but the White Leghorn still holds undisputed sway. Should it ever have a rival, it would probably be the Ancona, but the great American public likes a white bird, and the Leghorn will be hard to displace.

\section{American Breeds for the Farm}

If it is true that the White Leghorn is the best fowl for commercial egg-farms, it is equally true that it is not the best breed for the general farm or the back lot. In the first place, Leghorns and other high-flying Mediterranean fowls will go over fences; clipping wings won't stop them. They must be closely confined above as well as below, or out they go. In the second place, while the Leghorn cockerels make splendid broilers for the fancy trade and bring good prices, they are not satisfactory for a family that likes real chicken meat, and the farmer and back-lotter want chicken for their own Sunday dinner. In the third place, the Leghorn hen, when she is through laying, has hardly fifty cents' worth of meat on her bones, while a Rock or Orpington will always bring a dollar.

One is always safe in choosing for the farm flock or the hen yard of the city or suburban home one of the three American breeds-the Plymouth Rock, Wyandotte or Rhode Island Red. Rocks and Dottes come in all desired colors. The Red is always red, but there is a variety of shades, all beautiful. The Barred Rock is said to be the most popular fowl the country over. In the East Wyandottes are perhaps a little more highly esteemed. In the West the Rhode Island Red seems to be more popular. There can be no mistake in choosing one of these three, and there is no essential difference between them. Whatever 
difference there is, is a matter of strain and not of breed.

Robinson (Principles and Practice of Poultry Culture) classifies Orpingtons, Buckeyes and Javas with Wyandottes, Plymouth Rocks and Rhode Island Reds as general purpose fowls, and declares that "In what are called the practical qualities-egg production and meat properties-and in their adaptation to climatic and soil conditions and environment, they are substantially the same. The lighter breeds are usually more active and mature earlier, are less prone to put on fat, and have a longer productive life than the heavier, though the latter, while in suitable condition, are equally good layers. For table use the Rhode Island Reds are commonly rated rather inferior to Plymouth Rocks and Wyandottes, but this is wholly a matter of selection for meat quality. Some stocks of Reds are as good table poultry as any of the other breeds of the class. As first introduced the Orpingtons were probably of higher average table quality than the American breeds because of more careful selection along that line in England; as found now, they average with the others."

The Orpingtons cannot be excelled as broilers and soft roasters, but their weight inclines them to broodiness in summer, which is a great detriment to egg production, but which can be bred out by careful selection. They are also very hardy. Both Wyandottes and Rhode Island Reds make fine, quickgrowing broilers. The Light Brahma is best for large roasters, and the Plymouth Rock is possibly the best all-round table fowl. Certainly it is in great demand.

Only three of the many other varieties are worth the beginner's serious attention. These are the Houdan, the Minorca and the Ancona. The Houdan 
belongs to the French class, is a non-sitter, a prolific layer and has a meaty carcass which is the delight of French epicures. If egg-laying and table qualities are ever combined in one fowl, it is probably in the Houdan; but for some reason it has not been largely bred in this country. The Minorca belongs to the Mediterranean class, but is larger than the Leghorn and therefore a better table fowl and lays larger eggs. The Ancona is a Mediterranean, like the Leghorn, and its friends claim for it all the fine qualities of the Leghorn.

\section{Color of Eggs}

All hens of the Mediterranean breeds are nonsitters and lay white eggs. All the heavy breeds are sitters and lay brown eggs. These two considerations must necessarily influence choice of a breed. The San Francisco and New York markets pay a little higher price for white eggs. Boston prefers a brown egg, and Los Angeles has no choice, provided only the egg is fresh. The person who wishes to cater to a white egg market will therefore be obliged to select one of the Mediterranean breeds, but the Southern Californian may select the breed he likes, regardless of color.

\section{Only One Breed}

Whatever breed you select, get the best stock obtainable and keep that one breed and nothing else. There is enough to learn about any one breed to keep the average person busy for a lifetime. To try more is to court failure.

\section{WHICH SPECIALTY?}

In an age of specialists like the present, the man or woman who undertakes to raise poultry should 
have clearly in mind at the start what he or she is to aim at.

The different branches of the poultry industry are generally classified as (1) egg production, (2) meat production, (3) the breeding of fancy stock, (4) hatching baby chicks. But raising fowls exclusively for meat production has proven a failure so many times that it need not be considered as a separate branch of the industry. Meat production is profitable as a side line subordinate to the production of eggs, and has importance for the beginner only as it relates to the disposition of surplus cockerels and old hens. Any breed is more desirable if its cockerels make satisfactory broilers, but the broiler business as a business has rarely been anything but a failure.

Breeding fancy stock and the artificial hatching of chicks in large numbers, while they are both profitable branches of the industry, are what might be called graduate courses, and to be entered into only when the principles of breeding, mating, feeding and incubation have been mastered. This narrows the possible choice for the beginner to egg production only, and egg production is the foundation on which the industry rests.

There always has been and there always will be a demand for fresh, wholesome eggs, and this demand is increasing as the virtues of the egg as an article of diet become better known. High prices of feed the past few years have made it increasingly difficult to produce eggs at a profit, but this very difficulty is forcing breeders and students alike to a study of the principles of breeding which shall eliminate the drones from our flocks. There is plenty of profit in producing eggs with high-producing hens, and no profit at all in keeping drones. The sooner this becomes clear to all concerned, the better for the 
industry. Too many flocks in times past have been managed on the principle that "chickens is chickens," a most mistaken idea. Chickens, like cows, are producers or they are nothing.

In planning for the production of eggs, the merits and demerits of the different classes of fowls must be carefully weighed. The Mediterraneans will produce more eggs, but the heavy breeds produce more meat. It is also possible by careful selection to increase the production of the heavy breeds until they are almost equal to the lighter. Some of the best layers in recent egg-laying contests have been Rocks, Wyandottes, Orpingtons, Rhode Island Reds and Langshans. On the other hand, the frequent broodiness of the heavy breeds is a trial, but this can be bred out to a large extent. If there is any difference at all in quality of eggs, it is in favor of the heavier breeds, which usually lay an egg with a more solid shell and a firmer and better colored yolk.

I believe we shall see in the next few years, as prices of beef rise higher and higher, an increasing recognition of the economic importance of the heavier breeds. 



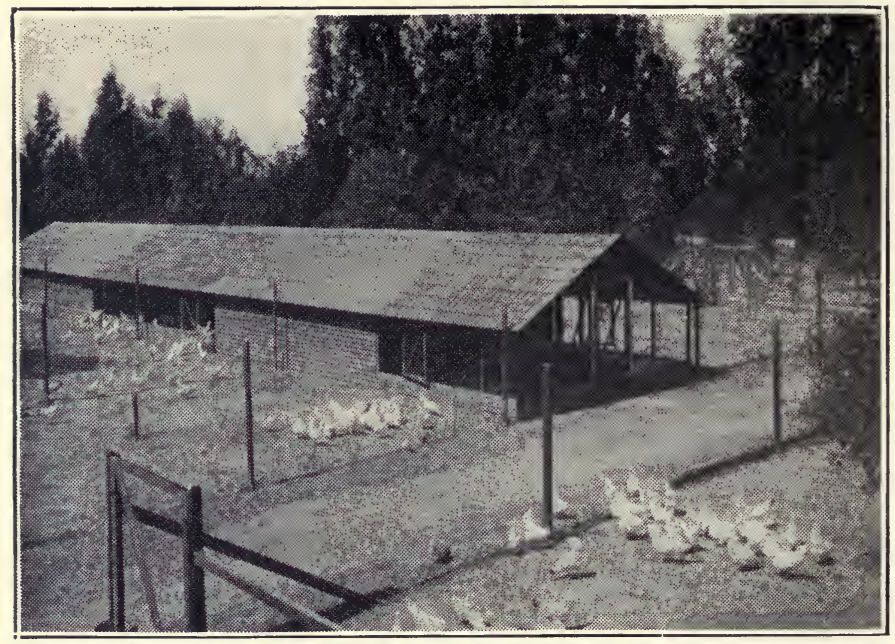

FIG. 1-SCRATCHING-SHED HOUSE ON BANDINI POULTRY RANCH, RIVERSIDE

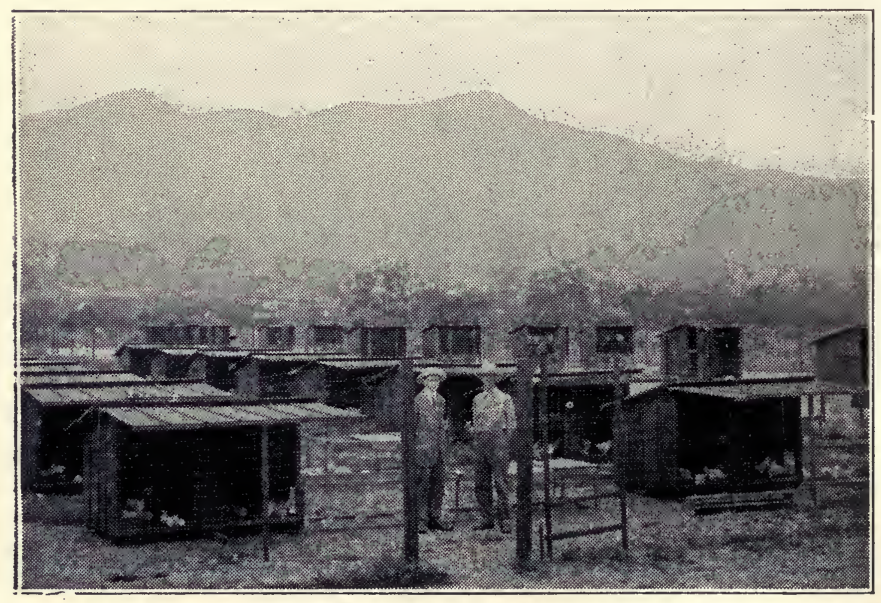

FIG. 2-SHED-ROOF COLONY HOUSES ON MONROVIA POULTRY RANCH 


\section{CHAPTER II.}

\section{Housing and Yarding}

\section{SYSTEMS OF POULTRY KEEPING}

The two systems of poultry keeping in general use are known as extensive and intensive, but there are so many degrees of intensiveness and so many gradations of areas over which fowls are permitted to run, that it is hard to know where one ends and the other begins.

\section{The Extensive System}

The extensive system in general may be defined as a system by which fowls are kept on free range without yards. Such a system was in use for many years at Little Compton, R. I., where a community of farmers built up by the simplest methods a very successful poultry business. The houses were scattered over the farms, allowing each flock room to forage for its own green feed. Feed was hauled to the houses by wagons or sleds once or twice a day, and the method of feeding was of the simplest. A system like this is the easiest and safest of all, but it requires a great deal of land.

\section{The Intensive System}

Fowls kept on the intensive system are yarded more or less closely, some in yards which have hardly space for the fowls to move about, some in yards where there is considerable room for exercise, others in yards where a good deal of green feed can be grown. The health of the fowls depends not 
so much on the size of yard as on the provisions which are made for sanitation and exercise. Leghorns kept for egg production are often kept in very

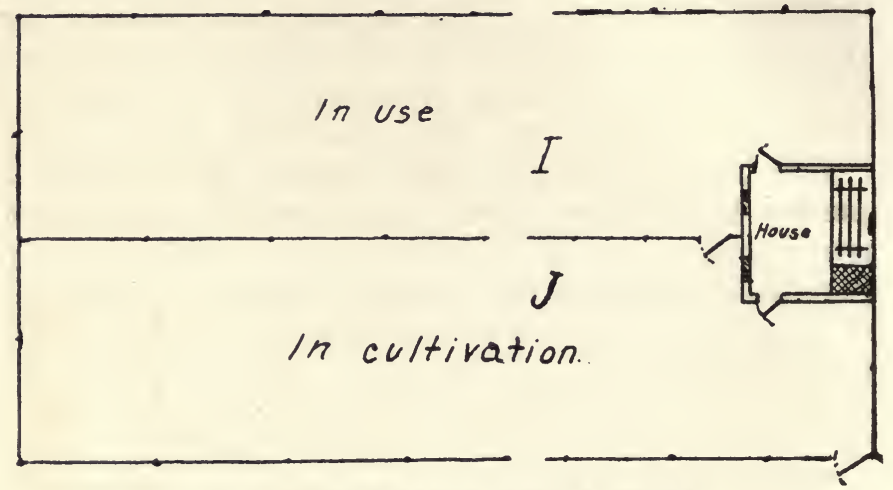

FIG. 3-DOUBLE RUNS AT FRONT OF HOUSE

close confinement, apparently without injury to their health, but where breeders are closely confined fertility is likely to suffer sooner or later. Figure 1

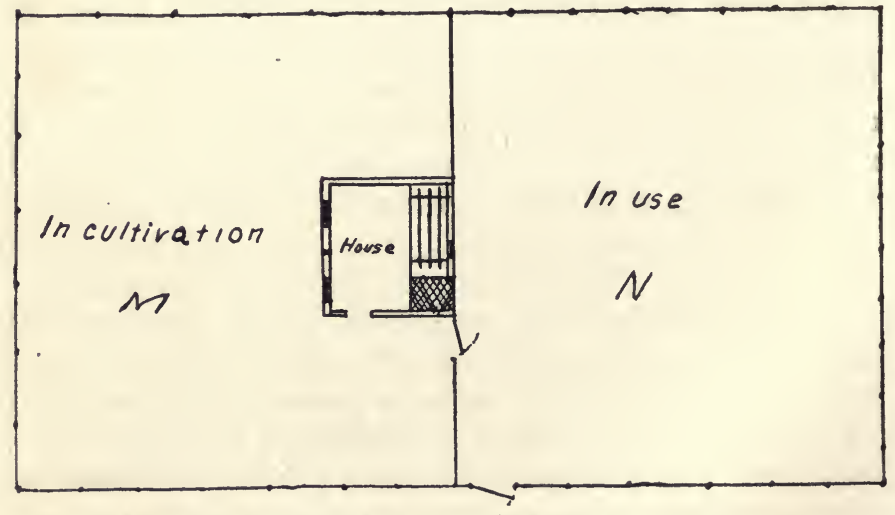

FIG. 4-DOUBLE RUNS, AT FRONT AND REAR 
shows a Southern California house where over 400 Leghorns are kept with but scant yards.

\section{The Two-yard System}

Many poultrymen strike an average between the intensive and extensive systems by keeping their hens in houses holding from fifty to one hundred each, and having two runs for each house. The fowls are kept in one yard while a green crop is grown in the other. Some such system is absolutely

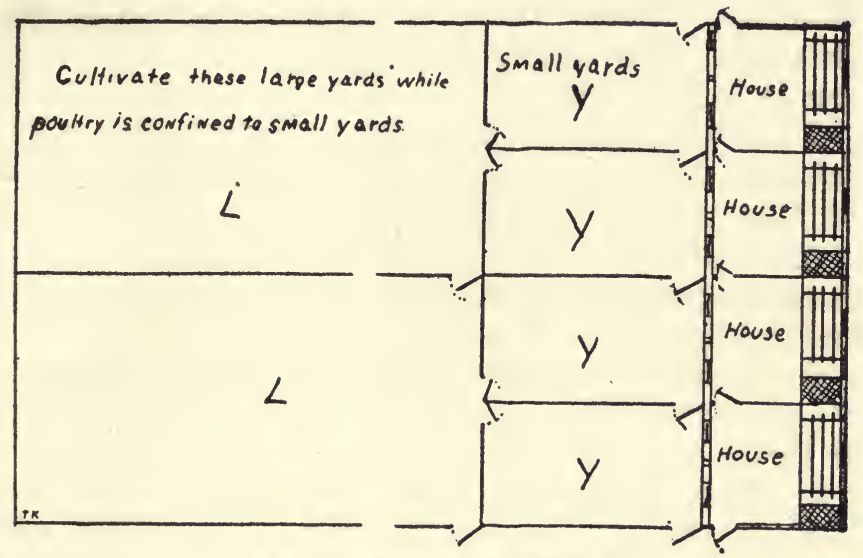

FIG. 5-TRIPLE YARD SYSTEM

necessary if fowls are to be kept for a series of years on the same ground, and it has the additional advantage of providing a good deal of green feed.

These double runs may both be in front of the house, as in Figure 3, or one may be at the rear, the south yard being used in winter and the north in summer. (Figure 4.) Where a house has several sections the plan shown in Figure 5 may be used, the fowls being confined to the small yards 
while green food is grown in the large yards. After the green food is up so that the birds cannot easily kill it by eating at it, the flocks from the two houses can be turned on it alternately.

\section{The Fruit and Poultry Farm}

Safest of all systems of poultry keeping in California is the combination fruit and poultry ranch, for the following reasons:

1. Water is so scarce and so high priced in most localities that it must be made to go as far as possible. Where green crops must be raised for chickens, little if any additional water is required for deciduous trees.

2. Manure is a valuable by-product of poultry raising which ought not to be wasted, and it cannot be more profitably used than in growing fruit.

3. The trees furnish shade for poultry, and the fowls in turn destroy insects and provide fertilizer and cultivation.

4. Instead of having his eggs "all in one basket" the man with a combination ranch has them in two or three.

5. The droppings and other litter from the houses keep up the supply of humus in the soil. California fruit men must keep more stock of some sort, and chickens are more available than cattle.

On such a farm the work is most easily done if the farm is divided into several fields, and the chickens housed in portable houses which can be moved from field to field as occasion requires.

\section{REQUIREMENTS OF A POULTRY HOUSE}

The natural habitat of fowls is the open air. The jungle fowl roosted in a tree and foraged for its living where it could get it. Obviously, these con- 



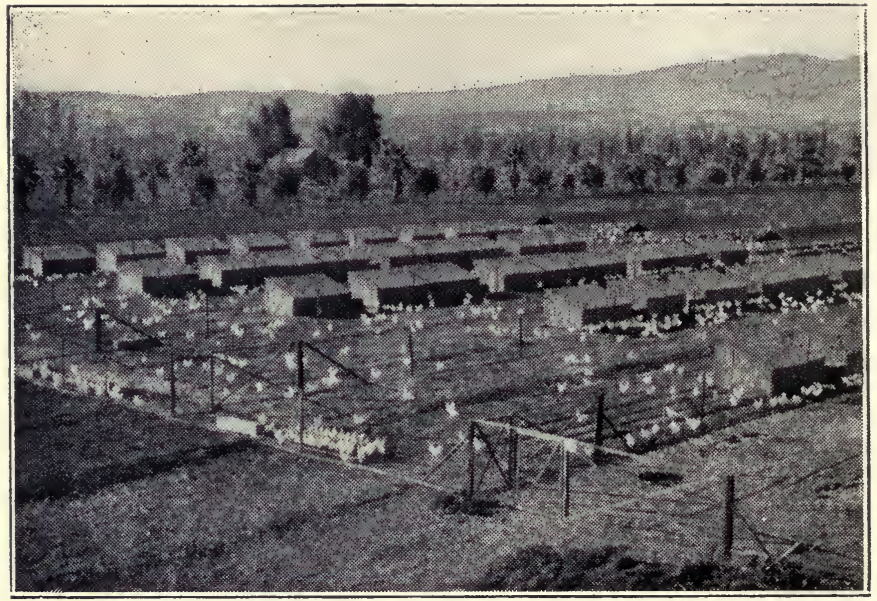

FIG. 6-COLONY HOUSES ON RANCH AT ARLINGTON

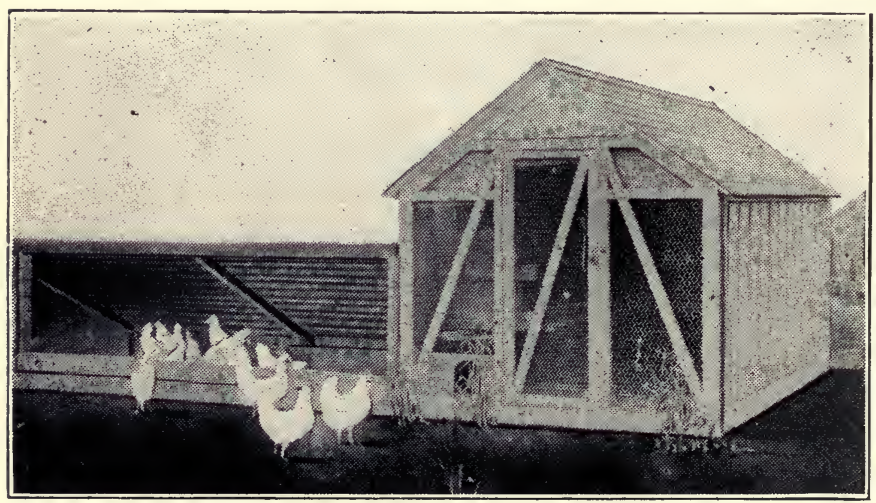

Fig. 7-COLONY hOUSE WITH SEPARATE SCRATCHING-Shed, IN USE AT OREGON STATION 
ditions cannot be met when fowls are kept artificially, but the more nearly they can be approximated, the better for the health and vigor of the fowls. The requirements of a sanitary, healthful poultry house are:

1-SUNSHINE.-Any house that does not admit the sun is unsanitary, no matter how well planned otherwise. Making the house front south and having its windows high, if it must have windows, and its front so that it can be open except in stormy weather, will meet the sunshine requirement. An east front is nearly as good as a south front and better in this respect, that it provides afternoon shade.

2.-FreSH AIR.-Roup, catarrh, bronchitis and a dozen other ailments follow in the train of bad ventilation. The open front is good as far as it goes, but a house open in front and closed on the other three sides is close in warm or foggy weather, and there should be windows or ventilators at the rear which can be opened or closed as the weather demands.

3.-PROTECTION.-Protection must be provided from (1) wind, (2) rain, (3) too much sunshine, (4) rats, weasels and other vermin.

In order to secure protection from the wind, the house must face away from the direction from which come the worst winds. This, in California, is north, so it is very desirable for this as well as for other reasons that the house front south or southeast.

But our rains come from the south and east, so a house which avoids the wind gets the rain. In Southern California, where the winter rainfall is small, a very satisfactory house is the portable colony house which can be turned to face in any direc- 
tion. If the scratching shed is built separately, as in the illustration of the houses used at the Oregon Station, the house need not contain more than two square feet per fowl. A house $6 \times 8$ feet would thus suffice for from twenty to twenty-five birds, and a house $8 \times 10$ feet would hold thirty-five or forty, which is all the beginner should put in one house. In this case the scratching pen with its sloping roof could front north and would give shelter from both sun and rain.

The shed-roofed house fronting south receives too much sun in the winter time for California, where the February hot spell is as much to be expected as the January cold spell. If there is a covered scratching pen like the one mentioned above, this will not matter. If the hens have no shade except what the house supplies, there will need to be curtains or shutters or a door, hinged at the top, which can be raised to make a little porch in front of the house. This is one of the most satisfactory ways of dealing with both sun and rain in a small house. Where a gable-roofed house is used, as at the Oregon Station (Fig. 7), there is no such problem. A gableroofed house, with the front slope of the roof shorter answers the same purpose as the shed-roof house with raised door.

The best protection against both rats and dampness is a cement floor and foundation. This is not practicable when the movable colony houses are used, nor is it needed. To make a good foundation for a permanent house, excavate about three inches and fill with a mixture of one part Portland cement, three parts clean, sharp sand and three parts crushed rock. On the surface of this foundation put a mixture of pure cement and water to fill up the holes in the surface. A concrete floor is hardly more ex- 
pensive than a board floor, and it is so much more sanitary than a dirt floor that it is well worth while.

4.-ROOM FOR EXERCISE.-In bad weather this is best secured by the combination scratching shed and roosting house, in which part of the house is open scratching shed and part enclosed roosting quarters, as in Figure 1, or by a model which is quite generally used at state experiment stations and also in the government work. In this house the roosts, with droppings board underneath, occupy half the house, facing the front, and the nests are built under the roosting platform, opening either in front or outside behind the roosts, and the whole floor is covered with scratching litter. In a very rainy climate some such arrangement would be almost a necessity, but for California the roofed scratching pen is ample protection. (Fig. 10).

5.-Simplicity of Construction.-The simpler the construction of the poultry house, the better. Both economy and cleanliness make this desirable. An open front, with some means of letting a current of air through; roosts which are protected from drafts; and some place, inside or out, where the fowls can scratch in all weathers; these are the requirements of a poultry house for the comfort of the fowls. Add to these movable roosts and droppings boards, so that each may be taken out and washed with disinfectant, and you have all that is necessary. Four square feet per fowl must be allowed when the scratching pen is inside, but only two square feet if the scratching pen is outside and the birds need the house only for sleeping. A square house is cheaper than any other shape, and a shed roof cheaper than a gable.

Every house that the attendant is expected to enter should be made sufficiently high for him to 
stand in it comfortably. Seven feet in front and five feet at the rear is a good height for a house with a shed roof. A house with a gable would need to be a little higher. A house which contains only roosts need not be more than five feet in front.

It must always be remembered in planning a poultry house that Rocks, Orpingtons and other fowls of the heavy breeds require more room than Leghorns and other Mediterraneans. A house that will house fifty Orpingtons will hold about sixty-five

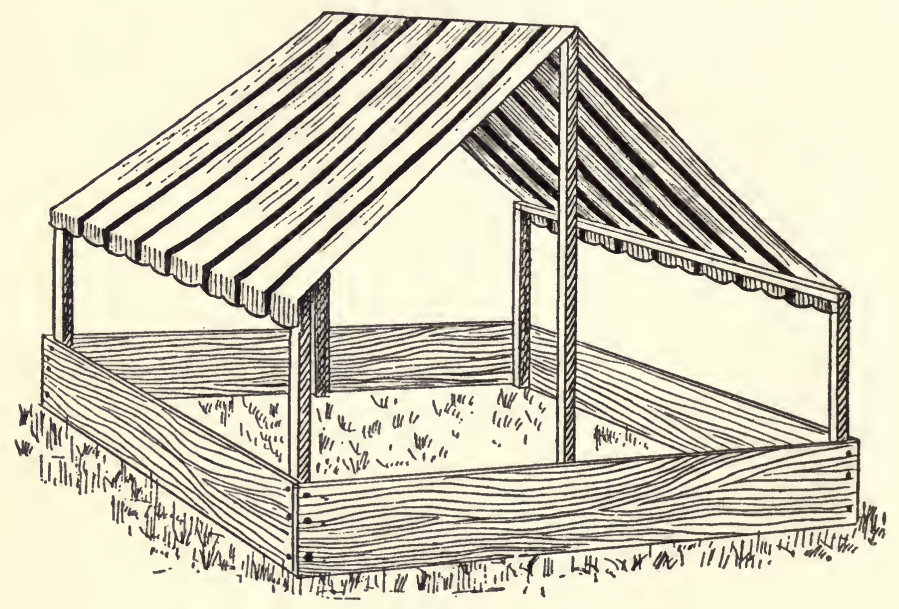

FIG. 8-CANVAS COVTRED SCRATCHING SHED

Leghorns. So, if we allow four square feet for the larger fowl, three or three and one-half feet will accommodate a Leghorn.

\section{THE COLONY HOUSE}

Without doubt the colony house holding a dozen to forty hens is the most popular and the most generally useful poultry house. Where a very large 



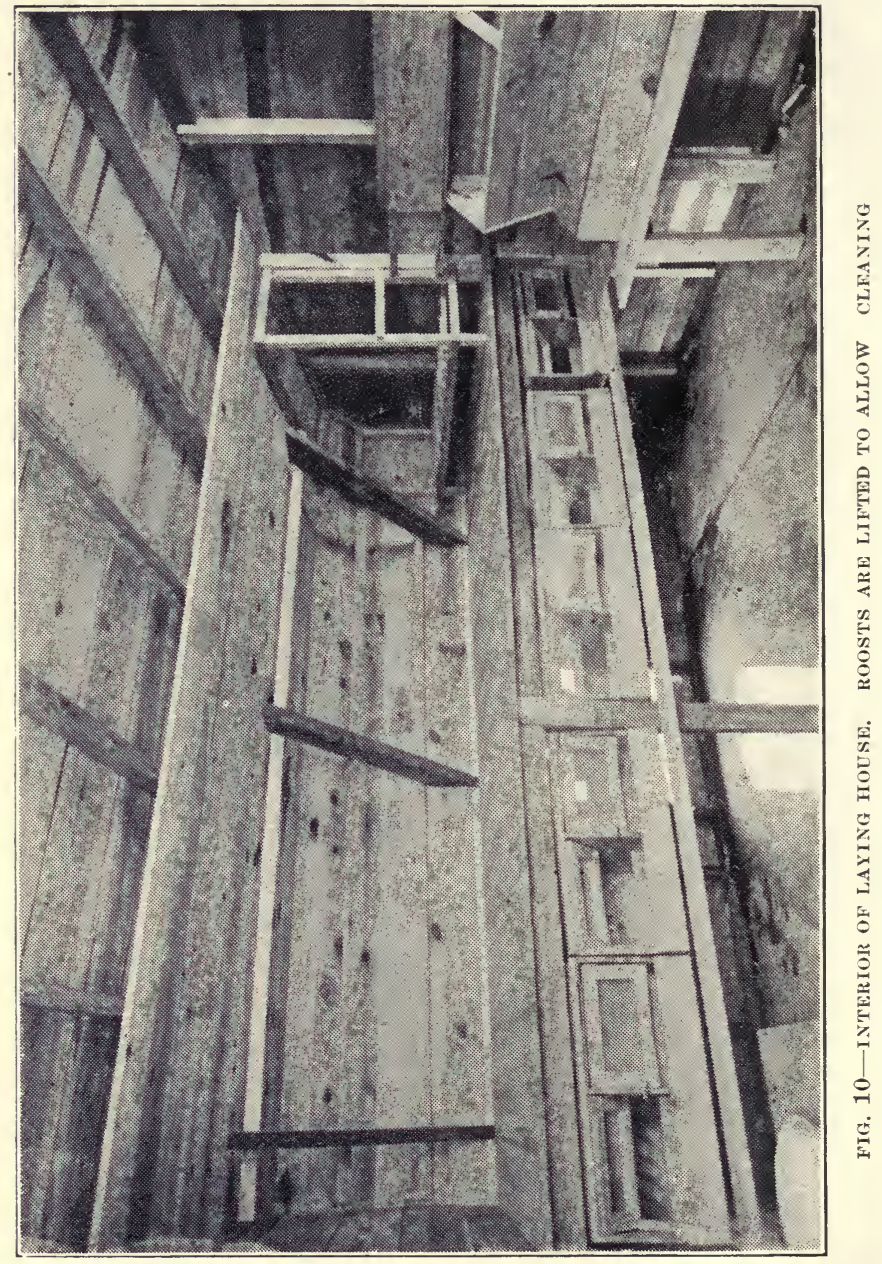


number of fowls is kept intensively, the long house may be more economical, but for the farm where a hundred or less are kept, for the fancy breeder who is obliged to keep his hens in small flocks, and for the back lotter who can keep but a few at the best, the colony house is best. Especially is it well adapted

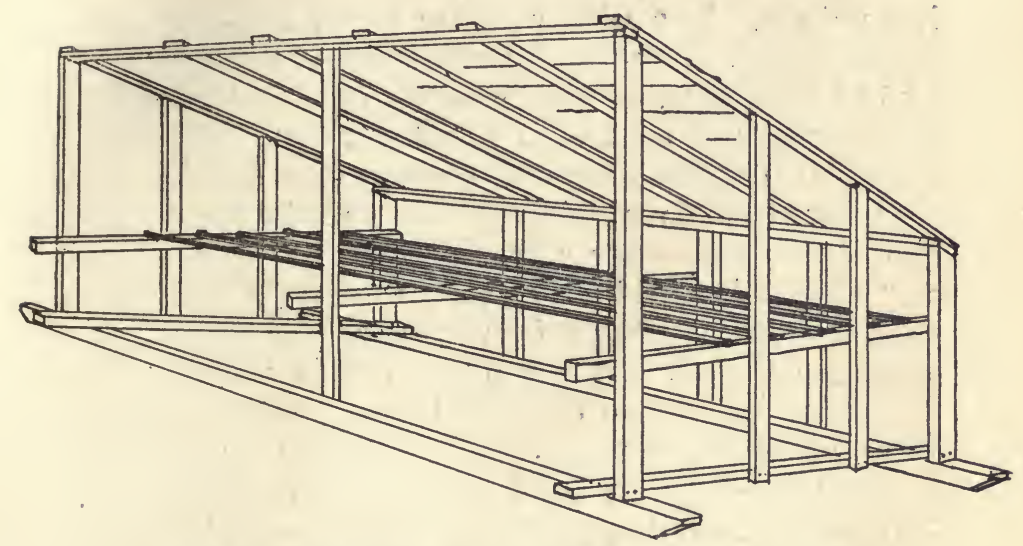

FIG. 9-FRAMEWORK FOR GOOD PORTABLE COLONY HOUSE

to our California conditions; where fowls need a maximum of fresh air and a minimum of protection from the weather, and where scarcity of water and high prices of land make it desirable in many localities that both land and water and the fertilizer which is a by-product of poultry raising be used to the utmost.

On the farm there is nothing better than colony houses holding twenty-five fowls apiece, scattered through field and orchard, so far apart that each flock will have room to forage without eating up the green crops which may be growing. These houses would be about $8 \times 10$ feet, and being portable, they 
can have no scratching sheds, and must have room to shelter the hens when they need shelter. A house $8 \times 10$ feet should give comfortable room for twenty heavy or twenty-five light hens. They can be moved from place to place as circumstances require, can be used with a heater for brooding young stock, and afterward with heater removed for the growing pullets. The colony house is, in fact, the universal house. Four such houses would house a flock of 100 Leghorns, or eighty to eighty-five Rocks and would cost not to exceed $\$ 1.00$ per hen. It is impossible to approximate the cost more nearly than this, for cost of materials differs and the houses are considerably cheaper when built by the owner than when labor is hired. The shed roof style with open side, or the gable roof style with open end, are equally suitable, but the shed roof is cheaper. If the house is built on runners it can be easily hauled from place to place.

Whatever plan is used, the house must be built in such a way that there will be no cracks to let drafts in. Matched lumber is best for the purpose, but even with matched lumber it is difficult to make the sides sufficiently tight. Probably the best way to eliminate drafts is to line with some sort of building paper. Rough boards battened are sometimes used, but one cannot be sure of tight seams.

In large houses it is a good plan to use matched ceiling back of the roosting platform and above it, but this makes a portable house too heavy, and building paper is, after all, quite as good for this climate.

Colony houses with a run for each house are quite generally used, both at experiment stations and on small poultry plants, East and West, and I think they are growing in favor, but they are not quite as 
economical of labor as the long house which has long been characteristic of the intensive plant. It takes longer to go from yard to yard on the colony system than from pen to pen of a long house, but this objection can be obviated by placing the houses along an alley, with the front of each to the alley.

\section{THE LONG HOUSE}

More birds can be kept at less expense for labor and housing in a long house than in any other way. When several hundred birds are kept in one long house, it is generally thought wise not to put more than fifty together in one apartment, though some poultrymen find that they can keep 100 to advantage. Where 100 birds are kept in one flock instead of in two, each bird has twice as much floor space to move about in as if the pens were half as large. Fifty birds, for instance, would require 200 square feet of house room if kept by themselves, and each bird would have but the 200 feet to move about in. Put the 100 birds in 400 square feet of floor space, and each bird has 400 feet.

A good plan for a long house is twenty feet wide and 100 feet long, eight feet high in front and five feet high in the rear, and is divided by sixteen-foot partitions into five sections. The partitions do not entirely separate the sections, an alley four feet wide being left the whole length of the front of the building, so that every fowl may roam over the whole 2000 feet. Each section contains roosting and scratching room for 100 Rocks or 120 Leghorns, so the entire house will house 500 Rocks or 600 Leghorns. This house is recommended by Director Quisenberry of the Missouri Experiment Station, and is similar to many in use in this state.

A laying house designed for 1000 hens is twenty 
feet wide and 240 feet long, with gable roof of unequal span, being nine feet high at the ridge pole, seven feet in front, and five feet at the rear. The pens are twenty feet square and hold about eighty hens each.

It is generally considered that hens will lay more eggs when they are kept in flocks of not over fifty. On the other hand they can be more economically cared for in flocks of 100 hens, and experts are still trying to find the happy mean where economy in care coincides with the maximum health and vigor of the flock.

In a long house intended for breeders, the sections will be much smaller if breeding pens are to be kept separately. If the breeders are to be kept in large flocks with several males to each, the house need not differ from the laying house.

THE FARM-FLOCK HOUSE

Sometimes the farmer does not find it convenient

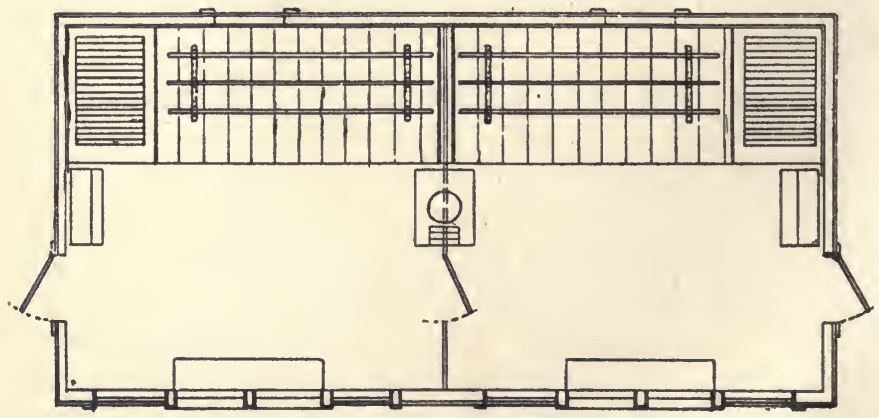

FIG. 13-FLOOR PLAN FOR FARMERS DOUBLE HOUSE. IT IS $14 \times 28$ AND ACCOMMODATES 125 LEGHORNS OR 100 HEAVY HENS.

to scatter his fowls over the place in colony houses, but prefers keeping them in one large flock. For this purpose a house fourteen feet square is recom- 


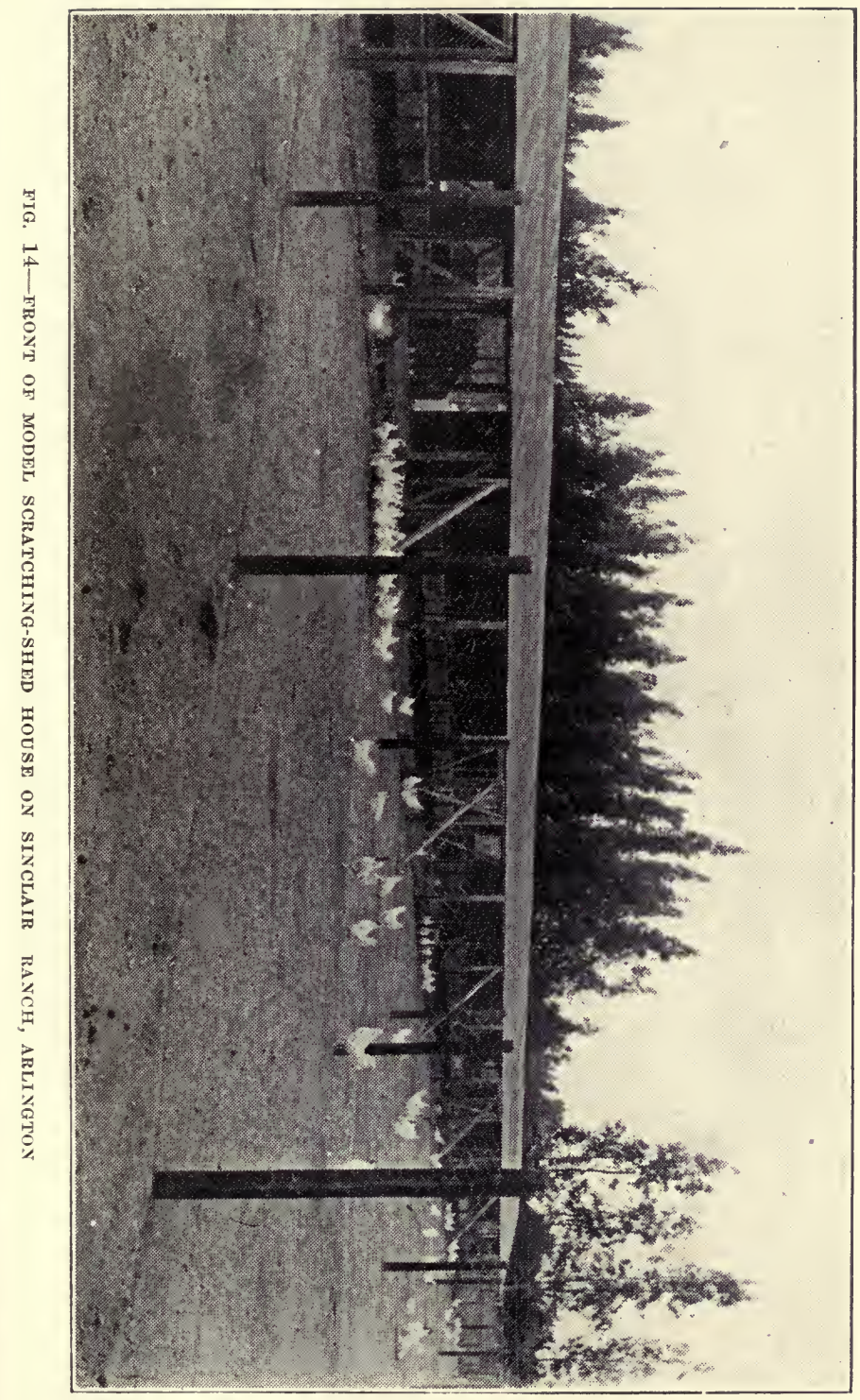



mended by Director Quisenberry. It will hold from fifty to sixty hens. If more than this number are to be kept, it should be built $14 \times 28$ feet, and divided into two sections of $14 \times 14$ feet each. Such a house with two yards, each containing an acre of land, which can be cultivated in turn, will be found a most satisfactory home for the farm flock of 100 hens or for the suburban place of several acres where two acres can be devoted to poultry. If the two acres of land is planted to fruit trees it will yield an additional income.

\section{A MODEL CALIFORNIA HOUSE}

Housing in California is not essentially different from housing in the East. In two particulars, however, slight allowance must be made for California

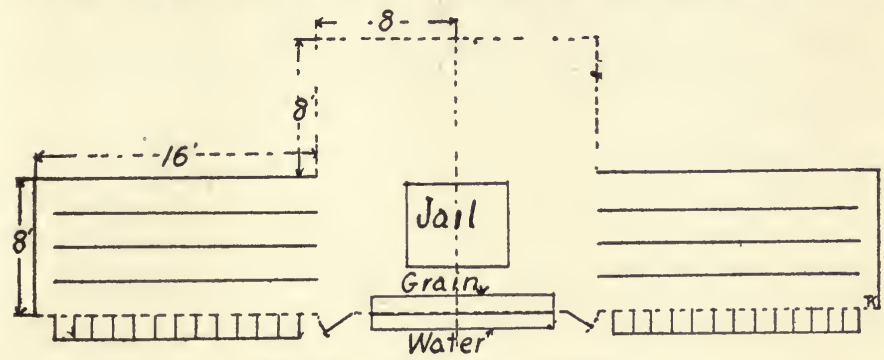

FIG. 16-HOUSING AND YARDING

climate. The open front house is in quite general use East and West, but in the East provision must be made for shutting out the winter storms. This is not necessary in most portions of California, but on the other hand our sunny climate necessitates more generous provision for shade.

A long house which is admirably adapted to California climate was built by the late S. C. Gregg on what is now the ranch of Sinclair Brothers at Ar- 
lington, Riverside County. Mr. Gregg had hunted far and wide for the design best suited to this climate and finally worked out the model, two views of which are shown in Figures 14 and 15.

In Figure 14 is a view of nearly the whole length of the house from a distance. It consists of a series of roosting houses sixteen feet long and about eight feet deep, with scratching sheds between, two roosting houses being alternated with two scratching sheds. The ground plan of two houses and two scratching sheds is shown in Figure 16. Feed boxes and water troughs are built along the front of each scratching shed, and the trapnests are in front of the roosting houses.

Each house holds fifty hens. All floors are of cement, and the roosts are unusually low-about eighteen inches from the floor-so that there may be no bruised feet from jumping down upon the hard floor.

Figure 15 shows the rear view of another long laying house on this ranch.

In both these houses the wide eaves, which measure about six feet on the slope, afford all necessary protection from rain. The houses front east.

\section{A NOVEL BREEDING HOUSE}

A house designed for breeders is shown in Figure 17. It is built with gable roof and divided in the middle by an alley. The pens, of which there are four on each side of the alley, are about $7 \times 10$ feet, and hold twelve to fifteen birds. Fountains and feed boxes are next the alley, and the roosting platforms are along the outside of the building. The end of one of them may be seen in the nearest pen in the picture, just inside the hinged door. The characteristic feature of this house is the doors, 
hinged at the bottom, which may be seen open in the picture, each just outside its roosting platform. In windy or rainy weather these doors are closed, thus affording ample protection. In warm weather they are down, as in the picture, providing abundant ventilation.

\section{THE TARRED-PAPER HOUSE}

A very cheap portable coop or house consists of a frame of light material-1 1 2 inches answers very well-covered with tarred building paper. When tarred paper is used for the roof, the top should be covered quite closely with boards, for this paper tears easily, and boards a foot apart on the sides give a much better foundation for the paper than the frame alone.

A very cheap coop may be made of the above Irame, with roof of shakes or paper, and the sides and back covered with burlap sacks.

Fig. 18 shows a portable coop of novel design which was seen in a back yard in Riverside. 


\section{CHAPTER III.}

\section{Incubation}

\section{WHEN TO HATCH}

There is a time for all things, it has been wisely said, and this is particularly true of hatching chickens. You can set a hen in California any month of the year, but it is not always wise to do it.

It is generally considered that the hatching season begins in January and ends in May or June, but many poultrymen hatch broilers in the fall, and many hatcheries run from November till July. Theoretically there is little reason for not hatching in June and July, for our summer is nearly always late. Practically it is likely to be time wasted, for these late hatched chicks do not grow as fast as the earlier ones, the cockerels, when marketed bring considerably less, and the pullets will not lay until January when the price of eggs is on the decline. The labor of caring for summer chicks is also greater, or seems so, and green feed is less abundant than in winter and spring.

In general the main thing to consider in hatching is that the stock be hatched in order to reach laying maturity at the right time. Pullets for winter layers must be hatched early enough to reach laying maturity by the first of November, and yet not so early that they will molt in the fall. Leghorns can usually be counted on to lay at six months of age; so April is the best month for hatching Leghorns. Rocks and Orpingtons, on the other hand, will not settle down to steady laying under seven 


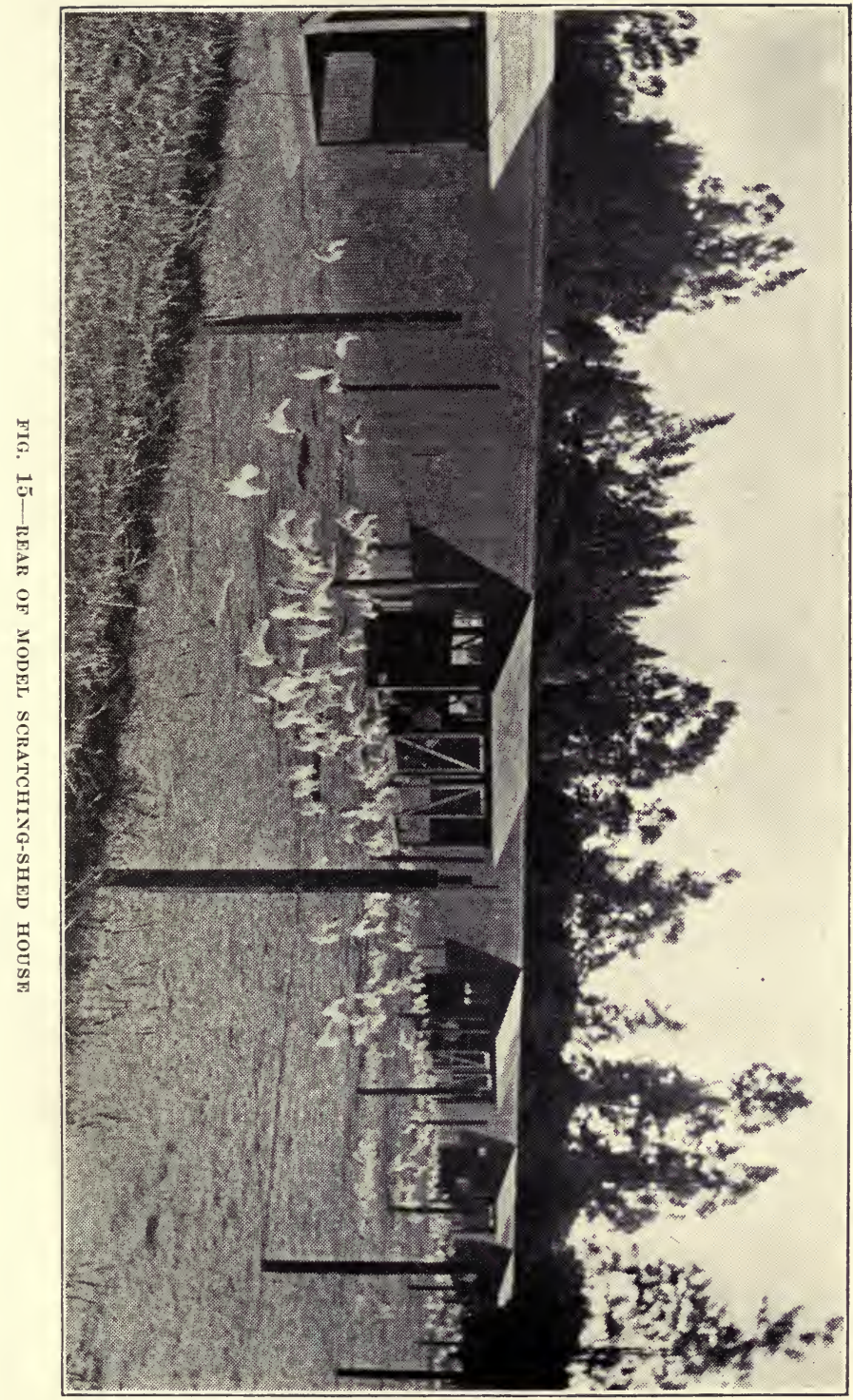



or eight months, though there are many individuals that begin to lay earlier, so one can hardly afford to hatch these breeds later than March if he wants fall eggs. If they are hatched as early as the first of March, they are likely to molt if fed too heavily, so the breeder must guide his bark between the evils of late hatching on the one hand and those of fall molting on the other. Pullets hatched in the last two weeks of March are not very likely to molt in the fall, and they should be ready to lay by November first if they are well fed.

January is the time for hatching early broilers and fryers. This is more profitably done with the heavier breeds than with the Mediterraneans, for they reach broiler size sooner. As an Orpington of good strain should weigh two pounds at nine or ten weeks of age, January and February hatched broilers will be ready for market in time to bring the cream of the high prices, which is usually from 35 to 40 cents per pound, live weight.

September is a good time for hatching either broilers or roasters. There is a particularly good market for soft roasters about the first of February when these September hatched birds should weigh from six to eight pounds.

In planning for fall and winter hatching, the cost of eggs should be taken into account. In August market eggs are worth 35 or 40 cents a dozen, in January about the same, and in December a little more. In March they will not bring over 25 cents retail. Thus the chick that is hatched in January costs, outside of expense of hatching, about twice as much as the April chick. On the other hand, January chicks in this climate are hardier than April hatched chicks. A larger per cent of the chicks hatched will live, and they will reach market size earlier. 
Pullets hatched in the fall are usually found to be better layers than those hatched in the spring. They also begin to lay at an earlier age. Orpington pullets hatched in September or October lay in March or April, while pullets hatched in March can hardly be expected to lay before October, and many will delay beginning till November. On the other hand the pullets which mature early lay more small eggs than those which delay their laying till the eighth month, and as they begin to lay when egg prices are at the lowest point they can hardly be said to be profitable layers for the first three months.

The great point in favor of the fall hatched layer is, that being the daughter of a hen that lays in the fall, she may perhaps be expected to lay more fall eggs than a spring hatched hen, but the question of inheritance of fecundity has not been settled yet. If, as the Maine Station recently declared, inheritance of fecundity comes through the sire and not at all through the dam, the fact that the mother laid in the fall does not indicate that the daughter will. But this is a delicate question and one that is open to careful investigation.

\section{HOW TO HATCH}

Except on questions of sanitation and hygiene, it is almost impossible to lay down any hard and fast rules for the management of a flock of fowls. The breed, constitution, age and individuality of the fowls, the location and size of the farm and the taste and ability of the poultryman have all to be considered as well as such contingent circumstances as the state of the weather and the price of feed.

In no part of the work of a poultryman is this more evident than in choice of the method of hatch- 
ing. In general, it is better for the beginner to hatch with hens. The hen understands her business better than an incubator can. Hen-hatched chicks are usually stronger and can be raised with smaller loss. On the other hand, the average hen will break at least one egg and kill at least one chick before the brood is safely out of the nest. It is rather surprising to learn that, in spite of the undoubted superiority of the hen as a hatcher, the average proportion of chicks hatched by hens is $\mathbf{5 5}$ per cent, as against about 50 from incubators.

After considerable experimental work on methods of incubation, the Oregon Station, in Bulletin 100, published the following summary of results:

1. From 879 eggs set, incubators hatched 533 chicks, or 60.6 per cent.

2. From 279 eggs set, hens hatched 219 chicks, or 78.8 per cent.

3. Eliminating eggs broken in nests, the hens hatched 88.2 per cent of eggs set.

4. The incubators hatched 78.5 per cent of "fertile" eggs, and the hens hatched 96.5 per cent.

5. Eggs incubated artificially tiested 22.7 per cent as unfertile, while those incubated by hens tested out 11.8 per cent.

6. The incubators showed 16.6 per cent of chicks "dead in the shell," and the hens 2.8 per cent.

7. Chicks hatched under hens weighed heavier than chicks hatched in incubators.

8. The mortality of hen-hatched chicks brooded in brooders was 10.8 per cent in four weeks and of incubator-hatched chicks 33.5 per cent.

9. The mortality of hen-hatched chicks brooded under hens was 2.2 per cent, and of incubator chicks 49.2 per cent.

10. In other tests the mortality was 46.5 per 
eent for incubator chicks brooded by hens and 58.4 per cent for incubator chicks brooded in brooders.

11. Hen-hatched chicks made greater gain in weight than incubator chicks, whether brooded by hens or brooders.

These experiments were made in the spring and summer months. Had they been made in January, February and March results would probably have been more to the credit of the incubator, for incubator-chicks do better in these months than later, while hen-hatched chicks have the advantage in warmer weather.

Hatching with hens is also cheaper where the hens kept are of a sitting breed. Professor Dryden, in Bulletin Six of the Oregon Agricultural Experiment Station estimates the cost of hatching and brooding equipment for 100 chicks at $\$ 63.60$, while the cost by the natural method is about $\$ 25$.

But all these reasons for using hens as hatchers apply only to the breeder who keeps a sitting breed. Naturally, the man who keeps Leghorns, Anconas, Campines or Buttercups, cannot keep a lot of heavy hens just for hatching. He must use an incubator, and very often he gets quite as good results as the man who uses hens alone. I visited a poultry plant recently where White Wyandotte chicks were being hatched by hundreds in incubators, while the yard was full of broody hens. "I can't bother with hens," the owner said, and the man who finds hens a "bother" is probably wise to hatch with incubators. Some people, too, have a knack at tinkering with machines, and they will no doubt get better results with incubators than others who hate machinery.

An incubator is necessary on even a small plant or farm, when early broilers and fryers are wanted. Hens have a perverse fashion of not wanting to sit 
in January or February. Even March, if it happens to be cold, finds most of them disinclined to the duties of maternity. Under such circumstances the incubator is the only hope, and it is by no means a forlorn one. Especially successful will the hatching of these early chicks be if broody hens can be found to mother the chicks. It will be noticed in the data given by the Oregon Station that incubatorhatched chicks do considerably better if they are brooded by hens, and while this is not always possible, it can often be managed. As soon as a hen becomes broody, put her in a nest away from the other hens, and treat her just as if she were to be given a clutch of eggs. When the incubator hatch is nearly due, give her a few eggs to hatch, and she will mother as many chicks as you wish to give her. The chicks should all be given her while she is still on the nest or as soon as she is put in the coop. When a hen becomes wonted to her brood she will often object to taking more chicks.

On any farm or plant where chicks are hatched to sell an incubator is a necessity. A few breeders do advertise hen-hatched chicks, but it is so difficult to hatch with hens in large numbers that only few attempt it. The manufacture of incubators has reached such a high degree of development that when the operator comes to his work with a reasonable skill satisfactory results are to be expected. When any great number of chicks are found dead in the shell at the close of the hatch it is more than likely that inbreeding or weak parent stock, which often is the direct result of inbreeding, is more to blame than the method of incubation.

THE HATCHING EGG

An egg consists of four parts: (1) the germ, 
(2) the albumen or white which under incubation becomes the chick, (3) the yolk, which is intended to furnish a supply of food for the newly hatched chick, (4) the shell, a double covering.

The germ, whether it has been fertilized or not, may be seen as a tiny round white spot on the yolk of the egg. As the egg is about 65 per cent water, it is easy to see that water plays an important part in the diet of the fowl and also in the incubation of the egg.

\section{Selecting Hatching Eggs.}

Not every fertile egg is a good hatching egg. Discard, in selecting the eggs you are to set, all undersized and all oversized eggs. The undersized eggs, if they hatch, will produce undersized chicks, and the oversized eggs are very likely to be infertile. Discard all eggs with chalky spots in the shell and all that are rough or unevenly colored. Select those of uniform size and shape and color, for you want your flock to produce eggs which will require the least possible grading. Select also the firm-shelled eggs and those of a size you can market as "extras."

\section{Care of Hatching Eggs}

Hatching eggs should be gathered several times a day in warm weather lest some broody hen start incubation ahead of time. They should be kept in a temperature of about fifty degrees, and turned every day to keep the germ from settling to one side.

Eggs that have been kept more than two weeks should not be used for hatching, and one week is better. The sooner incubation is begun after the egg is laid, the better is the chance of hatching a strong, vigorous chick. When eggs have traveled a 
long distance it is usually considered necessary to let them rest for a day before putting them under the hen.

\section{Fertility and Hatchability}

An egg may be fertile and yet not hatch. A chick may hatch and still not live. This is one of the problems of poultry culture. Certain things, such as the health and vigor of the parent stock, the care they receive, their food and exercise, the age and size of the male bird, and the number of hens he is mated to, are known to affect fertility, but the relation between fertility and hatchability is not so easily understood. It is enough for us to know that, other things being equal, the more perfect the physical condition of the breeding stock the stronger will be the germ and the greater the likelihood of a good hatch.

\section{HATCHING WITH HENS}

No better hatcher has yet been devised than the stupid hen. To be sure she breaks eggs and tramples on baby chicks and our patience sometimes becomes pretty threadbare when we struggle with her disinclination to settle down on a new nest; nevertheless, when all is said, she is the best there is.

Success with sitting hens is largely a question of patience, sympathy and imagination on the part of the caretaker. He must be able to "put himself in her place," for the comfort of the sitting hen is of the first importance. Is she too warm? Broken eggs will be the result. Is the nest too shallow so that she must keep a strained position or else rest her weight upon the eggs? Again, broken eggs will result. Has she more eggs than she can cover properly? At hatching time some of the chicks will get under her feet and perish miserably. Is 
she worried by lice or mites? She will leave the nest too often and perhaps ultimately quit before her job is done.

The man who undertakes to hatch with hens is entering into a partnership, and he cannot fairly blame the "stupid hen" for lack of the intelligence he might have furnished and didn't. Alone and unaided Mother Biddy is not always a success at incubation. Her instinct plus man's intelligence makes a combination which cannot be beaten.

\section{Rules for Hen-hatching}

1. Keep all sitting hens away from other fowls.

2. Provide shade, water, feed, grit, shelter and a chance to dust.

3. Give no hen more eggs than she can cover easily.

4. Dust at least twice during incubation with a good lice powder.

5. Protect from mites with tobacco stems or powder in the nest.

6. See that the nest is carefully shaped to fit the hen and so deep that she will not need to rest her weight on her feet to avoid breaking the eggs.

7. Remove all broken eggs as soon as discovered. Wash soiled eggs in warm water and replace soiled nest material.

8. See that the hen comes off every day to eat, and that she does not stay off too long.

9. When several hens are sitting at once let them exchange nests. Some hens have more bodily warmth than others.

10. Test all eggs the seventh or eighth day and remove all absolutely clear eggs. Neglect of this may cause considerable loss. 


\section{Nest Boxes}

Fourteen or fifteen inches square is the best size for a nest box, but if it is longer than wide it will do quite as well. A cracker box is exactly the right size, but an apple box answers very well. It is better to use new boxes each season, but a box that has never been infested with mites may be used again if it has been thoroughly washed and painted with kerosene and carbolic acid. A box which the mites have once found is never safe afterward.

When you are sure that the box is clean, fill the bottom with moist dirt, enough to shape out a goodsized nest, and cover with straw, hay or excelsior. Both the comfort of the hen and the success of the hatch depend in no small measure on the shape and depth of the nest.

\section{Setting the Hen}

Night is the time for setting hens. After the hen has commenced to show signs of broodiness, she should be left on the old nest for a couple of days. The second night, after dark, transfer her gently to the new nest, put a couple of dummy eggs under her, and cover her with another box, taking care to leave plenty of ventilation. Leave her covered twenty-four hours, then, if she remains on the nest after being uncovered, or comes off and goes back, she is ready for the eggs. If she comes off and returns to the old nest, cover her up again and let her sit on the dummy eggs another twenty-four hours. Nothing is ever gained by hurrying a sitting hen, and you may spoil your hatch by attempting it.

Fifteen eggs are generally sold as a setting, but it is only a large hen that can cover so many, and 
that only in warm weather. Thirteen eggs are enough for the largest hen in winter, and a small one cannot do justice to more than eleven. When you have a setting of expensive eggs it is well to divide them between two hens.

Next to freedom from insect pests, shade is probably the greatest item in a sitting hen's comfort. She is hot and feverish and unable to move about and find a cool spot or to take the frequent sip of cool water that means so much to a hen. In cool weather she will be comfortable in any well ventilated house or coop. In summer there is no place like the shade of a large tree. These details seem too minute to be worth while, but the success of the hatch often depends upon just such little things.

\section{The Hen-Incubator}

Much of the annoyance and worry connected with the care of hen-mothers will be avoided if a good many hens are set at the same time. When the clear eggs are tested out on the seventh day, the remaining eggs may be given to part of the hens and the rest reset. Then when the hatch comes off, the chicks may be given to part of the hens, twenty or twenty-five to each hen, and the other hens reset. In this way ten hens could easily hatch and raise 150 chicks in a season, and if a small incubator were set to help out the hens the second time, they could raise 200 chicks.

There are several devices for setting a number of hens in compact quarters, and these are known as hen-incubators. One is an arrangement by which the nests are banked against a house, each having its own door, so the hens may be kept confined except when they leave the nest to eat. By another plan the nests are arranged on the ground 
in a square or rectangle, separated from each other by boards and covered with wire. A very practical incubating coop, accommodating four hens, is recommended by the Oregon Station (Bulletin 6) . This coop serves the triple purpose of incubator, brooder and colony house. It is five feet long and three feet wide, with a shed roof three feet high at front and two feet at back, and is divided into four apartments. Movable partitions of canvas or burlap are fastened to a four-inch or six-inch board at the bottom and to a crosspiece at the top. It has an outside run three feet long for each hen, covered with wire netting, as shown in Fig. 21. The runs are hooked on to the house and are dispensed with when the chicks are old enough to be given their liberty. The door on the front is hinged at the top so that it may be closed in rainy weather, but open the rest of the time. When the chicks no longer need hovering the partitions are taken out and the coop is used as roosting house. Fifty chicks can easily be brooded at once in such a coop as this by two hens, and the coop will still accommodate the pullets after the cockerels are removed. Coop is shown in Fig. 21.

\section{Testing the Eggs}

Whether eggs are hatched by hen or incubator, they should be tested the seventh day. An egg tester is always part of the equipment of an incubator, but one can be bought for a trifling amount at any supply store. When a fertile egg which has been incubated seven days is held before the tester, the chick can be plainly seen inside as a spider-like body. An infertile egg is perfectly clear. A dead germ shows merely as a dark blotch, which is really 
a blood clot, or as a red ring, which is technically known as a blood ring.

There are three reasons for being particular to test the eggs on the seventh or eighth day.

1. Infertile eggs tested out at this time are perfectly good for food and ought not to be wasted.

2. Dead germs may be detrimental to the hatch. They certainly give out carbon dioxide, and if the incubator thermometer should chance to rest upon an egg containing such a germ instead of upon one containing a live germ, it would not tell the exact truth about the temperature in the egg chamber.

3. When several hens are set at once, after the clear eggs and dead germs have been tested out, the good eggs may be put under part of the hens and the other hens reset, thus saving considerable time.

The eggs should be tested again for dead germs on the fourteenth day. At this time the strong eggs will be opaque and nearly black, and the dead germs will show as blood rings or simply as an indistinct cloud.

\section{Feeding the Hen}

Sitting hens should be provided with hard grain, preferably whole corn or wheat, and should be taken off daily if they fail to come off regularly to eat. Old hens usually come off without being watched, but a young hen will sometimes stick to the nest till she is nearly starved. Give no soft food, for this may cause diarrhea.

A hen that is fed regularly can easily sit two terms, but one that eats only occasionally is worn out at the end of three weeks. The hen should be watched at first to make sure that she returns to her nest in a reasonable time. It is just as well not 
to let her off for the first two days, for the eggs are likely to be chilled if she is slow in returning.

\section{Moisture in the Nest}

Many people sprinkle the eggs under a hen two or three times the last week. The advisability of this depends entirely upon the weather. When it is very dry I try to keep the dirt under the nest moist by pouring a little water in under the nest litter now and then. If the eggs are sprinkled, warm water should be used, but not until the hen is ready to go back on her nest. The eggs are not as easily chilled the last week as they are the first, but it is best to be careful.

Where this is possible it is always best to set hens on the ground, for moisture from below is drawn up into the nest and helps maintain the right degree of humidity.

Hatching is more difficult in Southern California than in many places on account of the dryness of the air, and it is usually necessary, except near the coast or in very wet weather, to add a little extra moisture.

\section{OPERATING THE INCUBATOR}

It is always wise for the beginner to follow implicitly the directions that come with the incubator he is using and not to be led astray by anything he may have read or heard on the subject. It is sometimes hard to do this, but it must be done. The manufacturer of the incubator has given much time to learning how best to run it, and he knows more about its peculiarities than any one who has not become acquainted with it. When you have thoroughly learned your machine, its peculiarities and its faults, and the principles on which ventilation 
and moisture are provided for, it is time enough to experiment.

Here are some general rules for running incubators which are given, with much other valuable information on the subject, in Bulletin 585 of the Department of Agriculture, issued May 1, 1914 :

\section{Government Suggestions}

See that the incubator is running steadily at the desired temperature before filling with eggs. Do not add fresh eggs to a tray containing eggs which are undergoing incubation.

Turn the eggs twice daily after the second and until the nineteenth day. Cool the eggs once daily, according to the weather, from the seventh to the nineteenth day.

Turn the eggs before caring for the lamps.

Attend to the machine carefully at regular hours.

Keep the lamp and wick clean.

Test the eggs on the seventh and fourteenth days.

Do not open the machine after the eighteenth day until the chickens are hatched.

In setting up the machine, get it perfectly level. Do not plane off the door if it sticks, until the machine has been heated up and thoroughly dried. Run the machine at about 102 degrees F. for a day before putting in the eggs. Afterwards do not touch the regulator for several hours, as it takes this time for the machine to come back to its regular temperature.

The temperature should remain nearly even. When the bulb of the thermometer rests directly on the eggs the temperature is usually held at 1011/2 degrees to 102 degrees F. the first week, 102 degrees to 103 degrees $F$. the second week, and 103 degrees the last week; while a hanging thermometer is oper- 
ated at about 102 to $1021 / 2$ degrees $F$. the first two weeks, and 103 degrees $F$. the last week.

The eggs tend to throw off more heat as they develop, so that occasionally the regulator needs to be changed slightly, but it should not be changed any more than is absolutely necessary. The temperature of the egg chamber may be lowered by lowering the flame of the lamp in the middle of the day. Regulate the incubator before opening the door to tend to the eggs. Most operators tend to their machines two or three times daily.

\section{Selecting an Incubator}

In selecting an incubator, do not try to save a little money at the expense of future success. The best is none too good. There are many good makes of incubators, but all are not equally good in the same locality. Find out what make the poultrymen in your vicinity are using and whether they are satisfied with it. In this, as in many other things, it is best to follow the crowd.

Do not buy an incubator that is too small. One holding from 150 to 200 eggs is a good size for the man who raises but a few hundred chicks in a season. The fifty and sixty-egg machines may do at first, but it takes no more oil and no more care to run a 200-egg machine, and it is very desirable that you hatch as many chicks at once as possible. When I began using incubators, I bought two fifty-egg machines and kept them going half a hatch apart, thinking that in this way I could better save all my hatching eggs. I saved all the eggs but found myself utterly swamped by so many broods of different ages. One hatch from a 200-egg machine would have given me as many good thrifty chicks as I managed to raise that season, and I should have saved 
much time and strength. Saving labor is the heart and essence of poultry keeping, and money that saves it is well spent.

Professor Brigham in "Progressive Poultry Culture" gives the following points which must be carefully considered in selecting an incubator:

1. The heating system should be safe, of ample power, and under perfect automatic regulation, within reasonable limits.

2. The ventilating system should be capable of easy adjustment, so that the amount of pure air positively supplied to the eggs may be under complete control.

3. It should be possible to ascertain and regulate easily the amount of moisture in the atmosphere of the egg chamber.

4. The walls of the incubator should be sufficiently insulated to prevent the influence of outside temperature causing uneven temperatures on the level of the egg trays.

5. The machine should be made of first-class materials and carefully constructed.

\section{The Incubator Room}

Professor Brigham also makes these suggestions as to the room in which the incubator is operated:

"It should be held at an even temperature and not be liable to sudden fluctuations because of outside changes in the weather.

"Ventilation should be ample and under control, so that there will be no liability of strong drafts of air striking directly against the lamps or the incubators.

"The room should be well lighted, so that all of the operations, including the reading of the thermometers in the egg chambers, can be conducted 
without difficulty or discomfort so far as eyesight is concerned. The windows should be provided with shades if the sun is liable to shine directly upon an incubator while it is in operation.

"It is most important that the floor of the incubator house be firm and solid. I prefer an earthen floor, for then whatever is dropped upon such a floor it will not cause a shock to the embryo. It is always advisable to keep as quiet as possible in an incubator house during the time the machines are working, and for that reason a good lock should be fixed upon the door and only the one attendant allowed to go into the house. An incubator may be worked in a spare room of a dwelling house, and I have known several cottagers who have excellent results every season when using them in such places."

A cellar is generally considered the best place for running an incubator, but it must be dry, as well as well lighted and ventilated. Cement floors are generally preferred to wood or earth, but earth is satisfactory except for the matter of regulating moisture. A kitchen is a very poor place for the machine because of the constantly changing temperature.

\section{Use Good Oil}

Nothing is more certain to spoil a hatch than the use of cheap oil. It is economy to use the best. But the oil can should never be kept in the incubator room, and the eggs should be turned before the lamp is filled lest a minute particle of oil on the fingers touch the egg and kill the embryo. Kerosene is sure death to the germ. I once lost practically all of a hatch because the box in which the hen was sitting had been soaked with kerosene and not enough dirt put in the bottom to keep the oil from 
soaking through into the nest. On such trifling matters as this does the success of a hatch depend.

\section{Test the Thermometer}

The incubator thermometer should be tested at the beginning of every season. Any druggist will test the thermometer for you, or you can do it yourself by obtaining a physician's clinical thermometer, which is known to be correct, and placing the bulbs of both thermometers in water which has been warmed to 100 degrees. The difference should be carefully noted and allowed for in reading the incubator thermometer.

It is also a good plan to test the temperature of the egg chamber by placing several thermometers in different positions on the tray. If the temperature in one part of the egg chamber is lower than in other places, this indicates that that side of the tray is lower and needs to be raised.

\section{The Moisture Problem}

Many incubators require additional moisture at hatching time, but this is a matter that should not be meddled with until you are perfectly sure that yours is this sort of machine. It is a problem the best operator understands but partially, and there is almost as much danger of drowning the chicks by giving too much moisture as of their failing to get out of the shell for lack of it. If the air is too dry the moisture in the egg will evaporate too rapidly. If the air is too moist it will evaporate too slowly. There you are, between Scylla and Charybdis, for no one has yet devised a way of finding out certainly whether the vapor pressure, which is practically the same as humidity, is just right or not. When it has been proved, by previous hatches, 
that additional moisture is necessary, it is best added by sprinkling the floor of the incubator cellar, which should be of cement, if possible, often enough to keep it wet. Sometimes the eggs are sprinkled with warm water several times the last week; sometimes, when they are slow in pipping, a flannel cloth wrung out of warm water and laid on top of the eggs has good results; in many machines a tray of wet sand is used at the beginning and end of the hatch; in others a water pan is provided which is filled with water when moisture is needed, and with others the operator is instructed to dip the eggs, tray and all, in warm water on the eighteenth day, before the incubator doors are closed for the last time. I have found it a good plan, when I used a machine which made no provision for extra moisture, to insert the spout of a kettle full of boiling water in one of the ventilators. If the eggs were pipping slowly this always hurried them up.

Whatever you do, follow the directions with the incubator implicitly until you know you can improve upon them. I have an idea that more failures in artificial incubation come from not following exactly the printed rules for the particular machine used than from all other reasons combined.

\section{DEATH IN THE SHELL}

The death of chicks in the shell, at hatching time or shortly before, is one of the tragedies of poultry keeping, and a problem that has never been fully solved.

Among the reasons that have been advanced for these untimely deaths are the following:

1. Too much moisture, which makes the chick so large that it is cramped for room and cannot break through the shell. 
2. Too little moisture, which causes excessive evaporation. The chick lacks bulk and is unable to exert sufficient pressure to break the egg, or when it does do this the inner lining of the shell dries on it and $k e$ es it from moving.

3. Irregular temperature during incubation, wh i c h weakens the germ so that the chick dies before it can free itself.

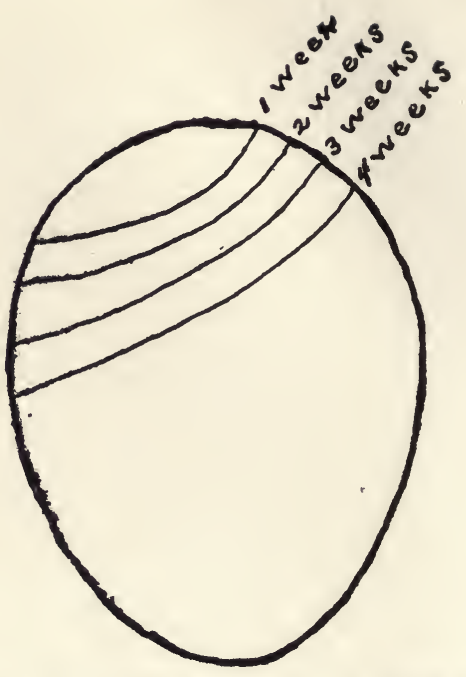

FIG. 19-DIAGRAM SHOWING AIR CELLS AT DIFFERENT STAGES OF INCUBATION

4. Weakness in the chick, due to lack of vigor in the parent stock.

5. Too high temperature the first days of incubation.

6. Too low temperature in the under parts of the egg.

7. Strangulation, caused by the chick becoming choked with unused albumen.

8. Lack of adequate ventilation during third week of incubation.

9. Excessive ventilation during last half of incubation period.

10. Keeping hatching eggs too long, which weakens the germ and causes loss of hatching power.

11. Failure to turn the eggs daily, which causes 


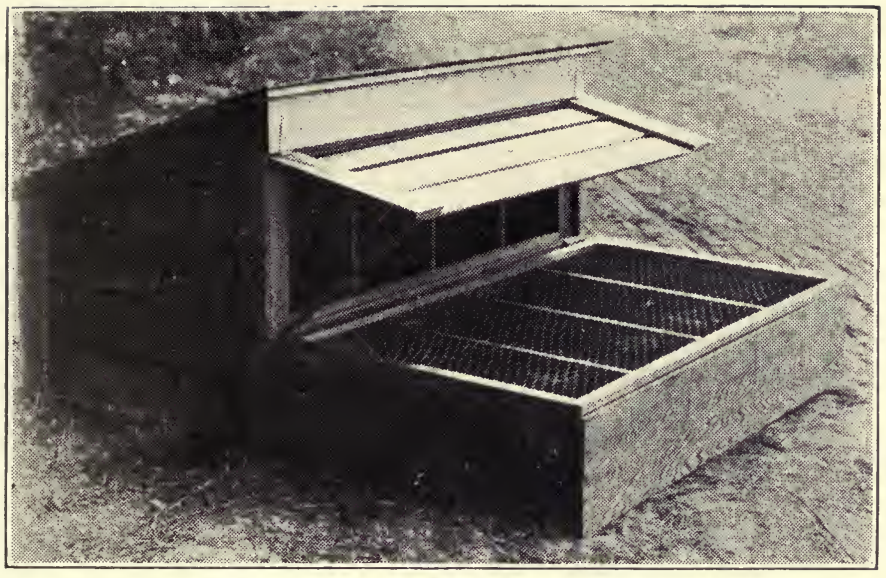

FIG. 21-HATCHING AND BROODING COOP

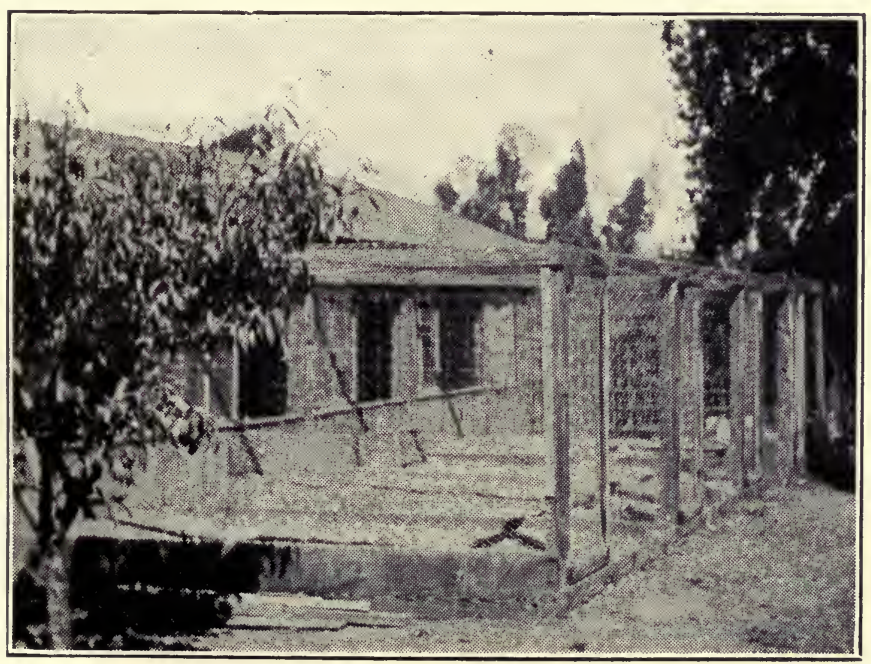

FIG. 22-BROODER HOUSE AND RUNS ON POULTRY RANCH, RIVERSIDE 

the germ to adhere to one side of the egg and prevents its development.

Chicks that have been unable to free themselves from the shell may often be freed by the operator after the hatch is over. Break the shell where the egg has been pipped, or make a tiny hole with a pin if you hear the chick peep inside an unpipped egg, being careful not to puncture the delicate membrane which surrounds the chick; then carefully break away enough of the shell so that the chick can work itself out. Sometimes dipping a pipped egg into warm water, without, of course, allowing the water to enter the hole, or wrapping it in a flannel, wet in warm water, will bring the chick out. The chick should always be laid in a warm place while it is hatching itself, and it is usually safer not to leave it under the hen. She is almost sure to crush the little helpless creature.

When the chick is weak because the parent stock was weak or on account of faulty incubation, there is nothing to be gained by helping it out of the shell. It will die sooner or later or, if it lives, will be a runt.

Recent investigations have shown that weakness of the germ is probably responsible for by far the larger part of these untimely deaths. A vigorous germ develops into a strong chick which will manage to get out of the shell somehow in spite of lack of moisture. It is noticeable in every hatch that it is the strongest chicks that come out first, while the late hatched chick is rarely worth raising. Vigor in the parent stock and frequent introduction of new blood are the best means of producing germs that will hatch in spite of faulty conditions. If one cannot afford to send away for new blood every year, he can usually manage to trade cockerels with 
a neighbor, and the result of this out-breeding will soon show in the increased hatchability of germs and livability of chicks.

The fact that the percentage of eggs hatched by hens is hardly larger than the percentage of those hatched by incubators seems to indicate that the failure of eggs to hatch is due to something farther back than incubation, a nd this som et hing is probably careless breeding. Very few amateurs can resist the temptation to breed from a large, well-colored bird, whether it is vigorous or not, and here is probably the secret of most of our trouble. Careful at-

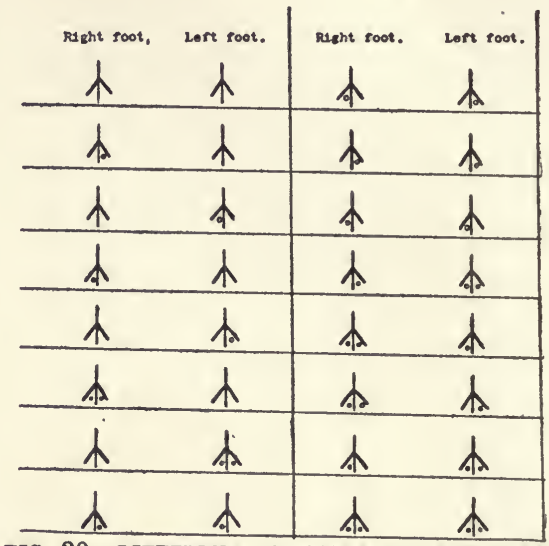

FIG. 20-DIFFERENT TOE MARKINGS FOR BABY CHICKS

tention to the principles of breeding, though it seems to entail present loss, will certainly lessen considerably this deplorable loss of life in the shell.

\section{Marking Chicks}

In order to know the age of chicks, and also of the adult fowls, and in order to know the parentage of different broods, some method of marking is absolutely necessary. After they are grown the birds may be banded with leg bands showing a number, and a complete record kept by number, but while they are small this is impracticable.

The best method of marking is to use a punch, 
which costs 25 cents, punching the web of the foot on one or both sides. Sixteen different markings are possible (Fig. 20). By keeping a careful record of these you may know the exact age of every bird in the flock.

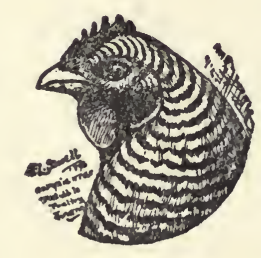




\section{CHAPTER IV.}

\section{Brooding}

\section{REARING BABY CHICKS}

The principles of chick raising are the same, whether the chicks are raised by hens or in brooders or in a box with a jug of hot water. Warmth, nourishment, fresh air, cleanliness, sunshine and exercise, and protection from insects and marauding animals are the sum total of the requirements, and the art of rearing every chick hatched, providing the parent stock is what it should be, is simply the art of giving careful attention to these details. Losses of chick life each year are enormous, averaging the country over, half the chicks hatched, and by far the greater part of these could be avoided by painstaking attention to these simple, essential requirements of all young life.

Rearing chicks with hens is easier and more satisfactory than raising them in brooders, despite the "crankiness" of the mother hen. It is Nature's way, and provides a combination of warmth with fresh air and exercise which can not be duplicated in any other way. Sometimes it is best, when several hens are caring for large broods all the same age, to put hens and chicks together in a large yard, confining each hen in her own coop. If they are together from the start, the chicks will run together, and the hens will know no difference, but will brood any chick that comes. By putting four hens with 100 chicks in such a yard the chicks can be fed with much less trouble, and a fine flock will grow up together. 


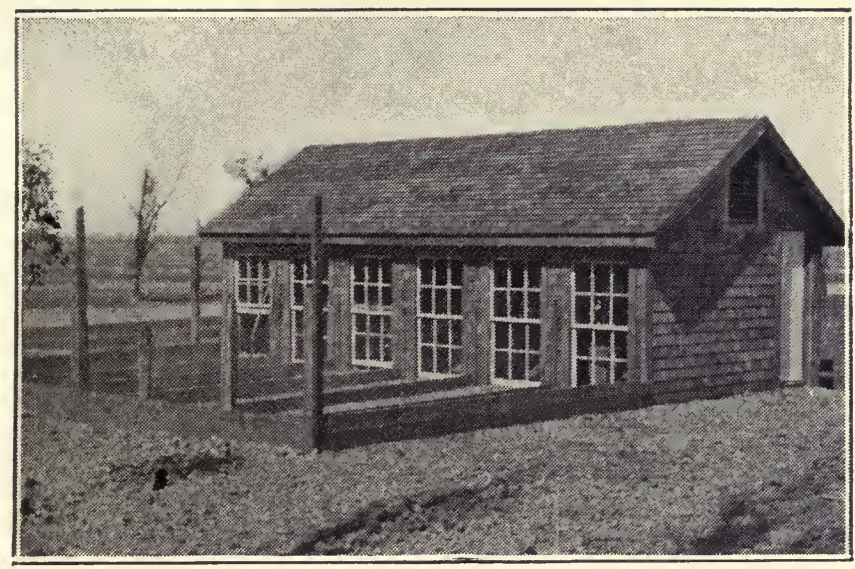

FIG. 11-BROODER HOUSE. 1200 CHICK CAPACITY

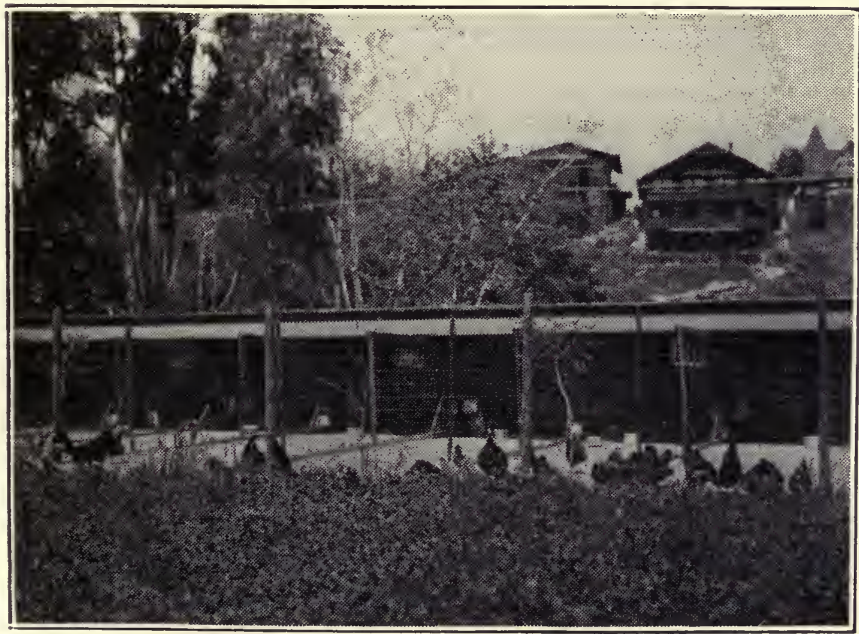

FIG. 12-SIMPLEST FORM OF LONG HOUSF FOR LAYERS OR BREEDERS ACCOMMODATES 125 LEGHORNS OR 100 HEATY HENS 

Such a plan is not possible on large poultry plants where thousands of chicks are raised yearly, but it is entirely feasible where 500 or 600 are raised.

\section{Warmth the First Essential}

Rest and warmth are the first requirements of a newly hatched chick. The last day of hatching it draws into its abdomen the yolk of the egg, and this is food enough for the first two days. All it needs now is to lie quietly in a warm place and sleep, but it must be warm or it cannot sleep. Lack of sufficient heat the first two days is the great cause of bowel trouble and death. A slight chill causes indigestion, there is diarrhea (not white diarrhea), the chick becomes pasted up behind, stands around "hunched up" and miserable, and soon dies. It is extremely important, therefore, that in moving chicks from incubator to brooder, or from sitting box to coop, every precaution be taken to prevent chilling; that brooders be so warm that the chick will lie down comfortably and sleep, and that mother hens, if they do not understand their business, be compelled to brood their charges or give them up.

Just how soon after hatching a chick should be fed is a mooted question among experts, but all agree that it should not be less than forty-eight hours. In most broods some chicks will begin to hunt for food while others are still resting under the hen. These older chicks should be fed when they seem hungry. Those that are not ready to eat will not eat.

Overcrowding is one of the greatest enemies to the growth and health of baby chicks. A brooder that is just right when the chicks are first hatched will be far too small when they are three. weeks 
old, for a normal chick doubles its size in three weeks. See that the growing chick has room to grow in. If it has not, it will be a runt. Chicks do better in flocks of not more than fifty, and when particularly fine chicks are wanted, they must be raised in smaller flocks than this. On large plants it is necessary to brood hundreds of chicks together, but losses are greater. The Leghorn, however, which is always kept on these large egg farms, can bear much more crowding than other breeds.

Protection from lice and mites and from all sorts of animal foes is a vital part of chick raising. No chick can thrive when it is infested with lice, and the red mite, which sucks its blood at night, is a deadly enemy. Dusting or greasing hen-hatched chicks when they are first hatched, and once a week afterward; dusting brooder chicks every week; keeping all sitting hens free from lice, and using some good lice paint on coops and brooders to keep mites from finding a hiding place in them, will keep chicks free from these troublesome pests.

Cats, dogs, hawks, squirrels and the like are not so easily guarded against. Covered runs are the best solution of the problem, but chicks ought to have range, if it is at all possible, after the first week or two, and it is a pity to be obliged to deprive them of this because of marauding animals. Every poultrykeeper will find his own way of controlling the neighbor's dog or cat. Sometimes the chicks will have to be shut up; sometimes the animals can be confined.

In California coops and runs for baby chicks should always front east, so that the chicks may have the morning sun and be protected from the western coast winds. Exposure to these winds is very detrimental to young stock, and they should 
always be provided with some sort of windbreak. Burlap sacks, fastened to the side of the coop from which the wind comes, make an excellent windbreak in ordinary weather, and in very stormy weather the coop may be placed in the lee of a house.

Hardly less important than warmth, even at the start, and even more important in the long run, is an adequate supply of pure air. Chicks cared for by hens in open coops breathe fresh air day and night. The brooder chick is handicapped in this respect, and the greatest care should be used in selecting a brooder to make sure that it has a good circulation of air under the hover. Professor Rice says in one of his Cornell bulletins: "Pure air is of more importance to fowls than it is to other domestic animals because of the warmer temperature of the fowl's body. This high body temperaure is maintained by combustion of the food nutrients contained in the blood in the presence of pure air. Without pure air perfect combustion is impossible. Without perfect combustion the chick cannot be warmed from within the body and therefore will not be comfortable nor healthy even in a warm brooder. The chick is a quick-growing, quickbreathing animal, requiring rapid digestive and assimilative changes, and therefore suffers seriously and quickly when closely confined and compelled to breathe impure air. Leg weakness is almost certain to result from close confinement and heavy feeding, which usually are accompanied by a close and more or less vitiated atmosphere."

\section{THE HEN AND HER BROOD}

When the hen is hatching she should be left quietly on her nest and not disturbed, except by slipping the hand under her to remove the egg shells, 
till the hatch is over. If she will eat from the hand she may be given a little whole corn or wheat, but she will not suffer if she is not fed. When the chicks come out from under the hen and begin to climb about the nest, it is time to remove them to the coop.

There is no better brood coop than can be made from a good-sized drygoods box sawed through the middle at an angle so that there are two coops, each with a shed roof. The roof must be made tight, and there must be no cracks in back and sides. Wire may be tacked across the upper part of the coop to keep out rats, and there should be a sliding door of two-inch wire so that the hen may be confined while the chicks go in and out. A wire run of oneinch mesh about two feet high, four or five feet long, and as wide as the coop, is used with it, and may be attached to the coop by a hook and eye. The coop should have a board floor. While chicks can be brooded on the ground in dry weather, they need a floor when it is wet.

A grocery box, if it is high enough for the hen to stand up in, makes a good brood coop, and has this advantage, that, having cost but little, it may be discarded at the end of the season. This is a great advantage in California where mites have always to be dealt with.

The old-fashioned A-coop may often be made from scraps of lumber, and is as good as any if it is not used with a run. It would be particularly suitable where several broods are kept in one yard.

Before hen and chicks are removed from the nest, see that the coop is perfectly clean, and cover the floor with a layer of clean sand covered with fine cut alfalfa. Scatter a handful of grit and another of steel cut oats over the litter. The addition of a 
fountain of clean water completes the preparation of the coop.

If the chicks are put into the coop the morning of the second day after hatching, the steel cut oats in the litter will be all they need till night. About five o'clock give a hard-boiled egg chopped, shell and all, with an equal amount of dry bread as an appetizer, or, if that is not convenient, scatter more steelcut oats or rolled oats. There is no special virtue in egg and bread, but the chicks like it and eat it a little more eagerly than they do the dry feed. A little onion chopped in is good for them. (Fig. 32.)

The second day a dish of dry bran may be set before them, and more steel-cut oats scattered. Cracked wheat may be added to the oats or commercial chick feed given instead. It is a good plan to give an occasional meal of egg and bread the first five days. Chicks grow faster when they are coaxed a little. After five days they can settle down to commercial chick feed and the Cornell chick mash, with lettuce once a day.

The hen should be confined in the coop for a week at least. If she does not brood the chicks as she should, darken the coop, but the confinement is usually sufficient. $\mathrm{A}$ hen that does not pay proper attention to her brood should be discarded. Let the chicks go back and forth through the wire door as soon as they are old enough to find their way back, but confine them in the wire run until they are several weeks old. If the weather is fine, and there are no dogs or cats about, they may be out after ten days.

Keep the hen in the run at all tımes. She will be much easier to manage and will not be able to tire the chicks out by dragging them too far or to chill them in the early morning dew, and the chicks 
will always know where to find her if they want her. The hen is the best mother for chicks, but she must be managed.

It is a good plan to have an oil cloth cover for the run, in case of rain, but burlap sacks are a better protection from the sun. Never leave hen or chicks without shade. The glare of the sun is uncomfortable for the hen and may kill the chicks.

Give fresh water every time the chicks are fed, and keep grit in a shallow box or pan where they can always reach it. On very gravelly soil this may not be necesary, but it is always safe.

Dry mash should be kept before the chicks at all times, and the grain scattered in the run or kept in a feeder. Where chicks have range they will not overeat even if not made to scratch for their grain, but where they are confined in the run they must be made to scratch.

Protection from lice is a more serious problem with hen mothers than when chicks are artificially brooded. The hen should be kept clean during incubation and dusted just before the hatch comes off. If the head and throat of each chick are greased with lard when they are put in the brood coop, there will be no danger of head lice, but hen and chicks must be dusted once a week or they will soon be infested with ordinary hen lice, and their growth hindered. This matter of lice is a vital one with chicks and turkeys and is of itself enough to make the difference between success and failure in the chicken business.

The coop should be cleaned out at least once a week, and clean nesting material put in. Hose out the coop whenever it is cleaned, and once a month paint with kerosene and crude carbolic acid-one part acid to three or four of kerosene. Coop and run 
should be often moved to new ground. Clean coops, clean ground and clean water are more important than the kind of feed, but all are very important.

\section{ARTIFICIAL BROODING}

In England, when brooders were first invented, they were called "foster mothers," a most suggestive title and indicative of what the brooder's function should be.

- Three types of brooders are in general use on farms and poultry ranches:

1. Fireless brooders.

2. Indoor and outdoor lamp brooders.

3. Colony-house brooders heated by gasoline, distillate or hot water.

\section{Fireless Brooders}

The fireless brooder has come to stay; there is no doubt about it. It is hardly suitable for use in very cold weather unless in a heated room where the temperature does not go below 40 degrees at night or 60 degrees in the daytime, but for ordinary weather, and especially in warm climates, it is more economical for the user and more healthful for the chicks than a lamp heated brooder.

The fireless brooder in common use is a box from fourteen to eighteen inches square, with a door on one side. A frame made to fit the box loosely, so that air may come in around it, rests on a peg in each corner, and to this is tacked a square of canton flannel which sags in the middle so that it rests on the backs of the chicks. On this is laid a quilt made of cheesecloth and cotton batting. If the night is very cold another quilt is added. Roofing paper covers the bottom, and the box is filled in with straw or chaff, so that the chicks have a warm nest to cuddle in under their quilt. 
A box like this accommodates twenty-five chicks, no less and not many more. A smaller number cannot keep each other warm, and a larger numbermore than forty, say-will crowd together and crush each other. In warm weather and when kept in a warm room these brooders are very successful, and it is often possible to keep chicks a week in one of the lamp brooders, and then transfer them to a fireless brooder where they have a better chance for fresh air and exercise.

\section{The Lamp Brooder}

Indoor and outdoor lamp-heated brooders have been very popular but are being discarded for the fireless brooders on the one hand and the colonyhouse brooders on the other. The objections to lamp brooders are:

1. Their small size. Most of them, though they may be advertised as holding 100 chicks, are really suitable for but fifty, and this, if several hundred chicks are to be raised in a season, is too small a number to brood at once. The more chicks you can raise at one time, the easier is the work of hatching, which is arduous enough at the best, and the easier is it to care for the growing chicks.

2. Lack of exercising space. The chicks do very well for a week or two, but the exercising room is of necessity too small to accommodate them long, and a stairway up and down which they must pass is a delusion and a snare.

3. Difficulty in getting the chicks far enough away from the heat. As the chicks grow they need to be more and more in the cool, fresh air, and this is not always easy to manage with a lamp brooder.

Probably the lamp brooder which most nearly meets the conditions of successful brooding is the 
style which is heated by hot water pipes and can be built, in a manner, into the brooder house. A brooder house fitted up with such brooders is shown in Fig. 22. The house contains four brooders, each with its indoor run and its outdoor run. The east side of the house, which the brooders face, is all windows, and these can be opened in warm weather or closed if the weather is cold and stormy. Four hundred chicks are cared for at once in this house, and the owner finds it much more satisfactory than brooding with hens.

\section{The Colony-House Brooder}

Where more than a hundred chicks are to be raised artificially, the colony-house brooder is the thing. A colony-house $8 \times 10$, holding from two to three hundred chicks, can be built and heated for about $\$ 30$. A house twelve feet square with a little larger heater will brood 600 chicks at once.

There are many different heating systems for these houses. Some heat with hot water pipes, some with gasoline or distillate stoves, usually with hovers, but sometimes without. A person contemplating such a brooder-house should investigate the different heating systems on the market and select one which is most generally used. The gasoline heating system in use at the Cornell Experiment Station is very highly recommended, and, as it is not patented, is not expensive. A descriptive circular may be had by writing the College of Agriculture, Cornell University, Ithaca, N. Y.

One advantage of such a system as this is that the house may be used the year round. After the chicks no longer need the heat, the heater may be removed, and the house used as roosting house for the young stock. Later, the house, if it is portable, 
as such a colony house should be, may be moved out into a field and used for pullets or breeding stock.

With a house of this style chicks may be given as much range as is convenient. A small side door allows them to come and go as they will, and there is no limit to the ground they may range over.

CARING FOR BROODER CHICKS

The trick of caring for brooder chicks consists largely in finding out what the fault of your particular make of brooder is, and then overcoming it.

\section{In Fireless Brooders}

All things considered, there is probably no more risk in raising chicks in fireless brooders than in other artificial brooders, and it is much cheaper. The brooder should be kept indoors the first week and should be under sheiter at night for several weeks, depending on the weather. If one is going to raise a considerable number of chicks in this way it is best to have a brooder house and to arrange for some kind of heat.

Breaking the chicks to the brooder is no more difficult with fireless brooders than with others. The chicks, when first taken from the incubator, should be covered up warmly and left to sleep till they are at least forty-eight hours old. Then let them out into the run with which every fireless brooder must be provided, and let them peck at the sand and take a drink of water. After half an hour, or less if they seem cold, shut them up for another rest, and after an hour or so let them out again and scatter rolled oats or steel cut oats on the sand. This program must be kept up till the chicks have learned to go in when they are cold and out when they are hungry, but the caretaker must remember that one chick 
alone will not be warm in the brooder, unless the sun is shining on it. Fireless brooders should always be put in a sheltered place where they will get the sun. Probably there is nothing better than a Philo coop fronting south for this purpose. When there is no sunshine, it is a good plan to give the chicks a jug of hot water, wrapped in flannel, to cuddle about during the day. At night when shut in the brooder, they will keep each other warm.

Just how often the chicks should be let out of the brooder these first few days is a question of temperature and the disposition of the chicks. If they wish to be quiet, leave them alone. If they are restless and impatient, let them out more. If they seem chilly, get them in at once. Never, never, allow chicks to huddle. The minute they begin to lean against each other, get them in. This is the sign that they are cold.

There are no set rules for raising brooder chicks. The best any one can do is to use his common sense. The caretaker of a brooder flock is in loco parentis always and must expect to do anything a hen does except cluck.

If the chicks do not seem warm enough, it is a good plan to set a jug of hot water in the brooder. The quilt will have to be removed, and a blanket spread over the top of jug and box, so that it rests on the backs of the chicks. This is a very satisfactory way of brooding chicks, for they like nothing better than to cuddle against something warm, but it is difficult to maintain the proper temperature.

\section{In Heated Brooders}

With heated, as with fireless, brooders the main problem is warmth, only in using the heated brooders it is still more difficult. Here you have over- 
heating as well as chill to guard against, and the ventilation problem as well. If I should attempt to classify the enemies against which one must contend with different ways of brooding, it would be something like this:

Hens-Vermin.

Fireless brooders-Chill and vermin.

Heated brooders-Chill, vermin and overheating.

The more artificial your system becomes, the more complications arise and the more watchful must the caretaker be.

Before the incubator hatch comes off, the brooder must be ready. It was disinfected when it was put away at the end of last season's work and again at the beginning of this season's, and it must certainly be cleaned and disinfected between hatches, not so much from fear of white diarrhea, as because of the wicked red mite, which is a more dangerous foe. After the brooder has been swept and washed till it looks clean, go over it with a cloth, wet in water containing a little creolin. If the brooder has been infested with mites, this will not be sufficient. Every bit of wood should be painted with the kerosene and carbolic acid mixture ( 1 part crude carbolic acid to 3 or 4 of kerosene). Go over it inside and out, for mites will go through if there is a tiny crack anywhere.

When it is thoroughly clean, cover the floor of the brooder with clean, coarse sand, and on top of the sand scatter cut alfalfa, either green or dry. A little dry straw under the hover will help to make the chicks comfortable. Scatter grit and steel-cut oats in the litter, and provide a fountain of fresh water, and your brooder is ready, except for the matter of heating.

The brooder lamp should be cleaned and filled 
and lighted at least twenty-four hours before the chicks are to be taken from the incubator, and the thermometer should |show a temperature of 100 degrees or more. Remember the chick comes from a temperature of 103 or 104 degrees, and while the temperature was lowered somewhat while he was in the nursery, it was not enough to harden him. Remember too, that the hen's temperature, if she were brooding him, would be 105 degrees, and that he likes to be very warm. If your brooder lamp, like one I used, does not heat the brooder sufficiently, add hot water in pails, jugs or jars till you reach the 100 mark.

Directions for using brooders usually say: "Leave the chicks in the incubator nursery twenty-four to forty-eight hours after hatching." This is all right for experts, but for beginners I believe it is safer to take the chicks from the nursery as soon as the hatch is over and put them in a flannel-lined box or basket. Cover them well with a warm blanket, and if they do not sleep quietly, let them have a flannelwrapped jug of hot water to cuddle about. I say this because I have found it very difficult to control the heat in the nursery of an incubator. If the thermometer is left hanging where it was during the hatch, it will not show what the temperature is in the nursery, and if it is placed in the nursery it is more than likely to be knocked over, so that you cannot see it at all. If the chicks lie quietly and sleep, the heat may be just right, or it may be too high. If they stand up or peep miserably, they are cold. A newly hatched chick never peeps if it is comfortable.

The idea is to gradually lower the temperature from the time the chicks are out of the shell, and you cannot do this unless you know the temperature. 
When the chicks are once in the brooder (of course they have been kept carefully covered in transit) you can soon find out whether the brooder is warm enough. If the chicks lie flat under the hover and sleep, they are warm; if they stand up, they are chilly. "Give them heat till they flatten out" is an excellent rule.

It will be necessary at first to fasten the chicks under the hover with a board, only letting them out to eat the first day, and they must be pushed back under the hover from time to time when they seem cold or when it is time for them to rest, till they have learned where to go when they are cold or tired. The mother hen calls her babies constantly the first few days, and they learn almost at once that that soft, comfortable cluck means comfort. The person who cares for an incubator brood must be just as unremitting in his attention as the mother hen. Neglect the first four days means great loss. After this time the chicks rapidly become hardened and may be left longer to themselves.

Chicks reared in heated brooders need heat for about six weeks, but chicks that have been transferred to fireless brooders at two or three weeks of age soon learn to do without artificial heat and are more vigorous without it.

\section{Cold Brooders}

When they have outgrown the need of heat, chicks in the colony-house brooder will begin to roost on low roosts which are provided in the same house. Chicks raised in lamp or fireless brooders can be transferred at this time to small coops, called cold brooders, where they can roost if they wish. It is not usually necessary to teach them to roost. They will learn gradually if the roosts are there. 
When I transfer chicks from the brooder to the cold brooder I give them a box or basket of litter to sleep in. This is cleaned out every day, so they

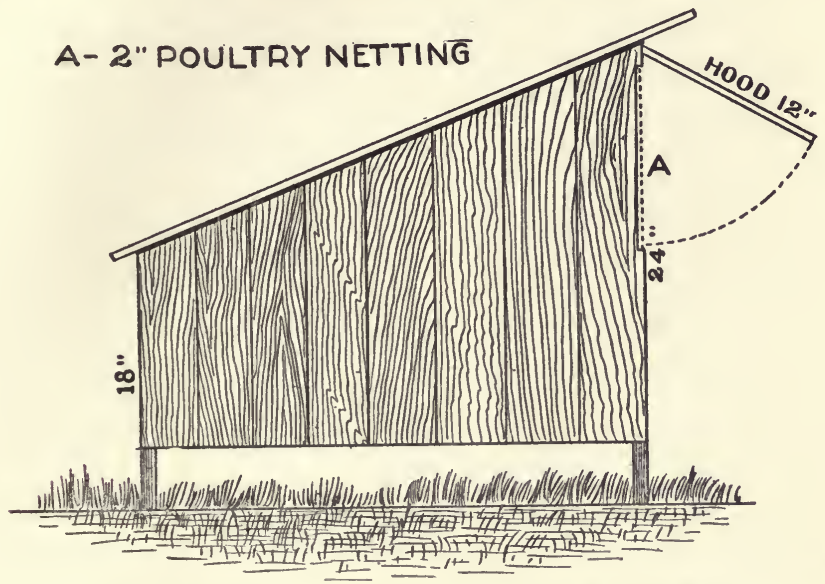

FIG. 23- COOP FOR CHICKS JUST OUT OF BROODER

have always a comfortable bed beneath the roosts. One by one they find their places on the roosts without further trouble on my part.

\section{EXERCISE FOR CHICKS}

With the exception of the necesary warmth the first week after hatching, nothing is quite so vital to the life and health of the chick as exercise. Its importance cannot be overestimated. It means good digestion, muscular development, all, in fact, that it means to human beings. Pullets that have not as chicks had sufficient exercise to develop the egglaying organs rarely make good layers. It is the sine qua non with all fowls, but especially with growing chicks, for they are laying the foundation for later vigor and usefulness. 
Green range is the best solution of the exercise problem. Chicks that are on range need no other exercise, and one has only to watch the activity of a brood of chicks two weeks old to realize what it means to be deprived of this outlet for the energies.

It ought to be possible on any farm to give chicks free range. On a back lot it is more difficult, but by fencing in the garden with inch-mesh wire some range may be given, and young chicks, if the hen is confined, will not hurt the garden.

A patch of alfalfa for the exclusive use of chicks may be easily had anywhere except on a city lot. Even a small patch will do. The chicks can pick their own green feed and much of their animal food in the shape of insects, and they get the exercise, which is beyond price.

When green range cannot possibly be had, deep scratching litter is the best substitute. At the California experiment station brooder chicks are made to dig for every grain as soon as they have learned to eat.

\section{KEEP YOUNG STOCK GROWING}

It is not enough to get chickens well started. While it is true that a chick three weeks old is half raised, there is still the other half of the raising to accomplish, and failure anywhere is fatal, not to life, but to profit. Lice, overheating, lack of ventilation, overcrowding, insufficient or improper food, exposure to chill winds, may any one of them give a setback from which the chick will not recover.

Pullets that are depended on for fall eggs must make steady growth from start to finish. The development of the egg-producing organs is not a thing apart which takes place just before the fowl begins to lay. It is coincident with the development of the 
rest of the body, and so small a matter as the constant teasing and irritation of lice is enough to affect it.

At two months of age pullets and cockerels should be separated, the cockerels confined and fattened for broilers and the pullets put in colony houses where they will have as much range as possible.

A colony house $8 \times 12$ will hold fifty Leghorn pullets and a somewhat smaller number of pullets of the heavy breeds. 


\section{CHAPTER V.}

\section{Feeding}

\section{POULTRY FEEDS}

Food substances are classified as (1) water, (2) carbohydrates, (3) fat, (4) protein, (5) ash.

Water constitutes about three-fifths of the egg and three-fourths of the body of the fowl. An abundant supply of pure water is therefore a necessity to both chick and laying hen.

Carbohydrates are the sugars and starches. They make up the greater part of all grains and are used to produce heat and energy.

Fat is stored up heat and energy. One pound of fat develops two and a quarter times as much heat as a pound of sugar or starch. In finding the nutritive ratio of any feed the amount of fat is multiplied by $2 \frac{1}{4}$, and expressed as carbohydrates. This is for convenience merely.

Protein is the general name for all substances which contain nitrogen. It is the muscle and tissue maker and constitutes all the solid part of the white of an egg. Chicks cannot grow nor hens lay without protein. Protein can take the place of carbohydrates as a producer of heat and energy, but nothing can take the place of protein as a repairer of the waste of the body or for making eggs.

Ash is the mineral matter which would be left if everything else were burned away. It is necessary for bone making.

The proportion which the digestible protein in any kind of feed bears to the digestible fats and 


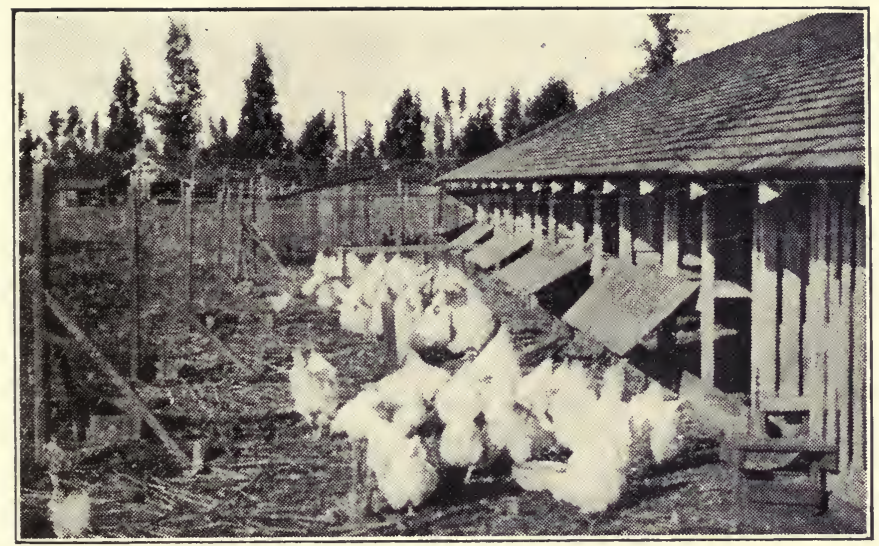

Fig. 17-BREediNg house With ADJUSTABle DoOrS

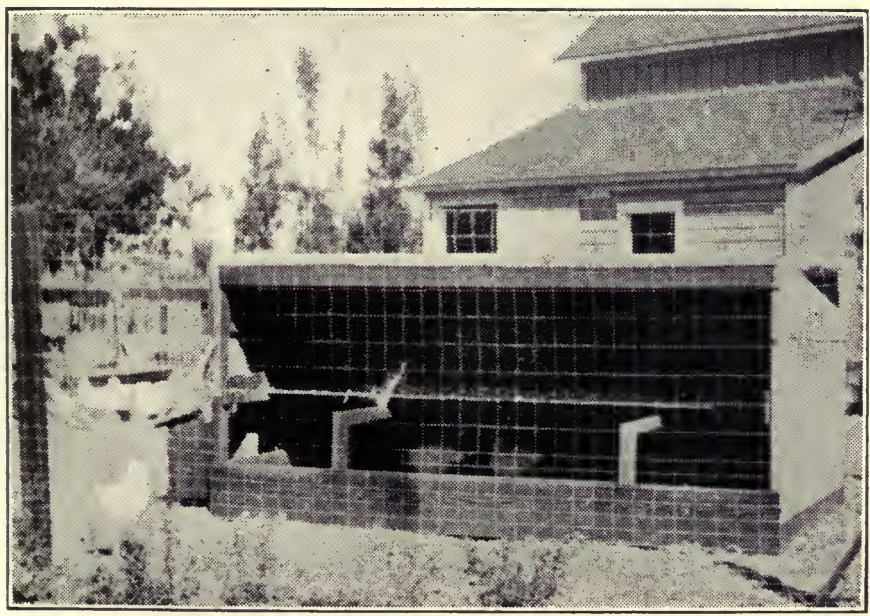

FIG. 18-PORTABLE TARRED-PAPER HOUSE 

carbohydrates is called the nutritive ratio. Thus, when we say the nutritive ratio of shrunken wheat is $1: 6.5$, we mean that the wheat contains one part protein to six and a half of carbohydrates and fats. There is a difference between the actual protein and that proportion of the actual protein which is digestible. Some substances like oat hay contain a good deal more protein than it is possible for animals to digest, while others like peas and beans contain the protein in such shape that it is nearly all digestible.

This matter of digestibility of protein in its various forms is a very difficult one to understand. Probably no one does quite understand it. Milo Hastings says in "The Dollar Hen": "In digestion these proteins are all torn to pieces and built up into other kinds of protein. Just as in tearing down an old house only a portion of the material can be used in a new house, so it is with protein, and laboratory analysis cannot tell us how much of the old house can be utilized in building the new one."

It is enough for us to know that protein is required and that some feed substances contain more of it than others.

Bulletin 164 of the Agricultural Experiment Station at Berkeley goes into the composition of various feedstuffs very carefully, and should be in the hands of every feeder of poultry. I quote from it the nutritive ratios of a few of the most common feeds :

Wheat, shrunken......... $1: 6.5$ or $1: 4.6$

Wheat, plump............... 1:6.9

Oats .................... 1:6.2

Barley ..................... 1:7.7

Beans, dried................... 1:2.9

Corn, Indian . . . . . . . . . . . . . 1:8.5

Corn, Kaffir ................. 1:10.3 
Linseed meal. ................ 1:2.5

Alfalfa, green ................ $1: 2.3$

Alfalfa, hay $\ldots \ldots \ldots \ldots \ldots \ldots \ldots \ldots$. $1: 3.3$

Cabbage .................. 1:5.1

Beet, mangel................ 1:5.1

Bran ...................... 1:3.4

Corn meal................. 1:11.5

Middlings ................. 1:5.1

Beef scrap............. 1:0.3 to $1: 1.1$

A narrow nutritive ratio is one in which the proportion of protein is large. A wide nutritive ratio is one which contains a larger proportion of carbohydrates. In California a nutritive ratio of $1: 4.5$ or $1: 5$ is preferred to the wider ratio of $1: 6$ generally prescribed in the East.

\section{The Balanced Ration}

Far easier to understand is the classification of foodstuffs into (1) grains, (2) animal food, and (3) green food. A combination of these three kinds of feed in the proportion which has been found best for maintaining the health of the fowl is called a balanced ration. Technically, a balanced ration is a combination of the food elements, carbohydrates, protein and crude fiber in a given proportion. Practically, no one needs to understand these chemical terms in order to be a good feeder. A grain ration of wheat and corn at night, with a dish of dry bran to add bulk, plenty of green feed, and fresh meat twice a week to take the place of the bugs and worms the fowl would find on free range, makes a perfectly balanced ration. It is only because a slightly different mixture may better suit the needs of growing stock or force a few more eggs from the laying hen, or because cheaper foodstuffs will answer the same purpose that we need to devise different mixtures. 
Variety is the main object and purpose of all rations. The hen will very likely pick through the mash that is set before her and select the ingredients she likes best, but at least she has been able to get them. It would probably be just as well to set hoppers containing bran, corn meal, beef scrap, etc., each by itself, so that the hen may balance her ration to suit herself, but this is not quite as convenient as mixing them, and feeders still have an idea they can make Biddy eat what they please and not what she pleases.

\section{Grains}

Wheat is the best single grain and is so nearly a balanced ration in itself that fowls will thrive on a diet of wheat alone for a long time. Its nutritive ratio of 1:6.5 or less brings it quite near the nutritive ratio of $1: 5$, which is considered best for fowls in California, and its lack of husk renders it very palatable to the fowl. The only objection to wheat is its cost, which is so great that other grains must be used with it.

Corn is used more than wheat in the East, but is too heating for this climate save when used in great moderation or for young or market stock. A little corn may be part of the grain ration for the Mediterranean breeds, but it is better left out of the ration of the heavy breeds. Corn meal is used in all mashes in winter.

Oats, with a nutritive ratio of $1: 6.2$, are nearer the perfect feed than wheat in theory, and not as fattening, but in practice the hulls are an objection. It is difficult on this coast too to get the large white oats which are recommended by English feeders, and those we do get are best fed sprouted. Rolled and 
steel cut oats are the best of feeds for young chicks and turkeys.

Barley is the one grain that is cheap in California and can well be used as the larger part of the grain ration. Fowls are not fond of it dry, but the whole grain soaked twelve hours and drained till it is nearly dry, or about twenty-four hours, and mixed with a small amount of wheat and whole corn, makes an excellent grain ration for Leghorns. Rolled barley may be steamed or soaked to make it palatable. Ground barley is largely used in mashes. Its nutritive ratio is $1: 8.1$, a little narrower than that of rolled barley and a little wider than that of whole barley. Barley meal is more expensive and contains more protein. It is very good in a ration for chicks.

Bran and middlings are by-products from the milling of flour and are an important part of mash rations all over the country. Bran has a higher nutritive ratio than wheat. Middlings contain considerably more digestible carbohydrates than bran, and hence are more fattening. Bran is valuable, not only for its high protein content, but because it adds bulk to the ration.

Stale bread can sometimes be had quite cheaply from bakeries and restaurants and is an excellent food. Its nutritive ratio is about the same as that of wheat. It is most satisfactory when used in the moist mash. Bread that has commenced to mold should never be used. No drying or heating can destroy the mold spores, and these are very injurious to fowls of all ages.

\section{Vegetable Protein}

Peas and beans contains a great deal of protein and are excellent for fowls when they can be bought cheaply and prepared in such a way that they are 
palatable. Peanut meal and the four oil cake meals, linseed oil cake meal, cocoanut oil cake meal, cotton seed meal and soy bean meal, are all very rich in protein and are used in the dry mash in addition to the animal food when a forcing ration is required and at molting time, but they are too expensive to be used in large quantities and are so rich in oil that they affect the bowels unless used with great care.

\section{Animal Foods}

Fresh meat is the best of all animal foods. Sometimes it can be had in the form of green cut bone or pluck cheaply enough to supply all the animal part of the ration, but usually this is impossible, and feeders are forced to depend on beef-scrap, one of the by-products of the big meat packing establishments, and fish scrap. Beef scrap contains a very large amount of protein and is therefore generally used in the mash to balance the grain part of the ration. Fish scrap has recently come into use as a substitute for beef scrap and is used with it in the mash, but does not altogether take its place.

Much of the beef scrap on the market is not fresh. The only way to find out whether it is fresh or not is to pour boiling water over it. If it gives out a good meaty odor, it is good.

Milk, in the form of skim milk, clabbered milk or cottage cheese, is the best animal food there is for poultry. The clabbered milk is particularly good for young chicks and is said to prevent the multiplication of bacteria in their intestines. Where enough milk can be had, and enough is all the fowls will eat, no other animal food is needed.

\section{Green Feed}

The importance of green feed can hardly be over- 
estimated. It is not primarily an egg producer, as animal food is, but it is so essential to the health of the fowls that there can be no steady production without it.

Green feed is equally important to growing chicks and contains mineral salts that are very essential to growth and well-being.

Probably alfalfa, containing as it does 4.94 per cent crude protein, which is nearly one-fourth the solid matter which composes it, is the best green feed for poultry. On most large poultry plants a patch of alfalfa is grown and cut up in the clover cutter for the daily noon meal of the fowls. Where other greens are needed, cabbage, kale, Swiss chard, collards, turnips, mustard and lawn clippings may all be utilized. Rape is excellent for growing in poultry pens. Kale requires less water than other greens and may be kept growing the year round. Lettuce is the best green feed for baby chicks.

\section{Sprouting Oats}

When a sufficient quantity of other greens cannot be had, sprouted oats are a very good substitute, but they must not be allowed to grow too long unless they can be cut fine. The fowls relish them most when the sprouts are from a quarter to a half inch in length.

To sprout oats, soak them twenty-four hours, then spread on the bottom of a box which has cracks enough for drainage. Spread a burlap sack over the oats and sprinkle sack and oats often enough to keep them moist. If they can be put in a rather dark place they will sprout more quickly. In four or five days they are ready to feed. By keeping sev- 
eral boxes going a supply of succulent greens may he had.

Barley can be sprouted in the same way.

\section{Egg Makers}

Condimental foods, egg foods, egg makers, and other preparations advertised to increase egg production are at the best of doubtful value and often positively injurious. These foods are all stimulants, and a hen, while she may lay more eggs for a time under their influence, will sooner or later suffer from the reaction which follows every sort of artificial stimulation. Feed a well-balanced ration, with plenty of green feed at all times and fresh meat when it can be had conveniently; plan for variety in the diet; give a hot moist mash containing vegetables and cut up greens on cold mornings or evenings. Above all, see that your hens have exercise. This is the best egg maker known.

\section{Grit and Shell}

Shell is very necesary to the laying hen, for, while she gets some lime in her food, she does not get enough to make good, strong egg shells. Oyster shell is better than clam shells for this purpose and should be kept before laying hens at all times. It is also necessary for growing chicks unless they have access to gravel.

Grit is called "the hen's teeth," and should be kept before all ages of fowls. If the soil contains a good many little stones, they may not eat much grit, but it is safer to keep it where they can get it. The fowl's gizzard is a powerful grinding apparatus, but it needs something sharp to help pulverize the food, and grit is cheap. Especially important is a good supply of grit for young turkeys, 
for their digestion is more delicate than that of chickens.

\section{FEEDING BABY CHICKS}

The feeding of baby chicks is not at all the difficult, complicated matter some have supposed it to be. Given mature, healthy parent stock and a chick well hatched and brooded in warm, clean quarters, and your chick will grow on any kind of suitable food. The chick cared for by Mother Biddy on range picks up, what? Little seeds, bits of weed and grass, a bug now and then, and a few grains of sand if it needs them. Imitate Nature in your feeding. Give little seeds and grains, suitable to the size of the chick, a little animal food, some green when it is old enough for it, and your chick will grow, if only other conditions are right.

Principles are always better than rules to go by, and I think we may lay down as the fundamental principles of chick feeding the following:

1 The chick is not ready to eat for the first day or two of its life. The yolk of the egg which it took into its abdomen the day it was hatched will suffice for forty-eight hours or longer, and that is all the food it needs.

2. The first feed should be dry and very simple.

3. Feeding should be progressive. Food which is sufficient for the first week is not enough for the second. Make the ration richer and more varied after the first week.

4. Chicks must have protein for building tissues and making feathers and ash for bones. The best and cheapest protein for chicks is found in milkskim milk, buttermilk, clabbered milk or dried milk. If they have all the milk they want they need nothing else. Bone meal is the best bone maker. See that it is in the mash after the first week. 


\section{The Nursery Feed}

Bread and hard boiled egg has been the timehonored "first feed" for baby chicks, and it does no. harm, but it is not necessary. Chicks do exactly as well when started on rolled oats or steel cut oats and cracked wheat. One of the most successful poultrymen I know starts his chicks on a simple mixture of steel cut oats and cracked wheat. At the California Experiment Station the first two days a grain mixture of fine cracked wheat, fine cracked corn and steel cut oats is given. The Oregon Station recommends rolled oats as the "first feed," and this has been my own standby. I give rolled oats scattered over the sand the first day, and steel cut oats or commercial chick feed the second. By the third day the chicks have a dish of bran to peck at, and this by the end of the first week is changed to the Cornell mash. A hard-boiled egg, chopped with bread crumbs, is "tasty," if given occasionally, and I have never seen any harm from it, but some poultrymen claim that it is constipating. Bread and milk is easier to prepare, and it does make them grow!

\section{Sample Rations}

California MeTHod.-At the University of California farm at Davis nothing but grain is given the first five days. Beginning with the sixth day a dry mash of two parts bran, two parts shorts, one part corn meal or barley meal, two parts beef scrap, one part ground bone (fine) and three-tenths part powdered charcoal by weight is fed at ten o'clock. For the next two weeks the chicks get this dry mash at ten o'clock, and the grain mixture scattered in deep litter early in the morning and at two o'clock 
in the afternoon. The mash is left before them for only a short time at first, but as they develop it is left longer, and by the time they are eight or ten weeks old they have access to it at all times.

CoRnell Mash.-At Cornell the first five days the chicks are given the following mixture, moistened with sour skimmed milk, five times a day: Eight pounds rolled oats, eight pounds bread crumbs or cracker waste, two pounds sifted beef scrap, one pound bone meal. The grain mixture, three pounds cracked wheat, two pounds cracked corn, one pound steel cut oats, is kept before them in a little tray. A little of the following dry mash, which after the fifth day is always before them in a hopper, is mixed with the grain in this tray: Three pounds bran, three pounds corn meal, three pounds middlings, three pounds beef scrap, one pound bone meal. From five days to two weeks they have the grain mixture in litter twice a day, the moist mash of the first five days three times a day, and the dry mash always before them. From two to four weeks the moist mash is given but twice a day and from four to six weeks but once a day. After four weeks the grain ration is changed to three pounds whole wheat, two pounds cracked corn, one pound hulled oats. Grit, charcoal, shell and bone are always before them and green feed is given freely scattered over the moist mash or separately.

MAINE RATION.-At the Maine Station several satisfactory rations have been used, the one best liked being as follows: First two days, hard-boiled eggs mixed with six times their bulk of rolled oats. From the third day on the rolled oats and egg mixture is fed at nine o'clock and at half past four or five o'clock. Early in the morning and at half past twelve they have the following grain mixture, fed 
in litter: Fifteen parts cracked wheat, ten parts steel cut oats, fifteen parts fine screened cracked corn, three parts fine cracked peas, two parts broken rice, five parts chick grit, two parts fine charcoal. After the chicks are three weeks' old the rolled oats and egg is gradually displaced by the following mash, which is fed moist: Two parts wheat bran, four parts cornmeal, two parts low-grade flour, one part linseed meal, two parts beef scrap.

There is no question I think that a moist mash is more forcing than a dry one, especially if it is mixed with sour milk, but it is a good deal more trouble, and most poultrymen do not consider it worth while.

The Missouri WaY.-At the Missouri Station a little clover chaff, shredded alfalfa or fine-cut straw is sprinkled over the floor of the brooder before the chicks are placed in it. A fountain of sour milk or buttermilk is provided the first half of the day, and longer if it is available. If not, water is given the chicks in the afternoon. The first feed is a mixture of two-thirds rolled oats and one-third wheat bran, with a small amount of charcoal. This is fed on a clean board or paper four or five times a day. After the fourth day commercial chick feed is added to the mixture, a little at first and the amount gradually increased till the grain is all chick feed. Rolled oats and bran are still fed morning, noon and night, and the chick feed is thrown into the litter between meals.

When the chicks are five days old a dry mash is kept before them. It consists of two parts wheat bran, one part corn meal, one part shorts, one-half part rolled oats or oatmeal. To every hundred pounds of the above mixture is added a handful of charcoal, a handful of bone meal, and a half pound of fine table salt. 
After the chicks are two weeks old a small quantity of dry beef scrap is added to the mixture and this is gradually increased till the sixth week, when the dry mash mixture consists of two parts bran, one part shorts, one part corn meal and one-half part high-grade dry beef scrap. If the chicks are on range, where they can find a liberal supply of bugs and worms, or if the mash is mixed with sour milk or buttermilk, the beef scrap is not needed. Onions chopped fine and fed either separately or in the moist mash are recommended for occasional feeding to keep the chicks in good condition.

At this time (six weeks), the commercial chick feed is exchanged for a mixture of cracked corn, wheat and Kafir corn. If the Kafir corn cannot be had conveniently, a mixture of equal parts of cracked corn and whole wheat will suffice. When the chicks are on range this is fed in hoppers where the chicks have access to it at any time.

PURDUE RATION.-All the Purdue rations are extremely simple. That for baby chicks is as follows:

Grain :

10 pounds cracked corn (sifted).

10 pounds cracked wheat.

10 pounds steel cut oats.

Dry Mash:

10 pounds bran.

10 pounds shorts.

5 pounds corn meal.

5 pounds meat scraps.

$21 / 2$ pounds charcoal.

Plenty of sour milk.

The grain is given in litter as soon as the chicks are ready to eat. The mash is not set before them till they are from five to seven days old, and it is 
not left before them all the time till they are several weeks old.

IOWA RATION.-The following ration is used successfully at the Iowa Experiment Station:

Cracked grains :

First eight weeks-

Cracked corn, 2 parts.

Cracked wheat, 1 part.

Steel cut oats, 1 part.

After eighth week-

Coarsely cracked corn, 2 parts.

Wheat, 1 part.

Oats, 1 part.

Ground feed:

First two weeks-

Stale bread, 3 parts.

Oat meal, 3 parts.

Eggs, 4 parts.

Bran, 11/2 parts.

Corn meal, 11/2 parts.

Ground bone, $1 / 2$ part.

After second week-

Corn meal, 3 parts.

Middlings or shorts, 2 parts.

Bran, 1 part.

Beef scrap, 1 part.

Ground oats, 1 part.

Ground bone, $1 / 2$ part.

Salt, 1-10 part.

The ground feed is moistened with sour milk as at Cornell, and the beef scrap or meat meal is fed in hoppers. The grain is fed twice daily in litter from one to six inches deep.

\section{Continuous Feeding}

The question is often asked by the beginner, "Shall 
I keep feed before my chicks all the time or feed them only at certain times?" Where a moist mash is given it is necessary, of course, that it be given regularly at stated times and that the chicks' crops be not already full when it is given, but the easiest and safest method for a beginner is to keep the feed always before the chicks, the dry mash in hoppers, and the grain in the litter, so that the chicks may be kept busy scratching. Where this method is followed there is no reason why a moist mash should not be given three times a day, care being taken to feed only what the chicks will clean up in a few minutes.

There is little danger of overfeeding by the continuous method, and the weaker chick has then the same chance as the stronger.

All grain should be fed in deep litter so that the chicks may have the exercise of scratching for it. Leg weakness and other troubles are thus avoided. All food and dishes should be clean. Never leave wet mash standing. It soon sours and is then unfit for food. Green feed should be fed at least once a day after the first week. Chopped lettuce is best at first. After a week, or whenever the chicks are strong enough to tear it to pieces, a whole head of lettuce may be given at once. Later Swiss chard or beet leaves will do, but there is no green the little chick likes so well as lettuce. Chicks that are on range will soon find their own green feed, and they are lucky if they have an alfalfa patch to run on.

\section{FEEDING LAYING HENS}

Two objects must be kept in view in feeding laying hens: (1) maintenance of bodily health and vigor, (2) egg production.

Maintenance of health is the first consideration, 
for without health egg production must inevitably cease. Your prolific layer is not the pale-combed hen that mopes in a corner or seeks the roost an hour before sundown. She is the first hen out in the morning and the last one in at night. She is first at the feeding trough and has no scruples about snatching any choice morsel from the beaks of the other hens. She is the hen with the bright, red comb and alert eye, the hen that scratches her toenails off.

Before a hen can begin to produce eggs, she must have consumed (1) all the food she needs to maintain bodily functions and repair waste, and (2) enough more to put some surplus fat on her body. It is quite plain, therefore, that she must be a good eater.

Experiments at Cornell, where a large number of Barred Rocks were killed and examined, showed that the fattest hens invariably had eggs nearly ready to lay in their bodies, while the leanest hens were dormant. "The best explanation of the fact that the hen must have fat in her body to lay well," says Professor Rice, "is that the egg is developed in the ovary in the form of little ovules. There are hundreds of these little ovules, so small that we perhaps cannot see some of them with the naked eye. These ovules form in follicles, and when ripe these burst and let the yolk or ovule fall into the oviduct and then pass down the oviduct where the white of the egg is formed about the yolk. A chemical analysis of these eggs shows that sixty-four per cent of the dry matter of the yolk of the egg is fat, and that it is the only fat in the egg, except a small fraction, the white of the egg being practically pure albumen, the shell being mineral matter. The very first part of the egg to be developed, therefore, must 
contain nearly half fat. How then can the hen start to develop the first part of the egg unless it has surplus fat in its body? And surplus fat is merely stored-up energy. We must have hens in reasonably fat condition before they will do their very best laying."

Liberal feeding is a necessity. Give the hen all she needs to keep her in perfect physical condition, and then enough more to put some fat on her body, but do not go to the other extreme and feed her till she is too fat to lay. This horn of the dilemma is a little worse than the other, for a lean hen can be fattened, but it is very hard to reduce an overfat hen.

The two things which most tend to make a hen overfat are (1) a ration too rich in fats and carbohydrates, (2) lack of exercise. She must have plenty of feed, but it must not be fattening feed, and she must be made to work for it. A narrow ration is best for breeds that take on fat too easily. Corn and cornmeal should be avoided except in cold, rainy weather, or balanced by a very liberal meat ration. Tests at the Massachusetts Experiment Station show that fat in the ration helps to digest the protein in beef scrap and other animal foods.

\section{Things to Consider}

"Things to consider when mixing a laying ration, says Bulletin 10 of Purdue University," are:

1. There is no best ration. It is not the number of pounds of feed consumed that controls results, but the quantity of digestible food material in the ration. There are plenty of good rations, and it makes no difference what they are made of, if they will produce results.

2. Hens should be fed what they like.

3. Hens know best how much to eat, but the 



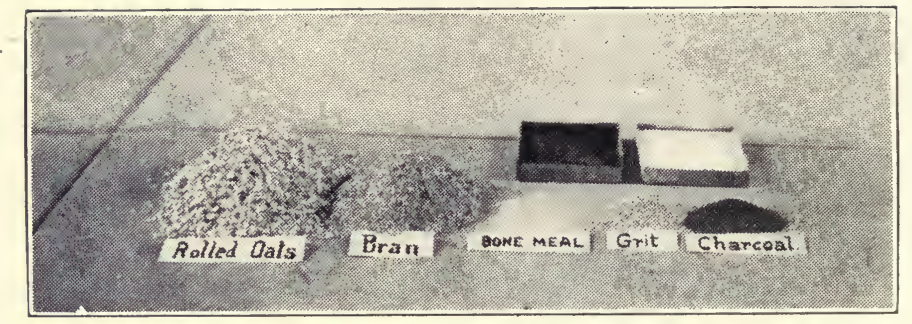

FIG. 32- "FIRST FEED" FOR BABY CHICKS. TWO PARTS ROLLED OATS, ONE PART BRAN WITH A LITTLE BONE MEAL, GRIT AND

CHARCOAL MIXED IN

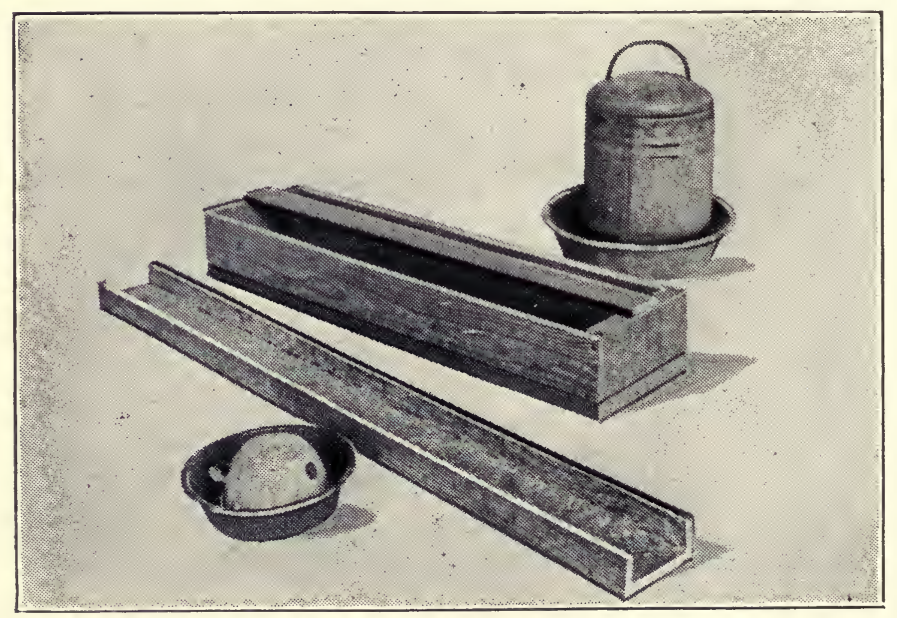

FIG. 33-HOME MADE TROUGH AND FOUNTAINS 
feeder should know in what proportion to mix the feeds in the ration. Give a hen all she wants of a ration made up of the proper proportion of different feeds.

4. A ration should contain a variety of feeds.

5. The ration must be cheap.

6. Fowls need grain, meat food, mill feeds, green food, grit, shell and water.

7. Quality and not quantity is important.

8. Exercise is absolutely necessary.

9. The conditions under which the flock is kept will influence any ration; for example, confined fowls need more green food and meat food than do farm fowls.

\section{Sample Rations}

The following rations, which are used at and recommended by various state experiment stations, will give a good general idea of what a ration should be:

PURDUe EXPERIMENT StATION.-Grain:

10 pounds corn.

10 pounds wheat.

5 pounds oats.

Dry mash:

5 pounds bran.

5 pounds shorts.

$31 / 2$ pounds meat scraps.

The mixed grain is fed in deep litter lightly in the morning, and all the fowls will eat in the evening. The dry mash is kept in a hopper open before such fowls as Leghorns at all times. For heavier breeds the hopper is not opened before noon, because of their tendency to eat too much and thereby cause digestive troubles. In order to keep the ration properly balanced, the $131 / 2$ pounds of dry mash 
should be consumed in the same length of time as the 25 pounds of grain.

Missouri EXPERIMENT STATION.-Grain Mixture -In winter the scratch feed is composed of $2 / 3$ coarsely cracked corn and $1 / 3$ wheat. In spring and fall it consists of equal parts cracked corn and wheat. In summer it is changed to 2 parts wheat and 1 of cracked corn.

Dry Mash-When ground oats are to be had a hopper of this feed and nothing else is kept before the fowls. When oats cannot be had the mixture consists of 2 parts bran, 1 part cornmeal and 1 part shorts. Sour milk or buttermilk is kept before them when it is available. When milk is not given 10 pounds of beef scrap is mixed with each 100 pounds of ground oats.

Between one and three o'clock each day the hens are given a little of this mash moistened with buttermilk. Three times a week they have sprouted oats. Sometimes cabbage, beets or turnips, chopped fine, are substituted for the oats.

NEW JERSEY EXPERIMENT STATION.-Grain Mixture: Morning, 1 part wheat, 1 part clipped oats. Evening, 2 parts cracked corn, 1 part wheat, 1 part clipped oats, 1 part buckwheat

Dry mash:

200 pounds wheat bran.

200 pounds middlings.

200 pounds ground oats.

100 pounds corn meal.

100 pounds gluten meal.

100 pounds to 200 pounds beef scrap.

100 pounds short cut alfalfa.

Gluten meal is a by-product of the milling of wheat which is quite extensively used in the east and is rich in protein. It is not known in California. 
MAINE EXPERIMENT STATION.-The feeding of the pullets after they are brought in from range the first of September is progressive.

The first month in the laying house they receive:

Grain mixture:

Morning, cracked corn.

Evening, 2 parts wheat, 2 parts oats.

Dry mash:

300 pounds bran.

100 pounds corn meal.

100 pounds low grade flour.

100 pounds beef scrap.

The second month in the laying house the scratch mixture remains the same, but the dry mash is changed to:

200 pounds bran.

100 pounds corn meal.

100 pounds low grade flour.

100 pounds gluten meal.

100 pounds beef scrap.

The third month 50 pounds of linseed meal is added to the above; the fourth month the linseed meal is omitted, and so on. The experts at the station find that by adding linseed meal only every other month they keep the pullets from moulting in the fall and maintain a higher degree of health.

ONTARIO EXPERIMENT STATION.--Summer ration for yarded fowls: Dry mash, in hoppers; for old hens, wheat bran; for pullets, equal parts bran, low grade flour and barley chop or meal. Grain fed twice a day, wheat in the morning and wheat and barley or corn in the evening, corn being used only when very cheap.

Winter ration: Dry mash as above. Morning feed, whole wheat from six to eight inches deep in litter; about noon, a little more wheat and whole 
mangels or clover hay; about 3:30 p. m., wet mash of boiled vegetables, waste bread and occasionally kitchen scraps thickened with the same meals used in the dry mash, about 10 per cent beef scrap or animal meal added, except when green cut bone is given as a separate feed; just before dark all the whole corn the birds will eat.

\section{West Virginia EXPERIMENT Station.-Dry mash:}

Corn meal..........31/2 parts by weight

Bran ...........51/2 parts by weight

Middlings .......... 3 parts by weight

Oil meal .......... 1 part by weight

Beef scrap ......... 21/2 parts by weight

Grain, whole corn and wheat in equal parts.

KANSAS EXPERIMENT STATION.-Dry mash:

Shorts (middlings) .....6 6 parts by weight

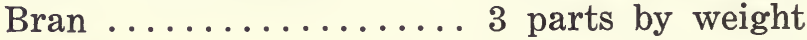

Corn meal ..........6 6 parts by weight

Beef scrap .......... 5 parts by weight

Alfalfa meal.......... 1 part by weight

Grain mixture, 2 parts wheat, 2 parts corn, 1 part oats.

Used in the proportions by weight of 21 pounds of mash to 25 pounds of grain, the ration has a nutritive ratio of $1: 4$, a very forcing ration.

CORNELL LAYING RATION.-Grain mixture:

Winter-60 pounds corn, 60 pounds wheat, 30 pounds oats, 30 pounds buckwheat.

Summer-60 pounds wheat, 60 pounds corn, 30 pounds oats.

Dry mash, summer and winter:

60 pounds corn meal, 60 pounds wheat middlings, 30 pounds wheat bran, 10 pounds alfalfa meal, 10 pounds oil meal, 50 pounds beef scrap, 1 pound salt.

CALIFORNIA EXPERIMENT STATION.-In Bulletin 
164 half a dozen dry mash formulas are given of which the following is typically Californian:

Bran ..........6 6 quarts or 3 pounds

Corn meal ....... 1 quart or 1.5 pounds

Barley meal .......2 2 quarts or 2.2 pounds

Alfalfa meal ...... 1 quart or 0.5 pounds

Soy bean meal..... 1 quart or 1.3 pounds

Beef scrap ........1 quart or 1.5 pounds

Coarse bone meal... 0.5 quart or 1.0 pound

This formula is calculated for 100 hens one day and is intended to be used with 9 to 12 pounds of grain and some green feed.

A SOUTHERN CALIFORNIA RATION.-The following formula has been successfully used by a large number of Southern California poultrymen. It is calculated for a ton (or about a ton) of mash:

300 pounds bran.

300 pounds shorts or middlings.

100 pounds feed meal (coarse corn meal).

200 pounds Kaffir meal.

150 pounds beef scrap.

150 pounds fish scrap or whale meat.

70 pounds fine ground bone.

100 pounds alfalfa meal.

400 pounds ground barley.

10 pounds salt.

With this is used, for Leghorns, a scratch feed consisting of 3 parts whole barley (soaked 12 hours and drained 24 hours) and 2 parts wheat, with a little whole corn mixed in.

\section{Methods of Feeding}

There are almost as many methods of feeding as there are feeders. According to that most generally followed, a light grain feed is scattered in deep litter in the morning, and a heavier grain feed given at 
night. The dry mash is kept before the hens in hoppers, so that they may help themselves at any time. At noon cut alfalfa or some other green feed is given.

Some feeders give no grain at all in the morning, but a very heavy feed at night, which will keep the fowls busy scratching the next day.

The dry mash is more generally used than the wet mash because it is more convenient, but many feeders still use the wet mash occasionally. Some keep the dry mash before the fowls in hoppers and give a wet mash in addition either in the morning or at noon. When a wet mash is used care should be taken to give no more than the fowls will eat up clean in a few minutes. Two advantages of the wet mash are (1) that table scraps, refuse vegetables and stale bread may be used in it more readily than in any other way, (2) that it is more appetizing and tempts the fowls to eat more than they would of the dry mash alone.

Tom Barron, the English breeder of White Leghorns, whose hens have distanced all competitors at the egg-laying contests at Storrs, Connecticut, and Mountain Grove, Missouri, uses a combination of the wet and dry mash methods.

In the early morning a mixture of a variety of grains is fed in litter, consisting of oats, wheat, cracked Indian corn, a little coarse wheat, a few split peas and a small quantity of dari or durra. Before them is always a hopper in which is a mixture of one part ground oats and three.parts bran.

At noon a small supply of the grains is again given, merely to keep them employed. In the afternoon a wet mash is provided, composed of about onethird bran, one-quarter thirds or middlings, onequarter biscuit meal, one-eighth meat meal-fish 
meal or granulated meal-and one-eighth clover or alfalfa meal. The thirds are sometimes changed for ground oats. In the water with which this is mixed a few bucketfuls of ground oats have been steamed, these being used in the mash, which is made crumbly. The birds are fed in troughs, as much as they will eat.

It is a good plan to use cooked vegetables as the foundation of the wet mash and to thicken the liquid in which they are boiled with stale bread and the ground grains which compose the dry mash. Potato skins and all kinds of refuse vegetables may be used to advantage in this way.

\section{Effect of Feeds on the Egg}

Experiments at the Oregon Station (Bulletin 157) have proved that it is possible to feed both color and flavor into the egg.

Kale and alfalfa give a good deep yellow color to the yolk. Sugar beets fed instead of alfalfa make a pale yolk. Lack of color in the yolk is an almost sure indication that the hens are not getting enough green.

Heavy feeding of onions, beef scrap or fish will flavor the egg. Soft shells are usually due to lack of lime. Give more oyster shell when you find your hens laying soft shelled eggs.

My own experience in all these particulars is that some hens lay better colored eggs and eggs with thicker shells than other hens will lay on exactly the same ration.

\section{Cost of a Dozen Eggs}

Investigation of the cost of producing eggs in various parts of the country have shown that a dozen eggs cost the producer anywhere from six to eight 
cents on farms of the Middle West, where the producer raises all his feed, to twenty-one cents on commercial egg ranches where all the feed is bought.

Every egg producer should know what it costs him to produce a dozen eggs, and, if he is not making a profit, he should manage in some way to reduce the cost. This may be done (1) by raising a larger part of the feed himself, (2) by feeding cheaper feeds, (3) by buying feed wholesale instead of at retail, as many small poultrymen do, (4) by avoiding waste in every possible way, (5) by giving his fowls more green range.

\section{FEEDING MARKET POULTRY}

No chicken of any age should be marketed until it has been confined two weeks and fed a fattening ration. Well fattened poultry brings a higher price and sells more readily.

\section{Rations for Broilers}

Cockerels which are to be marketed as broilers should be separated from the pullets as soon as the sexes can be distinguished, which is at the age of from one to two months, according to breed. They need a more fattening ration than is good for pullets and may be quite closely confined, provided their quarters are kept clean.

\section{Fattening Rations}

A recent government bulletin on "The Commercial Fattening of Poultry" gives these three rations found most satisfactory in a series of experiments extending over several years:

No. 1-3 parts corn meal.

2 parts low grade flour.

1 part shorts. 
No. 2-3 parts corn meal.

2 parts low grade flour.

No. 3-5 parts corn meal.

3 parts low grade flour.

1 part shorts.

5 per cent tallow.

All are mixed with thick buttermilk, except No. 3 , in which tallow takes its place.

The Cornell fattening ration consists of:

30 pounds beef scrap.

100 pounds corn meal.

100 pounds oat flour.

100 pounds ground buckwheat.

This is mixed with sour milk.

At the Missouri Experiment Station feeding experiments have shown that (1) whole grain does not fatten chickens, (2) it is cheaper to feed the grain finely ground, and (3) that the best grains can be had by feeding birds finely ground feeds when confined in crates. The following ration proved most satisfactory :

24 parts white bolted corn meal.

6 parts low grade flour.

1 part each of oatmeal, pea meal, buckwheat middlings and wheat middlings.

The flesh of the birds fed on this ration was creamy white in color, the fat distributed over the body, and the entrails were encased with fat.

At Purdue University the fattening ration consists of :

2 pounds corn meal.

1 pound shorts.

1 pound ground oats.

8 pounds buttermilk.

Professor Dryden of Oregon Agricultural College recently said in regard to fattening rations: 
"There are different rations that can be fed successfully. In some districts corn is the main item, and in others oats, barley, or other grain. The price of grain will govern the ration fed largely.

"There is no better fattening food, probably, than good plump oats fine-ground. Barley, ground up fine, is also good as part of the ration. A good ration would be ground oats, barley and middlings in equal parts and a little bran mixed with buttermilk or sour milk."

"If one cannot get milk it will be necessary to feed some animal meal or beef scrap, or a little blood meal. About ten per cent of the weight of the grain is the right proportion of blood meal.

"If corn is as cheap as the other grains, I would feed corn liberally. The grain should be mixed with about twice as much milk as of ground grain, so that it will be very soft and drip from the end of the stick. No green food is necessary.

\section{FEEDING PULLETS ON RANGE}

At the Maine Station, after the cockerels and pullets are separated, the pullets (and the breeding cockerels) are put on range and fed by the hopper method. Cracked corn, wheat, beef scrap, cracked bone, oyster shell and grit are put in separate hoppers and left where the pullets can help themselves. In another hopper is the dry mash, consisting of 1 part bran, 2 parts corn meal, 1 part middlings and 1 part beef scrap. This mash is suitable for use when the pullets are confined, but the grain should be fed in deep litter.

At the Missouri Station the pullets are fed a grain ration consisting of equal parts of cracked corn and wheat. The dry mash consists of equal parts of corn meal, bran and shorts. If sour milk or buttermilk 
is desirable, no beef scrap is needed. If not, 10 pounds of beef scrap is added to every 100 pounds of the mash. At 3 o'clock in the afternoon a feeding of the same mash moistened with sour milk is given, all the birds will clean up in twenty or thirty minutes.

It is very important that the pullets which are to be the layers of the following winter be fed a wholesome, nourishing ration, and have free range if possible. The egg organs cannot develop properly without exercise, and the best exercise is that found on free range.

Leghorn pullets which have been properly fed and cared for should begin laying at from five to six months of age. Pullets of the heavier breeds, Rocks, Reds, Wyandottes and Orpingtons, cannot be expected to begin before seven or eight months, though I have had many Orpingtons that began at six months and a few even earlier than that. Anconas and other Mediterranean breeds begin, like the Leghorns, at six months or a little before.

\section{FEEDING MOLTING HENS}

Opinions differ in regard to the proper feeding of molting hens, but the best practice makes little change in the diet at this time. A little richer and more stimulating ration is fed than at other times, and a little more generous supply of food is given, for the molting hen is manufacturing feathers and must have material to work with.

No change need be made while the birds are losing their feathers. Many hens lay right along during this period, and they should be allowed to lay as long as they will. When the new plumage begins to grow is a time of special strain, a time when protein and oil are needed. Give the hen that is making feath- 
ers a little corn and sunflower seed in the scratch grain, and add 1/2 part linseed meal to the mash. A moist mash fed once a day is especially beneficial during this period, and if a little fresh meat is cooked in this, so much the better. A sheep's pluck, which can be bought for five cents, cooked and chopped, and the soup in which it was cooked thickened with bran and middlings, makes a good breakfast for these molting hens, and is worth far more than it costs.

Many poultry keepers feed stimulants and tonics during the molt, but I have never found it necessary. A hen that is not vigorous enough to go through the molt in good shape without tonics had better be sent to the butcher.

The molting period is a good time for culling out the hens that are lacking in vigor. As a rule the older a hen is, and the later she molts, the more quickly will she molt. Hens that molt more slowly than their contemporaries or that seem weakened or depressed may well be eliminated from the flock.

Overfat hens should, of course, be "reduced" before they go into the molt.

The practice of starving the hens in order to force an early molt is condemned by nearly all experiment stations. After experiments with White Leghorns covering several seasons the Cornell Station declared that there was nothing whatever to be gained by forcing the molt. In the words of the bulletin (No. 258) :

"As compared with the fed flocks, the starved hens molted slightly earlier and more uniformly; were in somewhat better condition at the end of the molt; molted (average) in slightly less time; gained less above first weight during molt; gained slightly more in weight during the year; resumed production some- 
what more quickly after molt; laid a few more eggs during winter; were materially retarded in egg production; produced less eggs after the molt was completed; produced eggs at a greater cost per dozen; consumed slightly less food during the year; had slightly less mortality; showed slightly more broodiness, and paid a much smaller profit.

"The general conclusions were that with the methods employed with White Leghorn fowls one, two and three years old, it does not pay to 'force a molt' by starvation methods and that apparently it is good policy to encourage hens, by good care and feeding, to lay during late summer and fall, rather than to resort to unusual means to stop laying in order to induce an early molt, with the hope of increasing productiveness during early winter, a season which is naturally unfavorable for egg production. In short, it appears wise when hens want to lay to let them lay."

\section{Rules for Feeding}

Three things characterize the feeding of a skilful feeder :

1. REgUlarity. He does not give two meals today and three tomorrow, nor does he give a moist mash today at noon and tomorrow at night. If he has decided that it is wise to let his hens get their breakfast from the dry mash hoppers, he holds to this rule till he sees good reason for changing it, and does not feed breakfast today and none tomorrow. Neither does he permit kind-hearted neighbors to throw scraps over the fence at any hour of the day. He plans his regime according to circumstances, and then holds to it.

2. Punctuality. His fowls get their meals not only at the hour when they expect them, but also 
at the time when they need them. The first thing a hen does when she gets off the roost in the morning is to look for something to eat. If she finds nothing, every hour spent in waiting is time lost from the business of the day. The poultry-keeper who is not disposed to hustle out in the morning by $5: 30$ or 6 o'clock must set the table the night before. Throw grain in the litter the night before so that Biddy can get to work early, and if a moist mash is to be fed it can wait until she has scratched awhile.

3. VARIETY. It is not enough to feed a balanced ration. The ration needs to be changed from time to time lest Biddy's appetite lag. Feed a variety of grains every day and change the mixture occasionally. If you have been feeding wheat and barley for some time, try wheat and Kaffir corn or wheat and oats. If the meat food has been beef scrap, use fish scrap for a change, or add soy bean meal. The hen appreciates these little concessions to her taste and discrimination and will show her appreciation in a substantial way.

4. Plenty. The skilful feeder does not sit down to his own evening meal until he is certain his hens have had all they want. It may be necessary in feeding heavy hens to make the morning meal very light or omit it altogether, but at night every hen's crop should be full. There is no fixed rule for the amount to be fed to a hen in a day or at a meal. Hens differ in their needs and in their appetites. An Orpington needs considerably more than a Buttercup. A laying hen requires more than a hen that is not laying. It is a good plan to leave the mash hoppers always accessible, unless for some good reason it is desired to reduce the ration, and to throw in deep scratchng litter, either all at once or at different times during the day, sufficient grain to keep 
the hens scratching. In general the amount of grain fed for a single meal is approximately a quart to a dozen hens, but the main thing is to know that the fowls' crops are well filled when they go to roost. 


\section{CHAPTER VI.}

\section{Breeding}

\section{THE BREEDING PEN}

The breeding pen may well be called the heart of the flock. All else centers about it. When the breeding pen is not what it should be everything deteriorates-egg production, size, health, whatever is most desired in a flock-and in a few years the plant is "for sale at a sacrifice."

The foundation of the breeding pen is vigor.

\section{Culling}

The selection of breeding stock should begin the day the chicks are hatched. The first chicks out of the shell are usually the most vigorous. The sturdy, bright-eyed babies that crowd round the incubator window waiting for their weaker brothers and sisters to hatch, or peep out from under Mother Biddy's wings before half the eggs are pipped, are the ones to mark as possible future breeders. Put the weak, late hatched, sunken-eyed, pinched looking chicks by themselves where they can have special care and not interfere with the growth of the others, and in nine cases out of ten you will find as they develop that your best chicks are in the first lot.

Cull again as they feather. The strongest cockerels always feather out first. The slow feathering ones should be put by themselves and fed for broilers.

As the pullets approach maturity cull out again those which are largest and strongest for their age. Those which lag behind had better go to market with 


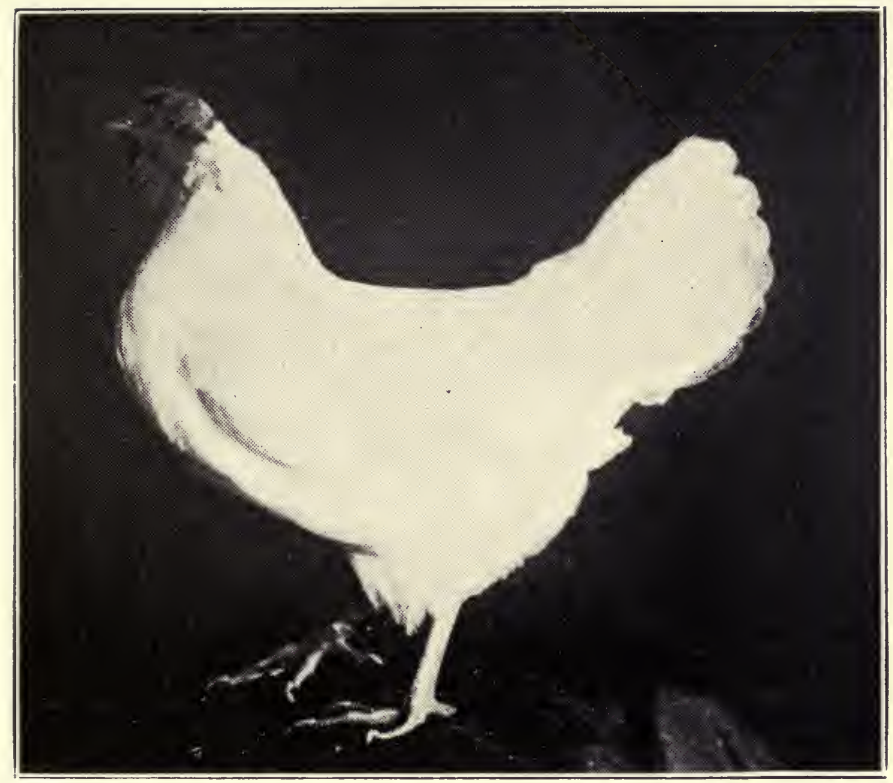

FIG. 24-TYPICAL WHITE LEGHORN HEN
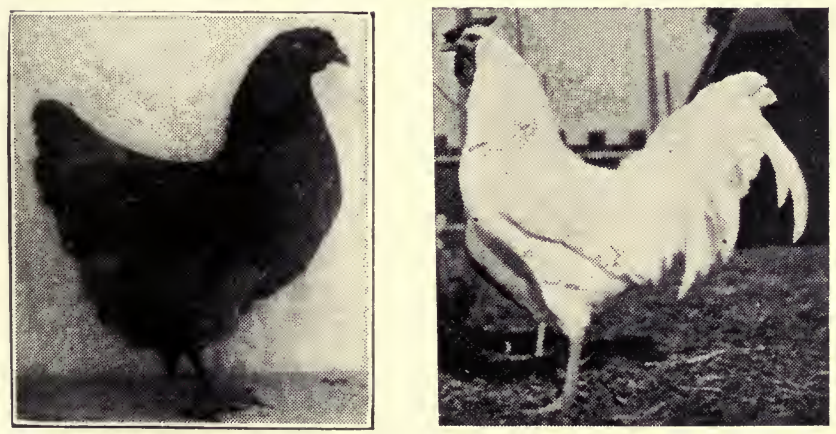

FIG. 25-PULLET OF HIGH VITALITY

FIG. 26-ROSE COMB WHITE LEGHORN 

the surplus cockerels. The pullets which lay earliest will probably be the best layers. Band these early layers and trapnest them if it is not convenient to trapnest the whole flock.

\section{Marks of Vigor}

Selection of individuals for the breeding pen should be based on one quality, constitutional vigor. Heavy egg production, while it is extremely desirable in a breeder, is not of first importance. In fact, many high producers break down under the strain and are unfit to transmit their fecundity to their offspring. The hen selected as a breeder should be a good layer, but she should be something more. She must be a good eater or she cannot manufacture eggs and at the same time keep up her own vitality. She must be absolutely healthy. She must, in short, have that indefinable something known as vigor.

In selecting for vigor, we look first at the shape of the fowl. The body of the vigorous cockerel or pullet always has a tendency to fill a parallelogram. Such a fowl will have good depth of body, full breast, full, well-rounded abdomen and a good broad back. It will have glossy, well-developed plumage, prominent, bright eyes, thick beak, short neck and heavy thighs, set wide apart. This last mark of vigor is particularly important in the male. Never use a male that is not wide between the legs, no matter how good he is in other respects.

The voice is another test of vigor. The rooster that crows often and loudly, as well as the hen that is always cackling and singing, is the vigorous bird. It is said that in some foreign countries it is customary to have crowing contests as a test of fighting quality. A weak cockerel very seldom crows.

The shape and appearance of the head are certain 
indications of vigor or the lack of it. The strong fowl has a fairly large head, well-rounded, with bright red, well-shaped comb. The weak fowl is apt to have what is called a "crow's head," rather long and thin.

A vigorous bird holds the tail well up. It is also active and alert in its manner. Suspect every bird that slouches around with its tail down or mopes in corners or on the roost. These actions may indicate illness, and they always indicate lack of a vigorous constitution. The hen that gets off the roost first in the morning and goes back to it last at night and is always on the move is the hen we want to breed from.

Well colored shanks of the color characteristic of the breed are another indication of vigor. Never select a breeding bird with pale shanks or shanks that are long and thin and cold.

Probably no one thing is a surer indication of the health and stamina of a bird than the appetite. The hen that stands back when the other fowls crowd around the feeding trough should be watched. Ability to consume and assimilate large quantities of food is an absolute necessity, whether we want eggs, good, fat market birds, or fertility. All birds should be examined on the roost at night from time to time, and those with little feed in the crop marked as probably of doubtful vigor. This is a test that rarely fails.

\section{The Male Bird}

The male bird chosen to head the breeding pen should have not only the marks of vigorous constitution which are common to all fowls, but he should have also the marks of a vigorous male,-in other words, he should be well sexed, with well developed 
comb and wattles and protuberant spurs. He should also be a bird that showed his sex early. Rev. Edgar Warren, a Massachusetts expert, says this is one of the surest marks of a good breeder. Watch your growing chicks for the first sign of sex, which is usually the developing comb, and mark the birds that you can first pick out as roosters. I have had Buff Orpingtons that showed their sex before they were a month old. The Mediterranean breeds seem to develop a little more slowly.

Gallantry to his hens is one of the essential marks of a good male. The cock that stands by indifferently and lets you pick up one of his harem and carry her off, or that crowds to the trough and helps himself without first seeing that the hens are served, may fertilize the eggs, but he will not increase the vigor of the flock. I am always glad to find in my flock a cockerel that flies at me and pecks my feet when I enter the pen, for a fighting disposition is one of the surest marks of a good breeder.

The male bird is often said to be half the pen. As a matter of fact he is more than half. Both color and fecundity are inherited from him. A male bird that is known to be the son of a heavy layer is the surest means of increasing egg production. Utility should never be sacrificed for color, but it need not be. By selecting for breeding males the best colored cockerels that are known to be sons of high producers, a well colored, high producing flock can soon be built up.

\section{The Hens}

Size and shape come from the hens. This is now a well established principle of breeding. If you want a flock that is up to standard size, you must breed from large hens. If you want birds of the 
long-backed, deep chested type, you must select hens of this type. It is important that the hens be good layers, but not so important as that the male bird should be the son of a good layer.

\section{The Cockerel Pen}

Every up-to-date poultry ranch now has its cockerel pen. The very best layers are chosen for this pen and are mated to a cockerel known to have been hatched from a good layer. The cockerels from this pen are carefully banded and are used to head the next season's breeding pens. In this way males hatched from high producers are always to be had for breeding, and the average production of the flock is raised year after year.

Where only a few fowls are kept the eggs from the best two or three layers may be hatched by themselves, and the cockerels from these eggs marked for future breeders.

\section{Mating}

Mate a cockerel to two-year-old hens, or a twoyear-old cock to pullets. The first mating is considered the best, but the second will probably give more pullets.

Cockerels under ten months old should not be used as breeders, and pullets should be used only when mated to old cocks. Never mate pullet to cockerel. Neither pullets or cockerels should be mated under ten months of age.

Matings of yearling cocks with yearling hens often produce very good results, but as a rule it is better not to mate fowls of the same age.

The number of females a male can take care of depends largely upon the season. In spring a cockerel of the Mediterranean breed can care for from 
15 to 20 hens, and one of the heavy breeds for 10 or 12. In the fall the number of hens must be considerably reduced, say-one male to six hens of the heavy breeds or eight or ten of the Mediterranean breeds. No absolute rule can be given, for much depends on the age and vigor of the birds and the conditions under which they are kept.

Eggs should not be used for hatching from a pen till the male has been with the females about two weeks.

\section{Prepotency}

Prepotency is the ability of a cock bird to transmit his own characteristics to his offspring. The prepotency of any given bird can only be learned by trial. Some birds, apparently perfect as breeders, beget only culls. Other birds, which make a far poorer appearance, prove the best of breeders. When a prepotent breeder is found, never let him go. Some very successful breeders use two brothers in the pen at the first until they learn which is more prepotent.

\section{Breeding for Eggs}

In order to breed for eggs we must first find the hen that lays the eggs. In every flock there are drones and layers. Merely to cull out the drones would be a saving of many dollars each year and a corresponding increase in profits, for the drone eats nearly as much as the hen that pays her board, but we must do more than get rid of the drones. We must pick out the hens that are doing our best laying and use them for the mothers of next year's cockerels and pullets.

Trapnesting is the only absolutely certain way of getting at the laying hen, but the trapnest is not for 
everybody. On the big poultry farm it is a necessity; on the farm or back-lot it is usually a nuisance. Some one must always be on hand to let out the hens that are on the nests and to record their numbers, and this means closer confinement than the women of the family are willing to submit to.

\section{Marks of the Layer}

1. The bred-to-lay hen is a vigorous hen. This she must be, whatever else she is or is not. She bears the marks of vigor which have been mentioned. Her comb is red, her manner alert, her eye bright, her appetite good. She scratches and sings from morning till night, and is never seen loafing in a corner or on the roost. Very often she may be known by her worn-off toe nails, the result of hard scratching.

2. The bred-to-lay hen is almost always of the laying type, long in the back, deep in the chest, wide in the fluff, for how can a hen lay unless she has room for her egg-laying organs? The body of the layer should be long, broad, deep and V-shaped as viewed from the side, the small part of the $\mathrm{V}$ lying toward the front of the body.

3. The bred-to-lay hen is the hen that commences to lay early in the fall. It has been proven again and again by trap-nest records that the heavy producers almost invariably lay their first egg in November. The pullet that does not lay her first egg till January need not, unless she was hatched very late, be considered.

4. The good layer is usually the hen with a comb that is large for her breed. Just what the relation is between laying powers and size of comb we do not know, but there is some relation. Leghorn breeders admit that a great mistake has been made in trying to breed a small comb on the Leghorn hen. The 
best laying strains are those with fairly large combs.

5. The best layer is usually the hen that is small for her breed. Rarely do hens over standard weight prove record layers. There are exceptions to this rule of course, but as a rule the best layers in any flock are those that are under, rather than over, standard weight.

6. The best layer is almost always a pullet that showed her sex early. If you will take the trouble to band the pullets that first show their sex, you will find most of the best layers in this bunch.

When the best pullets in the flock have been picked out by these signs, they should be placed in a pen by themselves and the record of the pen kept. If egg production falls below 50 per cent through the winter there will have to be more culling.

These pullets should not be used for breeders till their second year. If they must be used in the spring mate them to a two-year-old cock.

\section{Using the Trap-nest}

There are many good trap-nests on the market, and they may be readily made at home by a handy man or boy. The principle of all is the same. As she enters the nest, the hen closes the door, and is not able to get out till some one comes and notes the number on her band and lets her out.

When the object of trapnesting is merely to select the best layers and not to make complete records, the pullets need only be trapnested from November till March. The pullets that make the best records these four months, as has been proved by many experiment stations, are the best layers.

The ten or twelve pullets that make the highest records, mated to the best male you can afford, will 
give a good foundation for future work, and the best cockerels from this pen are the sons of high producers that are needed to head next year's breeding pens. Breeding a good laying strain is just a matter of raising the egg record a little every year.

The average production of the farm flock the country over is less than 100 eggs per y e a r. It should be easy, by careful selection and buying a good male of a different strain every two years, to add new blood, to raise the average production to 120 eggs.

\section{Line Breeding}

Line breeding is almost the exact opposite of b r e ed ing for

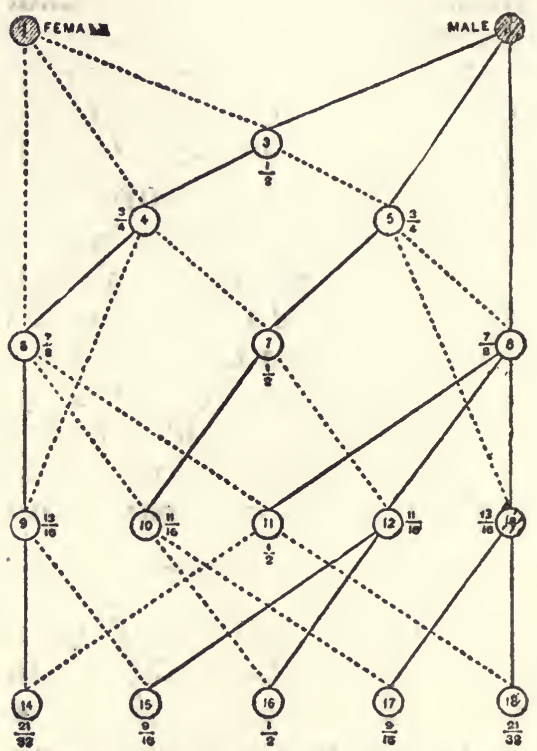

FIG. 27-FELCH LINE BREEDING CHART eggs. In breeding for egg production we begin with poor or mediocre stock and by careful selection for vigor and laying qualities breed up a heavy laying strain. In line breeding we begin with the two most perfect birds we can find, and by proper mating for type and color establish a strain which has the characteristics of the original parents. We may, now and then, produce a more perfect bird, but this we do not expect. 
Careful marking of each chick and keeping the records of each pen and its offspring is absolutely necessary in line breeding.

Director Quisenberry of the Missouri Station, in "The Poultryman's Guide," gives these instructions for line breeding, which are simpler and easier to understand than the Felch chart.

\section{Mating}

Pen No. 1-Ideal cock to ideal hen. Result of this mating contains $1 / 2$ blood of original male and $1 / 2$ blood of original female.

\section{Matings}

Pen No. 2-Male from No. 1 to original female$3 / 4$ original female and $1 / 4$ original male blood.

Pen No. 3-Females from No. 1 to original male$3 / 4$ original male and $1 / 4$ original female blood.

\section{Matings}

Pen No. 4-Females from No. 2 to males from No. $3-1 / 2$ original male and $1 / 2$ original female.

Pen No. 5-Males from No. 2 to females from No. $3-1 / 2$ original male and $1 / 2$ original female.

Pen No. 6-Males from No. 2 to original female$7 / 8$ original female and $1 / 8$ original male.

Pen No. 7-Females from No. 3 to original male$7 / 8$ original male and $1 / 8$ original female.

\section{Matings}

Pen No. 8-Males from No. 7 to females from No. $6-1 / 2$ original male and $1 / 2$ original female.

Pen No. 9-Females from No. 7 to males from No. $6-1 / 2$ original male and $1 / 2$ original female.

Pen No. 10-Males from No. 6 to females from No. 2-13-16 original female and 3-16 original male.

Pen No. 11-Males from No. 4 or 5 to females 
from No. 6-11-16 original female and 5-16 original male.

Pen No. 12-Females from No. 4 or 5 to males from No. 7-11-16 original male and 5-16 original female.

Pen No. 13-Males from No. 7 to females from No. 3-13-16 original male and 3-16 original female.

\section{Matings}

Pen No. 14-Females from No. 8 or 9 to males from No. 10-21-32 original female and 11-32 original male.

Pen No. 15-Females from No. 8 or 9 to males from No. 13-21-32 original male and 11-32 original female.

Pen No. 16-Females from No. 11 to males from No. $12-1 / 2$ original male and $1 / 2$ original female.

Pen No. 17-Males from No. 11 to females from No. $12-1 / 2$ original male and $1 / 2$ original female.

Pen No. 18-Females from No. 10 to males from No. 12-9-16 original female and 7-16 original male.

Pen No. 19-Males from No. 13 to females from No. 11-9-16 original male and 7-16 original female.

\section{Cross Breeding}

There is absolutely nothing to be gained by cross breeding, except perhaps in producing capons, and everything to be lost. A cross of a lightweight male on heavy females is sometimes advocated for broilers, but it would be hard to prove that the broilers produced in this way grow more rapidly or are better in any way than a pure-bred bird. In many cases they do not grow as fast. The bird produced by crossing will be larger than the one parent but smaller than the other.

At the Cornell Experiment Station experiments were tried in crossing White Leghorns and Barred 
Rocks, and it was found that in all cases the size of the offspring was between the size of the Leghorn and that of the Rock, but chickens produced by the cross of Leghorn male on Rock female were larger than those produced by Rock male on Leghorn females. In other words, size followed the female. Professor Rice says:

"We gained nothing in constitutional vigor, egg production or meat production over the pure breeds, but we did do this, namely, by bringing together the magnificent pure-bred varieties, Single Comb White Leghorns and Barred Plymouth Rocks, which have taken somebody from fifty to sixty years to develop in pure breedness, we have in one season undone the careful breeding of half a century."

A similar experiment of my own in crossing a Buttercup male with Buff Orpington females had the same results. The offspring were larger than Buttercups but smaller than Orpingtons, and their color was nondescript.

\section{INBREEDING}

Inbreeding, that is the mating together of fowls too closely related, has been blamed for nearly all the troubles the poultryman is heir to. Failure of eggs to hatch, failure of chicks to grow, failure of hens to lay, are all laid to the door of inbreeding.

It must be kept clearly in mind by the beginner that line breeding and utility breeding are two distinct and separate things. Line breeding belongs to the fancier and must be left in his hands. Utility breeding is the only thing that concerns us.

In line breeding there must of necessity be inbreeding, though not the mating together of brother and sister, which is the worst form of inbreeding. Daughter is mated back to sire, and son to mother, 
and again, sons and daughters of these matings back to the original parents and to each other. Fanciers claim that there is no loss of vigor from line breeding, but utility breeders claim there is.

Whichever of these views be right, and I daresay they are both right sometimes, it is much safer for the beginner to purchase, at least every two years, a male bird of different strain from his own, sending East for him, if necessary. If he prefers to use his own males, he can buy eggs from some good breeder instead of a male bird and mate his best male to the pullets from these eggs. In buying a male bird it is, of course, necessary to make sure that he is the son of a high producer, or the egg production of the whole flock may be injured.

\section{DETERMINING SEX}

To what extent the character of the mating determines sex is a question that has not been settled and probably never will be. One thing seems quite certain, namely, that the mating of an old cock to 25 or 30 pullets is a good way to secure a preponderance of pullets in the progeny. By mating a cockerel to from 5 to 10 old hens you will secure mostly cockerels. This is the finding of the Missiouri Station, and it corresponds with the experience of most poultrymen.

In general we may expect in hatching to have about an equal number of pullets and cockerels. Some have held that where the breeding pen is well fed and the fowls are contented and happy, conditions are right for producing females, but this seems to be mostly theory, as is the other opinion that more pullets are hatched in warm weather. The fact is we know very little, and it is not worth while pretending wisdom. 


\section{CARE AND FEEDING OF BREEDERS}

Hens used for breeding should be hens in their second season-or even older,-which have passed through the molt well. Sometimes the molt brings out virtues or defects which have escaped detection in the pullet year. As a rule, the best layers molt late. Watch, then for the biddy that lays on into September or October before she begins to drop her feathers. She may be the best layer you have.

From the time the hens selected as breeders begin to molt, which will usually be by the first of August, their treatment should be different from that of the hens kept as layers. Molting fowls ought to have range, with plenty of shade, but the breeders must have these pleasant surroundings if they are to produce hatchable eggs and strong chicks. Put all males by themselves at the beginning of the molt, in shady, comfortable coops, and give the hens the widest possible range. An orchard is a fine place for them, and a corn field is nearly as good.

If they are of the heavy breeds some of the hens are sure to be overfat after the rich laying ration of the winter. These should be put in a pen by themselves and their ration reduced till their surplus fat is gone. A fat hen is in no condition for making feathers.

\section{Feeding Breeders}

During the breeding season the breeders should not have the forcing ration which is fed to layers. What we want from them is not quantity, but quality. They require more hard grain, especially wheat and oats. Oats especially are considered conducive to fertility. Some poultrymen add rolled oats to the mash, others feed an extra amount of sprouted oats.

An abundance of meat and greens is a necessity to 
the production of fertile eggs. It pays to buy pluck or green bone once or twice a week for breeders.

\section{Exercise}

If exercise is important for layers, it is doubly important for breeders, for they must lay not only eggs, but fertile eggs. If the fowls cannot have range, give them deep litter to scratch in and make them scratch or go hungry.

Vigorous breeders, properly cared for, mean fewer chicks dead in the shell, fewer runts, less sickness among young and old stock, more eggs, quicker growth, earlier maturity, more profit all along the line. If things go wrong look first to the condition of your breeding stock.

\section{OLD HENS AS LAYERS}

Pullets for layers, old hens for breeders, is the rule adopted by most poultrymen, but there are many exceptions. Undoubtedly most hens lay more eggs in their pullet year than they do the second, but when the cost of raising pullets is considered, it is cheaper to use a hen two years as a layer than to raise a pullet to take her place. Many hens are still worth keeping in their third year. Of this the owner must be the judge. Assuming that it costs $\$ 1.50$ per year to feed a laying hen and that she must bring in a profit of $\$ 1.00$, she will need to lay about 100 eggs or eight dozen at thirty cents per dozen. Most of the hens kept by farmers lay less than 100 eggs in their pullet year, it is said. If this is true, the necessity of closer culling and better breeding is apparent.

On commercial poultry plants, where the stock has been carefully bred for egg production, many hens are found that will net a dollar profit or even more in their third year. At Cornell records of the 
four highest producing hens for three years showed surprising results. They were as follows :

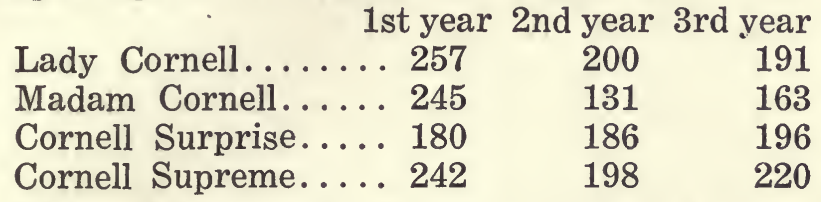

Three of these hens, it will be observed, actually laid more eggs in the third year than in the second, and one, Cornell Surprise, laid more in the third year than in either the first or second. In the case of Lady Cornell, the only one in which there is a steady decrease from the first to the third year, the decrease is so light that the hen may be assumed to have been a profitable producer for two years more.

Undoubtedly the advisability of keeping any hen after the second year must depend upon the hen herself, and the trap-nest is the only sure guide to a knowledge of her real worth.

\section{THE FALL EGG PROBLEM}

The secret of success with poultry is very largely the secret of getting eggs when eggs are dear, that is, in the fall. Producing eggs in the spring when every hen is laying requires neither skill nor knowledge, nor does it go far toward paying the feed bills for the rest of the year. The fall egg is the ultimate end and aim of all poultry keeping, the center about which all plans and schemes revolve.

Every spring matings are planned with the design of somehow catching that will o' the wisp. Every fall hears the same complaint, "Hens won't lay. What is the matter?"

Instead of asking "Why won't they lay?" it might be well to ask, "Why should they lay?" The jungle fowl never thought of laying in the fall. It was 
enough for her to lay a couple of dozen eggs in the spring. This gave her as large a family as she wished to raise. Why should she worry about more?

It is a far cry from the jungle fowl of the dim and misty past to the domestic hen of the twentieth century with her record of 300 eggs a year, and yet one little word bridges over the whole of the distance, just one word, "breeding." The twentieth century hen lays from 200 to 300 eggs a year because she has been bred to lay. Feeding and care have gone hand in hand with breeding, but they would have counted but little except for the selection, year after year, decade after decade, of the best fowls. Perhaps the selection has not always been very intelligent. Very likely it has been in many cases the survival of the fittest. Nevertheless, somehow or other the domesticated, laying hen, with her more or less high production, has been evolved out of that insignificant ancestor. What has been done can be done again, and it will be more effectively accomplished because of some things we understand now which were not understood even 20 years ago.

Fall laying, it must always be remembered, is contrary to nature. Spring is the natural mating season for birds and animals. Mother Nature herself is back of it all, and it is not easy to change the nature of things.

Egg-laying is reproduction, nothing more, and it is said that the pullets and cockerels which are most strongly sexed-that is, that show their sex earliest -are the pullet which can most easily be induced to lay out of the natural reproductive season, and the cockerel which will transmit this quality from mother to granddaughter. The question is an intricate and interesting one and worthy of the most careful attention of scientists and breeders. 
This much we know, however, that there are ways of increasing fall egg production and that the first of these is breeding for eggs. It is possible by selecting year after year the hens that as pullets laid well in the fall and the males that are known to be sons of high producers, and breeding from them, to produce a race of hens that will lay in the fall. This has been done in many cases. It is done systematically on all commercial egg farms. It will be done more and more by amateurs as the principle becomes more widely understood. Perhaps the time will come when all hens will lay in the fall as they now lay in the spring. Then there will be no more high prices for fall eggs, and we shall all be trying to change nature again. 


\section{CHAPTER VII.}

\section{Marketing}

\section{HANDLING EGGS}

Making the hens lay is only half the battle for poultry profits. Getting the eggs to market in proper condition is just as important. Investigations by the United States Department of Agriculture show that nearly 17 per cent of all eggs shipped to wholesale markets are a total loss because they are unfit for use. In Missouri alone it is estimated that carelessness in handling eggs costs the farmers of the state a million dollars a year. Think what a tremendous loss this means the country over!

These losses, according to the department, are divided as follows:

Dirty eggs.............. 2 per cent

Broken eggs..............2 per cent

Chick development...........5 5 per cent

Shrunken, due to holding......5 5 per cent

Rotten ................ 21/2 per cent

Mouldy or stale........... 1/2 per cent

17 per cent

It is further estimated that these losses would be wholly or nearly eliminated by better management at the point of production, by more careful grading, and by more systematic methods of marketing.

Better management on the part of the producer means eggs that are (1) fresh, (2) clean, (3) infertile, (4) of good size and all the same size, (5) of uniform shape and color, (6) well packed. The follow- 
ing rules may well be observed by every one who raises eggs for market:

\section{Rules for the Producer}

1. Keep all male birds out of the laying pens. Infertile eggs can be had in no other way, and infertile eggs do not spoil.

2. See that nests are clean and the litter frequently renewed.

3. Gather eggs twice a day and keep in a cool, well ventilated place.

4. Market all eggs at least twice a week.

5. Grade well for size and color.

6. Market pullets' eggs separately or use them at home.

7. See that all eggs weigh at least 22 ounces to the dozen. "Extras' should average 24 ounces.

8. Never wash eggs. Wipe with a damp cloth if necessary.

"Extras" in the San Francisco market must be all white, perfectly fresh, reasonably clean, must weigh at least 22 ounces to the dozen and average 24 ounces. In Los Angeles there is no distinction as to color.

An infertile egg never rots, but it does become stale and shrunken after a time, hence the necessity of marketing often. An egg is not "strictly fresh" if it is over two days old. In fertile eggs in warm weather the germ often begins to develop in a few hours, hence the extreme importance of marketing only infertile eggs.

\section{Selling Eggs}

Eggs may be sold (1) direct to the consumer, (2) direct to the retailer, (3) to commission merchants, (4) to the local poultry dealer or the wagon 
which goes through the country picking up eggs and poultry. The first method is the most profitable. Large poultrymen who can contract for a given number of dozen each week are often able to sell very profitably to hotels and restaurants. Smaller producers sometimes find good customers in the soda water fountains, but a good private trade is the best. There are many well-to-do people in all large cities who are willing to pay the highest market price the year round for eggs of guaranteed quality. A few will pay a little over the market price, but this cannot be counted on.

Sometimes selling direct to the retailer is as profitable as selling direct to private customers, but most retailers want too large a profit. The country grocer pays from five to ten cents a dozen under the market price. Some city groceries, which have particular customers, will take guaranteed eggs at two or three cents under the retail price. The producer who makes a point of quality can usually find some retailer who will do the square thing.

Now that parcel post is no longer an experiment, it is possible for the small producer in many cases to work up a family trade in eggs and dressed poultry, and such a trade, if goods are first class and attractively packed, should pay well.

\section{Packing Eggs}

Eggs shipped to commission men or the city grocer are packed in cases holding thirty dozen, and should be very carefully graded as to size and color. If you do not grade them yourself you will have to pay some one else to do it.

The postoffice department requires that eggs sent by parcel post be first wrapped separately in excel- 
sior, cotton or paper, and then packed in one of the containers manufactured for the purpose.

For eggs delivered by hand there are neat cartons which may be had for about a cent apiece.

\section{Improving Eggs}

When a poultryman finds that a large number of his eggs do not grade as "extras," there is just one thing to do, that is, improve the quality. If the eggs selected for hatching are all eggs that will weigh at least 22 ounces to the dozen, all the same size and color, and all with good, strong, smooth shells, the eggs of next year's pullets will be of more uniform quality and better size. Never set an egg that is not up to the standard. Hens that persistently lay thinshelled, badly shaped eggs, should be eliminated from the flock.

\section{PRESERVING EGGS}

The best method of preserving eggs, and the one now recommended by all experiment stations, is what is called the water glass method. Eggs preserved in a water glass solution will keep almost perfectly for several months. The taste is a trifle flat as compared with that of a fresh egg, but they are wholesome and sweet and will poach nearly as well as a fresh egg.

Water-glass (sodium silicate) may be bought from any druggist for twenty-five or thirty cents a quart, and a quart will preserve twenty dozen eggs. Boil ten or twelve quarts of water and let it cool. Then add a quart of water-glass and mix thoroughly. The mixture should be kept in a stone jar in a cellar or other cool place, and the eggs placed in it each day as soon as they are brought from the nest. Do not 
put in dirty eggs nor eggs that have been washed. The liquid should cover every egg completely.

When eggs that have been in a water-glass solution are to be boiled, pricking a hole with a pin in the large end of the egg will keep it from cracking.

By this method eggs may be stored at a very trifling expense in the spring when they are cheap and kept for family use in the fall when prices are high and fresh eggs are too valuable to use at home.

\section{MARKET POULTRY}

Market poultry may be classified as (1) broilers, (2) fryers, (3) roasters, (4) hens, (5) capons. Broilers weigh from one and one-half to two pounds. Fryers weigh from two to four pounds. Roasters are young birds weighing from four to six pounds. Roosters that have their spurs are no longer roasters.

\section{Broilers and Fryers}

Chicks intended for broilers should be hatched in the fall or early winter. September is an excellent month for getting out broilers for the Christmas market. Broilers hatched between the first of September and the last of January always bring a good price for the demand is sure to exceed the supply. Many poultrymen hatch for this special broiler market in the fall when their incubators and brooders would otherwise be idle. These chicks are fed a special ration after the first three weeks and are marketed as soon as they weigh two pounds unless they are intended for fryers, when they should weigh from two to three pounds.

The surplus cockerels from the spring hatches are not as profitable as these winter broilers, but if they are separated from the pullets as soon as they show their sex, confined quite closely and fed a fattening 
ration, they can usually be counted on to pay for their raising and something more.

The ration fed to the cockerels intended for market may contain a good deal more soft food than that of the pullets. A moist mash twice a day from the first month on, with cracked corn at noon, will keep them growing and bring them to marketable age at eight or nine weeks in the case of the heavy breeds, and about twelve weeks for light breeds.

Notwithstanding the fact that market quotations in early spring are higher for broilers than for fryers, my experience is that it is hard to get a good price for birds under two pounds weight, and from two to three pounds is really the most profitable weight to sell them. Outside of hotels and restaurants, few people care for a bird that weighs less than two pounds, and the hotel and restaurant trade is only for the poultrymen who make a specialty of broilers and can agree to deliver a certain number every week. Two-pound birds in early spring will bring from thirty to thirty-five cents a pound, live weight, perhaps a little more at times, and this is the most profitable time to sell them. Additional weight that might be added by holding them would not make up for the probable drop in price, to say nothing of the feed consumed.

\section{Fattening Cockerels}

When the young cockerels have nearly reached the desired weight they are much improved by being placed in crates which hold six or seven birds each.

Bulletin 10 of Purdue University Experiment Station gives these directions for crate fattening:

"A crate should be built in as cool and quiet a spot as possible, and divided into compartments capable of holding six or seven fowls. These divisions can be 
made 35 inches long, 24 inches deep and 16 inches high. Slats make the best front and can also be used for sides and top. The bottom should be made of half-inch hardware cloth wire to allow the droppings to pass through, thus insuring sanitation and clean feet. Under the wire bottom should be placed a metal pan to catch the droppings. This can be removed when necessary and easily cleaned.

"Only birds with good vitality and apparently good vigor should be used, for the feeding capacity of the fowl has much to do with the gain in weight. When the birds have been selected and placed in groups in the coops, they should be starved for 24 hours in order to clean out the intestines and make them hungry for the fattening ration. This is fed in a trough placed outside the crate in front of the birds. The birds should appear ravenous and eat greedily. If
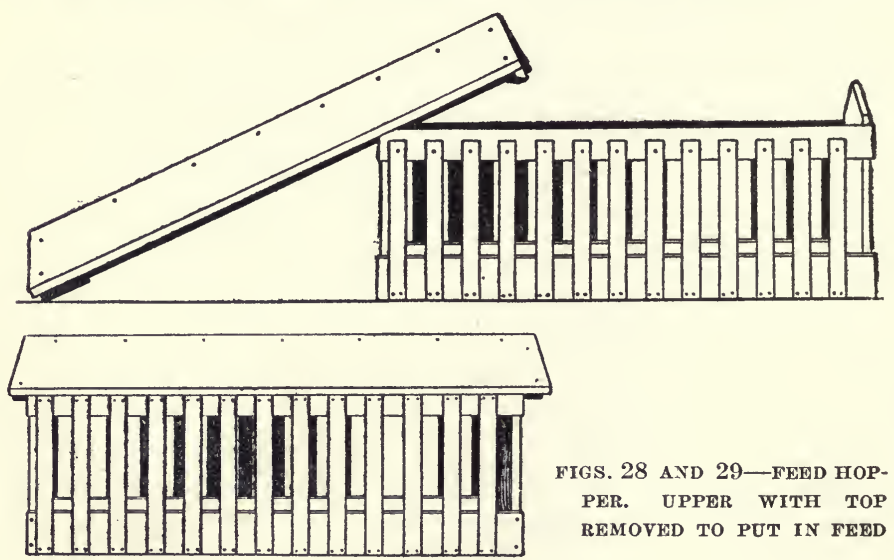

FIGS. 28 AND $29-$ FEED HOPPER. UPPER WITH TOP REMOVED TO PUT IN FEED

they do not, there is something wrong with them, and they should be removed from the coop. When the birds have eaten greedily for thirty minutes the 
trough should be taken away, thoroughly cleaned and allowed to dry.

"Water is not necessary except in hot weather. It is advisable to feed grit every few days. Two weeks is a good average length of time to feed.

"The greatest gain should be made during the first week, but it is profitable in most cases to continue for another week. A three to four-pound cockerel should make a gain of at least one pound in the two weeks at a cost of not over seven cents for feed."

A good fattening ration consists of 2 lbs. corn meal; 1 lb. shorts; 1 lb. ground oats; 8 lbs. buttermilk.

\section{Roasters}

Birds intended for roasters are hatched in the fall, preferably in September, and marketed anywhere from the last of January till the middle of March, when they bring twenty-five to thirty cents a pound, live weight. When one has plenty of room and the right kind of birds roasters may be handled in this way very profitably as a side line. The pullets make excellent spring and summer layers.

Whatever the age of the bird it is always best to confine it for a couple of weeks before killing and feed a fattening ration. The birds will weigh more and command a better price.

The most profitable way to market poultry, except where private customers can be found for dressed birds, is alive. Fattening and killing requires special equipment which the poultryman as a rule does not possess. Dressed poultry is also very perishable and it is difficult to find a market save in a small way.

\section{KILLING AND DRESSING}

Fowls that are dressed for market, whether public 
or private, should make as presentable an appearance as possible, and for this three things must be observed:

1. The fowl must bleed thoroughly. Failure to do this leaves discolorations on the skin.

2. The head must be left on. There are exceptions to this rule. Private customers do not care to see the head, and broilers are marketed without it, but in general, the public prefers to see the head, and so the head is left on.

3. The skin must be unbroken.

4. The fowl must be plump and appetizing.

In order to satisfy the first two conditions, the fowl must be bled without removing the head, and the only way to accomplish this is to kill by the method called "sticking." First, hang up the bird by the legs, then, according to directions of the Department of Agriculture, "grasp it by the bony part of the skull. Do not let the fingers touch the neck. Make a small cut with a small, sharp-pointed knife on the right side of the roof of the mouth, just where the bone of the skull ends. Brain for dry picking by thrusting the knife through the groove which runs along the middle line of the mouth until it touches the skull midway between the eyes. Use a knife which is not more than two inches long and one-fourth inch wide, with a thin, flat handle, a sharp point and a thin cutting edge."

If it is properly "stuck" the bird will bleed freely. Now hang a blood can on the fleshy part of the lower mandible and "dry-pick." The skin will be smoother and whiter if the fowl is dry-picked instead of scalded, and if the feathers are pulled in the direction in which they grow, they can be easily and quickly removed without danger of breaking the 
skin. An experienced picker can dry-pick a bird in less than a minute.

\section{CAPONS}

Very little has been done on this coast with capons, but a wave of new interest is spreading over the Middle West, and it is bound to reach California sooner or later. The arguments pro and con are: The capons are made from late hatched cockerels which would bring a very low price as broilers or fryers. Unsexed and allowed to grow till February or March they easily reach ten pounds in weight and bring from twenty-five to twenty-eight cents a pound. On the other hand, six months is a good while to feed a bird, even though you make a profit of a dollar on him, and he takes up room which is needed by the growing pullets. These objections are trifling. The more serious one and the one which probably deters many persons from trying the experiment is that capons cannot be made from Leghorns or any other of the light breeds. The best capon is made from a Brahma or from a cross of a Dorking or Rock male on a Brahma female. Orpingtons, Rocks and Wyandottes make good capons, but they do not reach the size that a Brahma capon does. In other words, in order to make a success of caponizing it seems to be necessary to keep a special breed for this special purpose. The capon is not, except in a few instances, a by-product of egg production, as broilers and fryers are. Still, the Missouri Station says they are the most profitable of all market poultry, and the manager of a large Los Angeles commission house, whose opinion I asked, held, that considering the cheapness of eggs from which June chicks are hatched, capons should be more profitable than early broilers. 


\section{CHAPTER VIII.}

\section{Sanitation and Hygiene}

\section{PREVENTING DISEASES}

A vigorous flock of prolific fowls is an impossiblity without sanitary surroundings and intelligent feeding. Take the finest, hardiest pen of fowls you can buy, house them in an unventilated coop, allow filth to accumulate on the floors and mites to breed among the filth, neglect to spade or to plant the runs, and in a very short time your vigorous, red-combed birds become roupy, worthless stuff. Up-to-date poultrymen understand this so well that the modern poultry plant is almost as clean as my lady's kitchen.

Roup is the most common result of contaminated air. Scaly leg arises directly from filthy runs and yards. Chicken pox is passed on from generation to generation in houses where disinfectants are never used. Dirty drinking water is the source of diarrhea and other intestinal troubles. Moldy scratching litter causes a disease of the lungs and air passages which is as hard to cure as roup. Foul soil breeds the pestilent gape worm, and who can catalogue the trouble and loss that follow when filthy houses and coops once become infested with mites?

Cleanliness is the first essential in the care of fowls, and in order to attain perfect sanitary conditions there must be, as the Maine Station has tersely put it:

1. Clean Houses.

2. Clean Air.

3. Clean Food. 
4. Clean Water.

5. Clean Yards and Clean Range.

6. Clean Incubators and Brooders.

7. Clean Birds, Outside and Inside.

\section{The Clean House}

A clean poultry house will have (1) a clean floor, (2) clean walls and nests, (3) movable roosts and fixtures.

\section{A Clean Floor}

The cleanest floor is a cement floor. Swept daily and washed clean with the hose once a week, it gives no chance for mites to breed. When a cement floor cannot be had, a board floor is next best. It has cracks, to be sure, where mites may hide, but they will not if it is kept clean. A dirt floor is the least sanitary, and only by removing the droppings every day or two can it be kept clean.

Objection is sometimes made to cement floors on the ground that the fowls' toe nails are broken or worn by scratching on them, but the use of a little dirt or sand, with six or eight inches of straw above should save the fowls' feet.

\section{Movable Fixtures}

Mites always breed under something. No use looking for them anywhere else in the day time. At night you will find them on the hens. The sanitary house or coop must have no place that cannot be reached and cleansed or disinfected. Under the ends of the roosts, under the droppings on the floor or the droppings-board, under the litter in the nests, in every crack and crevice, these pests may be found in a mite-infested house; hence the extreme importance 
of being able to move everything and cleanse underneath.

Droppings-boards are a great help in keeping a house sanitary. They too should be movable and should be cleaned very often.

\section{The Garden Hose}

No weapon is more effective in the war against mites than the common garden hose. A house hosed well once a week, walls, ceiling, roosts and nest boxes, is likely to be free from mites. If the hosing is followed twice a month by painting roosts, nests, and the walls next to the roosts with kerosene and crude carbolic acid (1 part acid to 3 or 4 of kerosene) there will be little trouble from mites or other vermin.

In a large house where the hose cannot be conveniently used, it is necessary to spray once a month in cold weather and at least twice a month in warm weather, but on a small place the hose is cheaper and more easily used and just as effective.

\section{Summer Quarters}

Here is a little secret of my own, and I have not been bothered by mites since I discovered it. When hot weather comes, get your hens out of the main house into temporary quarters. On the farm this is easy, for it is only necessary to build a burlap-covered shed in the orchard or stubble field. On a back lot it is not so easy, but it can often be done. When the birds are out of the houses during the mites' breeding time, the mites do not breed there, and a good painting with lice killer when the fowls return in the fall will keep them out for a good while. Even when the fowls cannot be removed from all the houses, if they have been properly culled in June, 
they can be bunched together in the shadiest runs, and part of the houses left vacant.

\section{Nest Material}

Clean nest material is of vital importance in the production of clean eggs as well as in the elimination of mites. Shavings and excelsior are preferred to straw, because they do not so readily harbor mites. Tobacco stems in the nests will keep both lice and mites from breeding there, and there are various medicated nest eggs on the market which are said to do the same thing.

\section{Ventilation}

Since fowls cast off the waste moisture of the body, not through the skin and kidneys, as we do, but through the lungs and air passages, it is easy to see that ventilation is of vital importance. Not only should the poultry house be an open front house, but it should have circulation of air, that all impurities may be carried off and a supply of oxygen provided.

Circulation of air is also important as a preventive of dampness, which is a more deadly foe to the health of fowls than even close air. If the dirt floors of your houses are wet by the rain soaking under the foundation, see that everything is open and a good current of air blowing through as soon as the rain stops. Dampness and close air are the most prolific causes of roup and other respiratory diseases, and neither should be tolerated for a moment.

\section{Purifying the Land}

Fowls can bear more abuse than any other domestic animal, it is said, and it is astonishing how long they will continue to thrive on filthy soil, but there is always an end. To keep fowls, as I have seen 
them, in yards where droppings are piled so thick and high that the hens can by no possibility touch clean ground with bill or toes is to invite disaster.

Spading up the soil of the runs and scattering lime over them is one way of purifying the soil, but the best way is to plant green stuff. In this way the manure which cannot be raked up is utilized in growing poultry feed, and the soil, if it is left vacant till the green crop is grown, is thoroughly purified.

Rape is one of the best greens for this purpose. Fowls like it and it makes a rapid growth. Oats, barley or any other grain may be planted and will grow in a few weeks to a height suitable for feeding. Where a system of double runs is maintained a new crop can be planted once a month in the alternate pens. Corn is an excellent crop for runs which can be spared for several months.

When runs and yards must be used for a year without growing a green crop, they should be raked and spaded as often as they seem to need it. Sandy soil can be kept clean in this way much longer than adobe or heavy loams. It is a good plan sometimes to plant oats or barley in occupied runs, covering them so deep that the fowls will not dig them out before they sprout. If the ground is kept moist three or four days and then turned up with a spade, the succulent sprouts furnish both green feed and an incentive to scratch.

\section{Shade}

In all those localities where the sun is liable to be hot almost any day in the year, shade is more important than some poultry keepers seem to think. Chickens cannot change their clothing to suit the weather and they suffer much more, I am sure, than 
we humans do, from the direct burning rays of the sun.

Baby chicks left exposed to the glare of the sun soon die. I went to church one hot April morning and forgot to shade a Philo coop which held thirtyfive or forty young chicks. When I returned three hours after one chick was just breathing its last, and they dropped off, one by one, till the entire brood was gone. Adult fowls can bear more heat than chicks, but they are very uncomfortable and this should be reason enough for protecting them.

Hens and chicks alike prefer the shade of a lowgrowing tree or vine to anything else. Nothing pleases them quite so much as a grape vine. Corn is a particularly good shade for young chicks. The shade is low and not too dense.

Deciduous trees make a very satisfactory summer shade and are profitable besides, but they are of no use in February, when shade is often greatly needed. For a permanent shade, good all the year round, nothing is such a pleasure to fowls or such a satisfaction to their owner as a pepper tree. It might make too dense a shade in a north-front yard, but in a south-front yard, especially on a southern slope, it is ideal. Vines when they can be made to grow are excellent shade, but unless the vines are started ahead of the chickens they are impossible. Castor beans are good but ugly.

When there is nothing else a wooden frame two or three feet high covered with burlap sacks makes a very good shade, but it is not pretty, and every poultry keeper ought to plan for some permanent green shade. Whether you have a tree or only a makeshift burlap shade, try throwing a pail of water under it every day, just enough to keep the ground moist and make a wallow for the fowls. This helps to keep 
them free from lice and gives a great deal of comfort.

\section{Government Whitewash}

A thorough whitewashing once a year, inside and out, goes far to keep buildings clean and sanitary. The following is the formula for whitewash which is recommended by the government:

One peck of lime slacked in boiling water and kept just covered by the water while slacking. Strain through coarse cloth. Add two quarts of fine salt dissolved in warm water, one pound of rice meal or ground rice boiled in water to a thin paste, onequarter pound of whiting, and half a pound of glue dissolved in warm water. Mix all thoroughly and let stand covered for two or three days, stirring occasionally. Heat the mixture before using. Sometimes a quantity of crude carbolic acid is added to this wash, but this changes the color somewhat and is no more effective than whitewashing the houses and then painting roosts and nest boxes with the acid.

\section{INSECT PESTS}

Probably the control of insect pests is the hardest task the poultryman has to face, and this is especially true in the warmer climates where they breed the year round. Summer and winter the fight must be waged. There is no let-up, though cleanliness and properly constructed houses make it easier. Lice kill baby chicks and turkeys, stunt the growing stock and make hens unproductive and prone to disease. The little red mite always lies in wait to devour and is sure death to young stock and sitting hens. Ticks and fleas are found only in certain localities, but are very hard to get rid of.

There are eight kinds of lice and eighteeen species 
of mites besides the tick or dovecot bug, and several kinds of fleas.

\section{Lice}

Lice are the most widely distributed parasites of poultry and are to be found in almost every flock that is not frequently and persistently treated with lice powder or some other means of removing them. The common body louse is yellow and may easily be seen in the fluff below the vent.

The dust bath is of first importance in handling these pests. In every hen yard there should be a place where the soil is kept moist by sprinkling, and frequently spaded, so that hens may dust themselves freely. Wood or coal ashes added to this dust bath make it still more effective. Some hens will almost keep themselves free from lice when they have unlimited opportunity for dusting, but there are few flocks where other treatment is not necessary.

There are three methods of treating lice: dusting, dipping and greasing. Dusting is the method most generally employed. Buhach or any good louse powder rubbed well into the fluff around the vent and under the wings will keep down the lice for a time, but the dusting must always be done twice at intervals of five or six days, so that the nits which hatch after the first dusting may be killed.

Dipping in sheep dip, tobacco water or kerosene emulsion is very effective, and, it is said, will keep fowls free from lice a whole season or longer, but it is not generally practiced, because it is very troublesome and can be done only in the warmest weather.

Blue Ointment-A mercury preparation which is recommended by many experiment stations, is said to be very effective in ridding the hens of lice, but must be used with great care for it is a powerful 
poison. As used at Petaluma the blue ointment, which may be purchased at almost any drug store, is diluted with lard, a pound of the ointment being mixed with a gallon of lard. This is rubbed about the vent and under the wings, and is not dangerous, nor is it as effective as the blue ointment mixed with an equal quantity of vaseline. When the stronger preparation is used a very small quantity should be taken on the finger and carefully rubbed about the vent.

LOWRY POWDER.-The Maine Station recommends this lice powder as the cheapest and most effective treatment: 3 parts gasoline, 1 part crude carbolic acid, 90-95 per cent strength. If this strength of the acid cannot be obtained, use 3 parts gasoline, 1 part cresol. Mix these together and add gradually while stirring enough plaster of paris to take up all the moisture. As a general rule it will take about four quarts of plaster of paris to one quart of the liquid. The liquid and dry plaster should be thoroughly mixed, and the resulting mixture will be a pinkishbrown powder, which is to be worked into the feathers and fluff like any other powder. This is called the Lowry powder, after its inventor, Mr. R. C. Lowry of Cornell University.

Sitting hens should be well dusted before the eggs are given them and two or three times during incubation, so the young chicks may be free from lice, which are fatal to them. It is safest, also, to grease the heads and throats of hen-hatched chicks with lard, for it is hard to be sure that the hen is perfectly clean. Hen and chicks should be dusted every week or two or the lice will find them.

Lice powder or tobacco powder or tobacco stems in the sitting hen's nest will go far to keep her free from lice, and it is said that kerosene sprayed with 
an atomizer into the mother hen's feathers, under the wings and around the vent once a week, will keep her and her brood absolutely clean.

Incubator chicks are free from lice when hatched and will remain free if brooders are disinfected for every new brood and are kept clean and at a distance from all hens, but it is just as well to dust them occasionally as a matter of precaution. Dr. Salmon says: "When anything is the matter with a horse the maxim is 'Examine his feet,' and when anything is found wrong with poultry or other domesticated birds the maxim should be 'Look for lice.' "

DUST AND DisTillate.-A friend of mine has devised a clever method of keeping lice from baby chicks. She finds a nice, dusty place in the back yard and sprays the dust full of distillate. The chicks' coop and wire run are then placed over this dust bath, and the chicks wallow for several days. Their down is soon filled with this oily dust, and the lice never find them.

\section{Mites}

The most common and injurious of the eighteen species of mites is the little red mite (Dermanyssus gallinae), which is found in nearly every hen house that is not kept very clean. Cement floors and a thorough sweeping out of all droppings every week will go far toward keeping these pests away. If in addition houses are washed out with a garden hose every two weeks or oftener and sprayed or painted once a month with some good spray, mites will rarely find shelter in them. Nest boxes must be cleaned often, painted with lice killer, and fresh nest material put in.

It must be remembered that whereas lice live on the bodies of the fowls themselves and "subsist upon 
the productions of the skin and fragments of feathers," mites suck the blood of their victims by night and find their home in cracks in the walls, under the ends of roosts and in corners of nest boxes, and are found in great numbers among the droppings on a dirt floor. Absolute cleanliness is therefore the only preventive, and when they have once found a home in a poultry house only a strong disinfectant will kill them.

Here are several good mixtures, either one of which should be effective in ridding a house of mites:

1. Kerosene AND CRUde CARBolic.-For spraying and painting houses and coops there is nothing better than a mixture of kerosene and crude carbolic acid, three parts kerosene to one of the acid. This is recommended by the Maine Station and is very generally used.

2. Kerosene Emulsion.-The Department of Agriculture recommends a kerosene emulsion which is prepared as followis: Shave one-half pound of hard soap into one gallon of soft water and boil the mixture until the soap is dissolved. Then remove it to a safe distance from the fire and stir into it at once two gallons of kerosene. Dilute this stock mixture with 10 parts soft water and apply as a spray or with a brush, being careful to work into all cracks, crevices and joints.

3. CResol Disinfectant.-The Missouri Station recommends the following emulsion: "Shave a 10cent cake of laundry soap into a pint of soft water, steep it until a paste is formed, stir in one pound of commercial cresol, beat or allow to stand until the paste is dissolved, and stir in one gallon of kerosene." Cresol is a very powerful disinfectant, costing about 30 cents a pound. Care must be taken not to get it on 
the hands or face. It should be applied undiluted with a brush.

\section{Watch the Brooders}

Brooders and coops where young chicks are kept should be examined and treated often for mites, for nothing will so quickly stunt the growth of young stock. For coops for hens with their broods it is a good plan to use clean new boxes and never to use one a second time, and the same may be said of nest boxes for sitting hens. If every one of these boxes is destroyed as soon as the hen or the brood is through with it much trouble will be saved.

Tobacco powder scattered through the litter of the sitting hens' nests will usually keep mites away, but all nests should be watched.

MUTTON TALLOW.-A very simple method of keeping mites out of poultry houses is to paint the roosts twice a year with hot mutton tallow. One of the largest poultry plants in Southern California uses this successfully. The tallow is melted and then is kept hot over a small oil stove while the caretaker goes from house to house and paints the roosts with it. On this plant all the roosting houses have cement floors, and between the cement below and the tallow on the roosts, with a good cleaning out twice a week, no mite has a chance to find shelter.

Carbolineum, zenoleum and other coal-tar preparations are highly recommended for this purpose. They are applied with a brush to roosts and walls.

\section{Ticks}

The tick or bedbug of poultry closely resembles the bedbug found in dwelling houses. It is found only in certain localities, usually on very sandy soil, but where it does exist it is a terrible pest. The 
Maine Station's bulletin on poultry management says the sprays recommended for mites will destroy ticks as well, but California poultrymen have found painting or spraying the infested house with corrosive sublimate solution (8 ounces of corrosive sublimate to 20 gallons of water) the most effective remedy. When houses can be tightly closed they may be fumigated with sulphur or formaldehyde or with the cyanide process used for citrus trees.

With ticks as with other pests, the best remedy is prevention. A house that is kept perfectly clean is not likely to be infested.

\section{Fleas}

The common hen flea (Pulex gallinae) is also found in dirty houses and runs, and especially in nests where straw is used. Theobald recommends the use of excelsior or shavings for nesting material because fleas do not breed as readily in them as in straw.

The most effective remedy for fleas is perfect cleanliness. Whitewashing with a wash to which crude carbolic acid has been added (1 pint acid to 12 gallons whitewash), and throwing or spraying it into all the cracks and dark corners will usually drive them out, but the houses must be watched and cleaned again and again. To get the fleas off the hens dip them in Zenoleum or a good sheep dip.

For sticktight fleas and sand fleas spray or wash the houses with hot salt water and apply corrosive sublimate to the fleas found on the chickens. In handling corrosive sublimate care must be taken to keep it out of the chickens' or the attendant's eyes, for it is a very deadly poison. 


\section{HYGIENIC FEEDING}

Sanitation looks to the external conditions which surround the bird; hygiene to internal conditions; and when we refer to internal conditions we usually mean conditions affecting the digestion, for the fowl's digestive tract, like man's, is "where he lives."

There are six essentials to hygienic feeding:

1. PURE FOOD.-Don't buy moldy corn or ground grain because it is cheap. It may prove to be very dear. Don't buy beef scrap without knowing whether it is made of hoofs and horns or of something more digestible. If grain gets wet and molds on your hands, don't feed it. The fowls may be able to eat it without suffering, and they may not.

Don't feed moldy bread or spoiled table scraps, and be particularly careful about spoiled meat and putrefying fowls and animals. Every bird that dies about the place should be buried deep or burned. Limberneck and ptomaine poisoning result from the fowls getting this kind of food.

2. Clean Water.-Water has been called the cheapest of poultry foods, and fowls drink a great deal when it is clean and cool. Never set water before your fowls that you would not drink yourself.

3. Clean Fountains and Feed Troughs.Crocks and pans should be scalded once a week and rinsed every day. They should also stand on a table or platform where the fowls cannot scratch filth into them. A galvanized iron pan is more easily kept clean than the porcelain crocks which are often used.

Troughs or pans in which wet mash is fed should be scraped clean every time they are used, and washed often. Never leave wet mash standing before the fowls. It molds quickly and then becomes unfit for food.

4. Clean Scratching LitTer.-Moldy scratch- 
ing litter is just as dangerous as moldy grain. The mold spores enter the air passages and form a growth which spreads through the lungs and often into the digestive organs.

5. GREEN FEED. - The health of the fowls as well as egg production demands a plentiful supply of green feed. The mineral salts and especially the chlorophyl in the fresh, succulent greens are better than any medicine for keeping the liver in order. Never stint your stock, young or old, on green feed.

6. EXERCISE.-Health and productiveness depend on exercise, and for fowls closely confined scratching for their grain is practically the only means of exercise. Every poultry yard should have a scratching pen either in the house or outside, and this should be kept full of litter-six or eight inches is none too much-and every bit of grain thrown in this litter for the hens to dig out. Dry leaves and corn stalks may be used if straw and hay are scarce, but there is nothing quite so good as alfalfa hay.

\section{Droppings Indicate Health}

The condition of the droppings furnishes a good indication of the hen's health. They should be of sufficient consistency to hold their shape, but should not be too solid. In color they should be dark, tapering off into grayish white. If the droppings are soft or pasty and of yellowish or brownish color, it indicates too much carbohydrates or a lack of meat. If, on the other hand, the droppings are watery and dark with red splashes of mucus in them, it indicates too much meat. A greenish, watery diarrhea usually indicates unsanitary conditions, either in the surroundings, the feed, or the water. 


\section{CARING FOR HENS IN SUMMER}

The care of hens in summer must be considered from two points of view, i. e., comfort and diet.

Many hens begin to molt by the first of July, and while molting is a natural process, it is still something of a drain on the system. The molting hen is not a sick hen, but if she has been doing her part at filling the egg basket she is a tired hen. If she has been loafing, she should be disposed of before the molt begins.

The key-word to the care of hens during the molting period, which begins the first of July and lasts till December, is rest, and rest means comfort. All hens that are not to be kept through another season should be sold in June, so that the molting hens may have more room.

On the farm or on the poultry plant of considerable acreage there is often a shady orchard into which the hens can be turned for their summer rest. On a large plant this is not, of course, practicable, but the hens kept on these large plants are invariably White Leghorns, and they, for some reason, adapt themselves to crowded conditions and lack of range much more readily than do the heavy breeds. For Rocks, Reds and Orpingtons an orchard, planted to rape or barley, where the hens may range and loaf, is an ideal vacation ground, and they will need less feeding if allowed to forage for part of their living. The summer outing is not more valuable to the tired business man than it is to the "business hen."

The hen that is allowed to range a little will find a place where she can wallow in soft dirt in the shade of a tree. When she is confined, such a place must be provided for her.

Drinking vessels should receive special care dur- 
ing the summer. Rinse them out thoroughly at least once a day and scald once a week to remove every bit of the algae which grows so quickly in warm weather. Keeping the vessels in the shade helps to keep down this troublesome green growth. Cool, fresh water means much to the comfort of hens in hot weather and should be provided twice a day always, oftener if necessary. On one of the largest poultry plants in Southern California the water troughs are emptied and rinsed three times a day.

Comfort at night is quite as essential as comfort during the day. Hens that are crowded in close, stuffy quarters, or worried by lice and mites, cannot sleep well and will be fagged and worn before the summer is over. Every roosting house should be provided with windows at the rear, which may be opened in warm weather. Where only a few hens are kept, or where they are moved to the orchard for the summer, temporary coops of $1 x 3$ covered with muslin or burlap make inexpensive summer roosting places. If the hens happen to roost on top no harm is done; in fact, sleeping out of doors is just as good for hens as it is for folks, and an out of door roosting place can often be managed if only one thinks of it. Nearly all my pullets this summer left their coops and roosted outside, and they are in the pink of condition.

The same principles that govern the diet of human beings in summer apply also to the feeding of hens. A lighter diet, less of meat and all heating foods, and more of succulent greens, is as necessary to hens as is an increased proportion of fruit and vegetables to the rest of us. Omit corn and corn meal from the ration until it is needed for making feathers; allow access to the mash for half a day only; give all the greens the hens will eat, and sprout 
part of the grain instead of feeding it dry. Whole barley, soaked and allowed to stand two or three days till the sprouts begin to show is one of the best of summer feeds. This sprouted barley in the morning, with wheat in the litter at night, greens at noon, and half a day's access to the dry mash hopper, makes a good summer ration for stock of all ages.

Some Leghorn breeders feed a little whole corn with the wheat and barley right through the summer, but this will not do for heavy hens.

Overfat hens are in no condition to go through the molt and must be put by themselves and their ration reduced. This is very necessary, for an overfat hen, while she drops her feathers easily, cannot so easily manufacture new ones. 


\section{CHAPTER IX. \\ Fixtures and Conveniences}

\section{WATER VESSELS}

On a poultry plant of any size it is necessary for water to be piped to each pen or to each two pens. If the hydrant is between the pens a single pan placed under it will answer for both.

Galvanized iron pans or basins are more easily cleaned than those of tin, but the large stone crocks which are still used in many places have the advantage of being very firm, so that a bird alighting on the edge is in no danger of tipping them over.

There are various systems by which a large plant may be supplied with water, some of them working automatically, but for the beginner there is nothing better than the faucet and movable pan. The pan should always be upon a raised platform so that the birds will not scratch filth and litter into it.

For baby chicks there is nothing better than the galvanized iron fountains which are sold by all supply houses.

A handy water fountain is made of a ten-pound lard pail. Cut notches in the upper edge about two inches wide and three inches deep. Four or five of these may be cut so that several hens can drink at once. Put on the cover and hang up by the bail at a convenient height. This fountain protects the water from all contamination and costs practically nothing. 


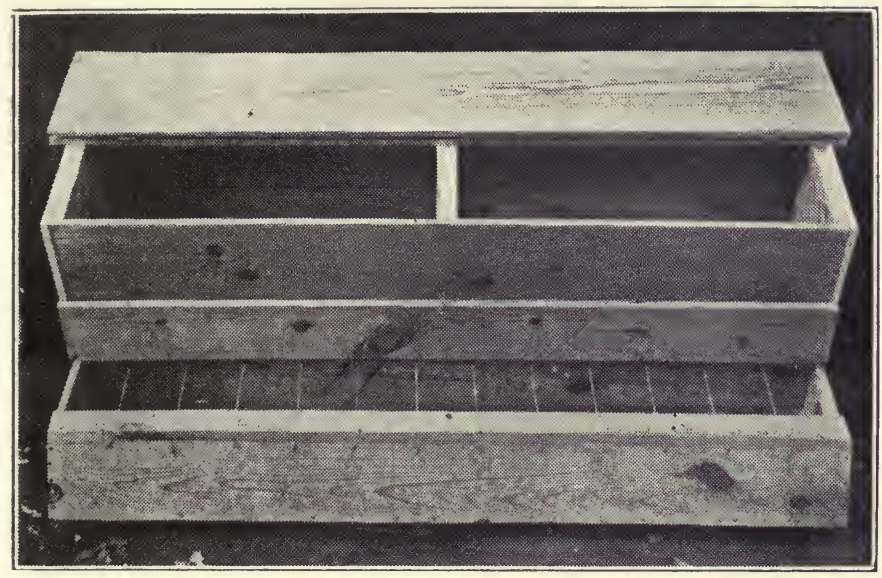

FIG. 30-MOVABLE HOPPER

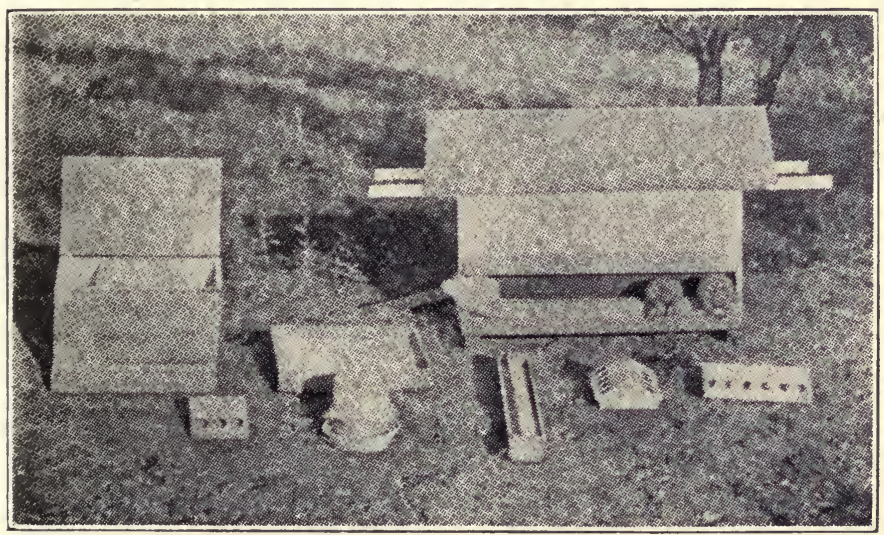

FIG. 31-FEED HOPPER FOR BABY CHICKS 



\section{HOPPERS AND FEEDERS}

Feed hoppers should be large enough to hold at least a week's supply of mash. They may either be separate and movable or built into the house. A very convenient style, which may be used either indoors or out, is used at the Missouri Station (Fig. 23).

California poultrymen generally prefer a long trough which is built into the house, either along the front, where the open front house is used, or along the alley, where a house with two sections and an alley between is used.

In the model laying house described in Chapter I, the feed box and water trough are side by side along the outside of the scratching shed.

A very good trough for feeding moistened mash to baby chicks is made in the usual triangular form and covered with a slat roof of the same shape, with the slats sufficiently far apart to allow the chicks to put their heads between.

Every house should contain a bin for grain, so that there may be no carrying of feed through the rain in wet weather nor unnecessary steps in warm weather.

\section{THE BROODY COOP}

On a farm where hens of the heavy breeds are kept, and to some extent on any poultry plant, a coop for broody hens is a necessity. Such a coop is best made of slats, with slat bottom, so that the hen can never find a warm place to sit in, and should be built into the house, if possible, so that she may have all the protection others have. At the Missouri Station the sides of the coop are made of two-inch mesh wire, as in Fig. 34. Such a coop need be only large enough for the hen to turn around in. If a hen is 
confined as soon as she is seen remaining on the nest at night, and kept in the coop four days, she will be broken of her desire to sit and will usually begin to lay again in a week. While in confinement she should be well fed, so that she may be in condition to begin laying as soon as possible. Starving hens, shutting them up in the dark or turning the hose on them are methods of treatment that are worse than useless. The broody hen must be helped to forget her desire to incubate, and only gentle treatment will do this.

\section{ROOSTS}

Roosting too early is generally believed to be the cause of crooked breastbones. Whether or not there is any foundation for this belief it is well to guard against any such trouble by not trying to force young birds to roost before they are ready.

Chickens of different breeds and often of the same breed differ greatly in the age at which they wish to roost. Last spring some of my young Orpingtons which had been deserted by their mother began to roost in a tree when they were barely a month old, but this was exceptional. Most chicks do not try to roost before they are six weeks old, and some delay till two months or even longer.

When the chicks are about six weeks old and no longer need other warmth than that of their own bodies, it is a good plan to place them in colony coops which have roosts but are also bedded with straw. Sometimes I put a shallow box or basket half full of straw or dry leaves on the floor of the coop under the roosts, and the first night I put all the chicks in this. They soon learn to go to bed in the right place, but little by little the more venturesome find the roosts and go there instead of into the bas- 


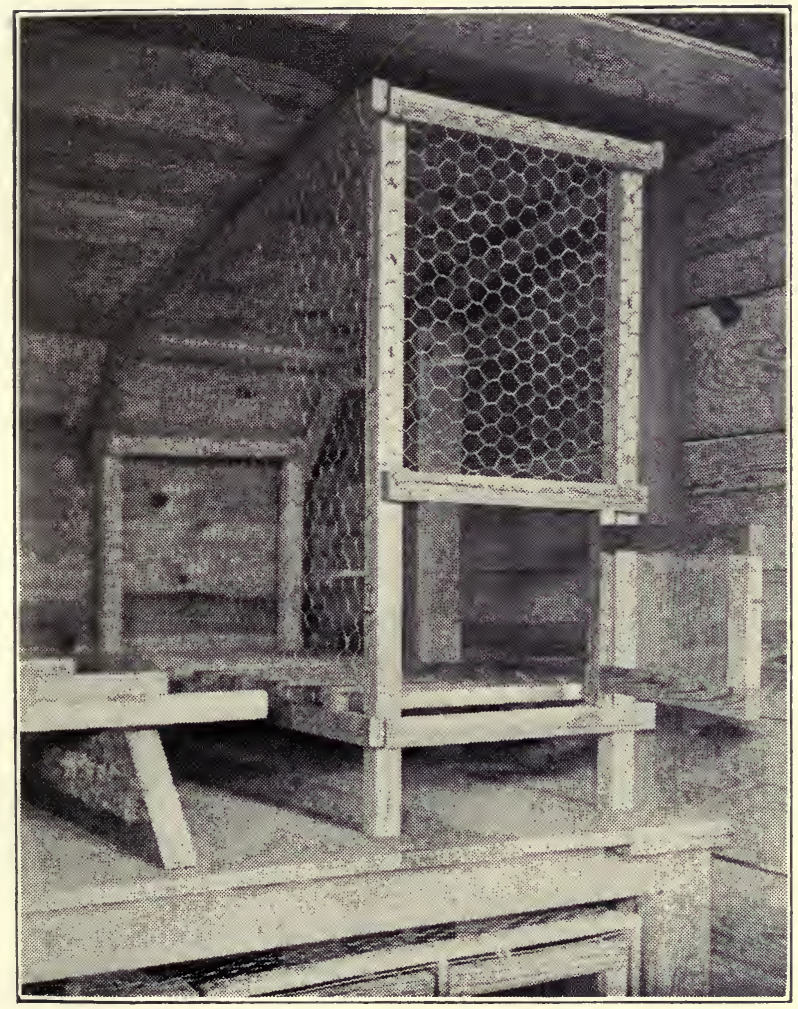

FIG. 34-BROODY COOP 

ket, and after a short time I find them all on the roosts.

Roosts for young stock should be two inches wide. For adult fowls three inches is a better width, for the efforts of a large fowl to keep itself on a narrow roost by grasping it tightly with its claws sometimes result in bumblefoot. Chickens should be able to rest comfortably on a perch without having to cling.

Roosts for heavy fowls should be not over two and one-half feet from the ground. Leghorns may roost considerably higher, but an Orpington or a Rock, in jumping from a high roost onto a hard floor frequently bruises its feet and causes bumblefoot. Place all roosts on the same level. If they are of different heights all the birds will crowd upon the highest.

A very good roost is made of $2 \times 2$ material with the upper sides rounded. This is recommended by the Department of Agriculture.

\section{A GOOD NEST}

The proper sort of nest is a very important part of the poultry house plan. On the farm or the back lot where only a few hens are kept, a grocery box, if it is of the right size and contains sufficient litter, answers very well, but the poultry house which is destined to hold many layers must contain nests that are well planned and efficient.

A favorite way of building nests is to put them under the droppings boards. Some of the best experiment stations do this, and it is a very good way where the requirements of cleanliness are observed. Others build them along the front of the laying house where they are entirely away from the roosts.

The proper size of the nest must receive careful consideration. It should not be too small, for two hens will often crowd upon one nest, with resulting 
breakage. Professor Graham of the Massachusetts experiment station recommends a nest 16x24 inches. This is large enough to permit several hens to go on at the same time, and he has found that it reduces the number of cracked and broken eggs to a minimum.

Some experiment stations recommend the nest with a bottom of wire cloth as being more easily kept clean from mites. Others prefer a nest in which the sides rest upon the bottom without being nailed, so that they may be lifted off and the bottom thoroughly cleaned. This could only be managed by having sides which extended but few inches above the bottom, leaving an opening above where the hens could crawl from nest to nest.

Hens like a nest that is rather dark and secluded, and it is absolutely necessary that all nests be kept clean.

\section{HOMEMADE CONVENIENCES}

While it is true that the commercial poultry keeper and the large breeder must have the best equipment, and enough of it, it is also true that the farmer and the side-line poultryman can often manage without putting very much money into equipment. A little ingenuity will devise brooders that are quite as good as the patent sort, and sometimes better.

In a backyard plant I saw 300 White Wyandotte chicks, just out of the incubator, being cared for in a clever modification of the Philo brooder. The coops used were the regular Philo coops, all facing south. Half of the top was covered with cheesecloth, and about half the other end with wire, leaving a space in the middle for the Philo brooder, which was uncovered except for a six-pane window sash. The sash extended far enough beyond the sides of the 



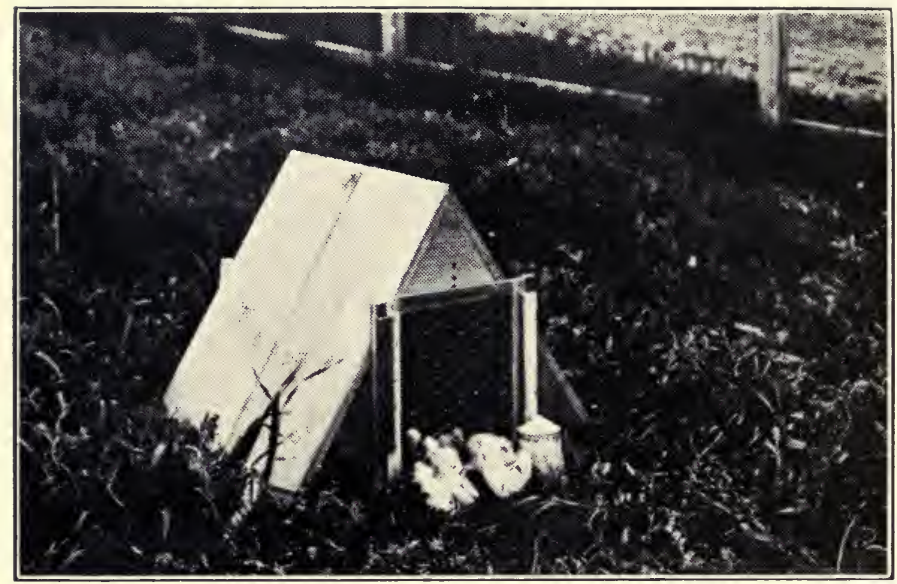

FIG. 35-BROOD COOP MADE OF GROCERY BOX

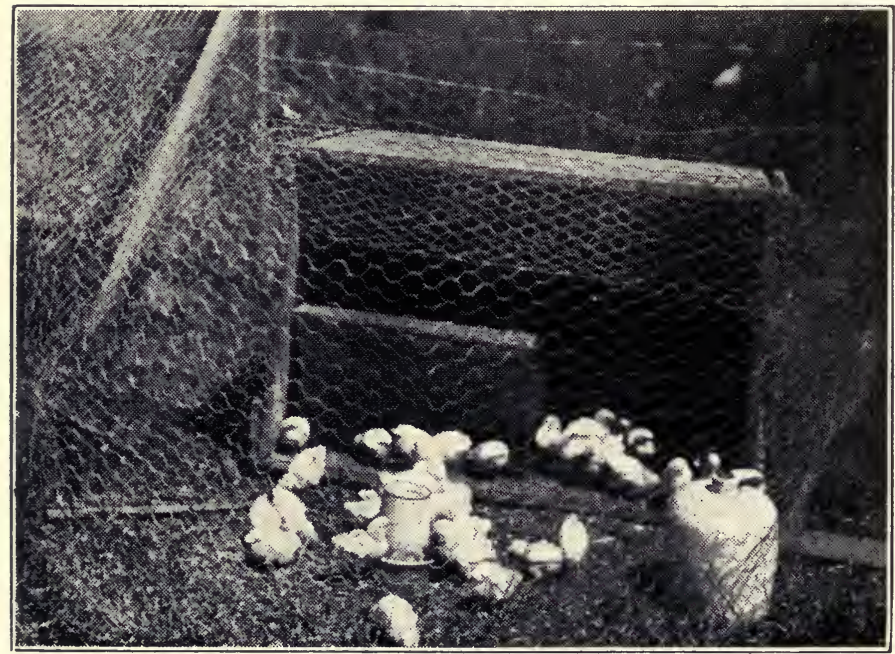

FIG. 36- "JUG MOTHER" AND SIMPLE BROODING COOP 
brooder so that it partly protected the wire-covered run at the end into which the brooder door opened. This arrangement gave the chicks the three temperatures which a newly hatched chick requires: the high temperature of the brooder which, with the sun shining on the glass, was very warm indeed; the cooler, but still warm space just outside the door but under the glass; and the out-of-door but well protected space under the wire, where the drinking fountain and some scattered rolled oats awaited the enterprising chick that dared venture so far. The cheesecloth-covered end of the brooder was entirely fenced off, but would be used later. At night a quilt or flannel hover was substituted for the sash. There were six of these brooders, each holding fifty chicks.

An easy way of caring for baby chicks without a brooder or brooder house is to have a small pen fenced with inch mesh wire and built against the east side of some building so that it is entirely protected from the prevailing westerly winds. Facing east, with its back against the house, place a goodsized dry goods box which is perfectly tight on three sides. The floor of this box is covered with sand and chaff or finely-cut straw. The fireless brooder, with its twenty-five chicks, stands in this box, with door opening into the box so that the chicks have a little run inside for the first few days. When they are four or five days old, sooner if the weather is warm, they are let out into a little run which is wired off for them just in front of the box; for baby chicks are such foolish, helpless creatures that they can never find their way back if they once get away from the brooder. After a week or two, according to the weather and the disposition of the chicks, this inside fence is removed and the chicks have the run of the pen, but they must never be allowed far from the 
coop until they are brooder broken, that is, till they have learned to return to it wherever they are.

There are various ways of keeping baby chicks warm at night in these fireless brooders. A vinegar jug filled with hot water and wrapped in flannel makes a splendid mother, but if this is used the frame with the quilt attached to it must be replaced temporarily with a blanket or old sweater.

When the jug of hot water is used, and it is an effective but troublesome method, the brooder is more easily constructed of a box about the size and shape of an apple box. This must be made tight on all sides and is then placed on its side with the open top facing the side of the box coop. The hover is attached to a frame which rests on cleats at the two ends of the brooder, but the quilt or blanket must be large enough to drop down over the sides of the jug and rest on the backs of the chicks. It is a delight to see the comfort of a brood of chicks cuddled about a jug with a blanket tucked close about them.

CANS AND PANS.-There are tricks in all trades, and one of the tricks the side line poultry keeper must learn is to use what he has and not spend money for what he can do without. Nothing about the house is more useful for supplying the needs of baby chicks than the empty baking powder can. The cover makes a splendid receptacle for grit, charcoal or bran, and the can itself, with a little nick in the edge of the top, makes a very fair fountain when inverted in a saucer. When the chicks outgrow baking powder can covers I give them their dry mash in tuna cans. When the tuna can in its turn is outgrown, they get an old basin which has served its day in the kitchen. I worked out for myself a dry mash hopper for grown fowls, which I considered merely a temporary makeshift until I read that a 
very similar device was used at one of the egg-laying contests. It is a tin or agate basin-a tin milk pan is about right size, and costs ten cents-with a square of inch-mesh wire over the top which is held down by half a brick in the middle.

\section{TRAP-NESTS}

In planning trap-nests for a laying house, one trap-nest should be provided for every four or five hens. It is necessary to visit the nest several times a day to release the hens that are confined on the nest. This is more work than most farmers are will-

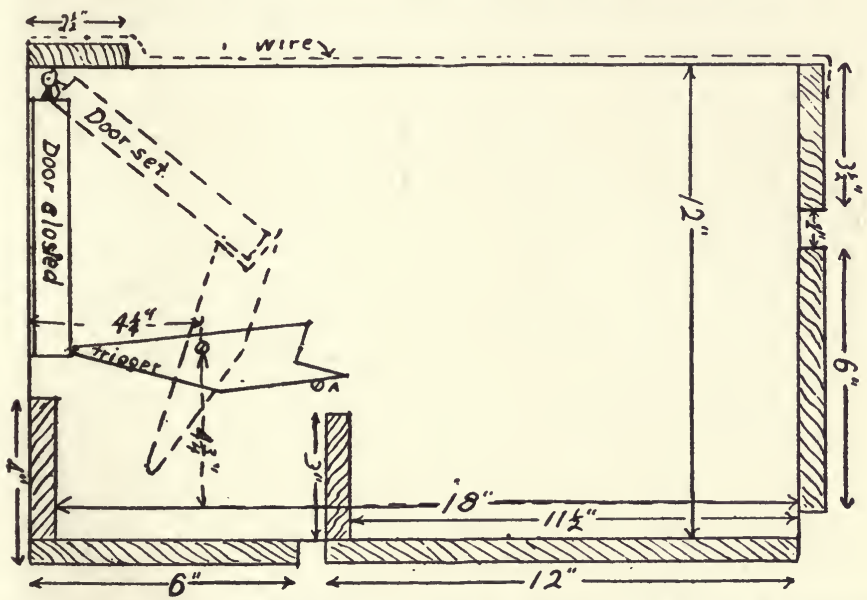

FIG. 39-DIAGRAM OF MISSOURI TRAPNEST, SHOWING ACTION OF TRIGGER

ing to undertake, but it is the only certain way of finding the best layers. As each hen is released from the nest, her number is noted, and a record made.

\section{Oregon Trap-Nest}

The Oregon trap-nest has been in use twelve years and is one of the simplest and cheapest designs. As 
the hen enters the nest, her weight closes the door, and it is impossible for her to get out or for another hen to enter. When the nests are built in a single tier the hen may be taken out either through the door or through the top.

This nest can be made from one 10-foot board. The material required consists of :

1 board $1 \times 12 \times 10$.

6 screw eyes No. 210 bright.

2 pieces iron rod $3-16 \times 12$.

2 pieces rawhide $9 \times 1 / 2$.

After nailing together, turn the nest on its side and bore the holes in the sides for the 3-16-inch iron

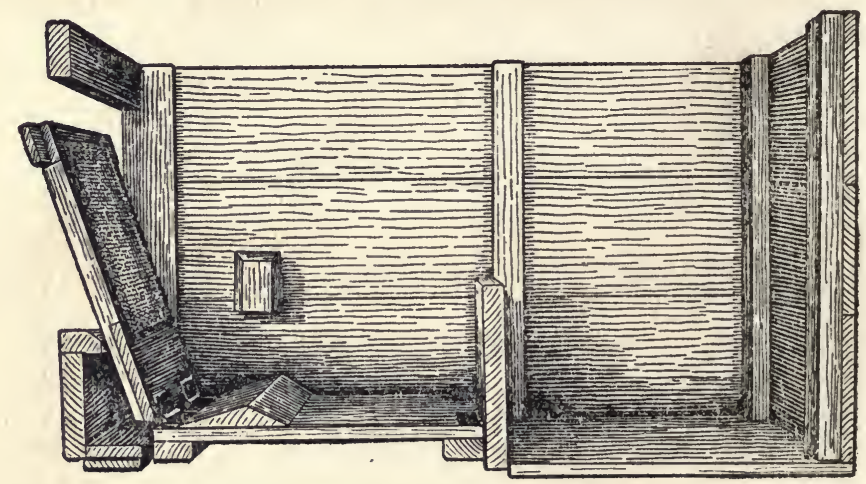

HOME-MADE TRAP-NEST RECOMMENDED BY UNITED STATES DEPARTMENT OF AGRICULTURE

rod. The holes are 1 inch from the bottom and 11/4 inches from the nest front.

On the bottom of the trip-board, put a screw eye $7 / 8$ inch from the end and 1 inch from each side. At the other end of trip-board, bore $3 / 8$-inch holes, 1 inch from one end and 3 inches from each side.

On the bottom and at each side of the door put in 


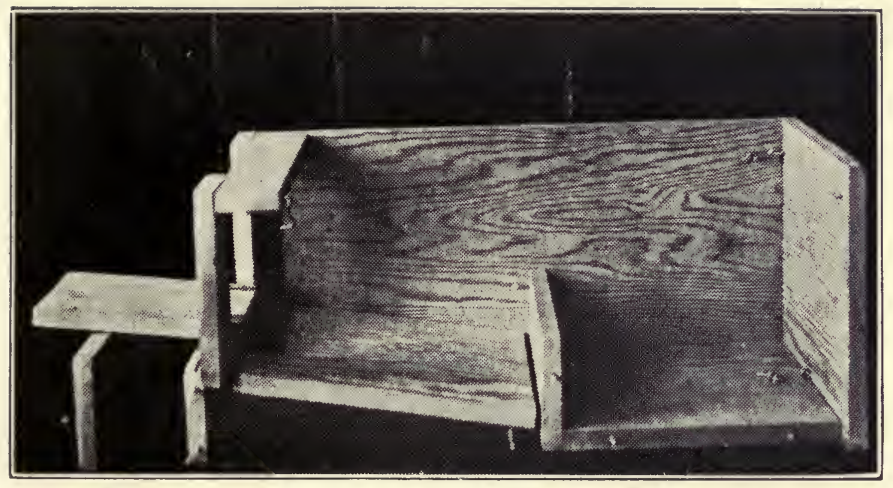

FIG. 37-OREGON TRAPNEST'

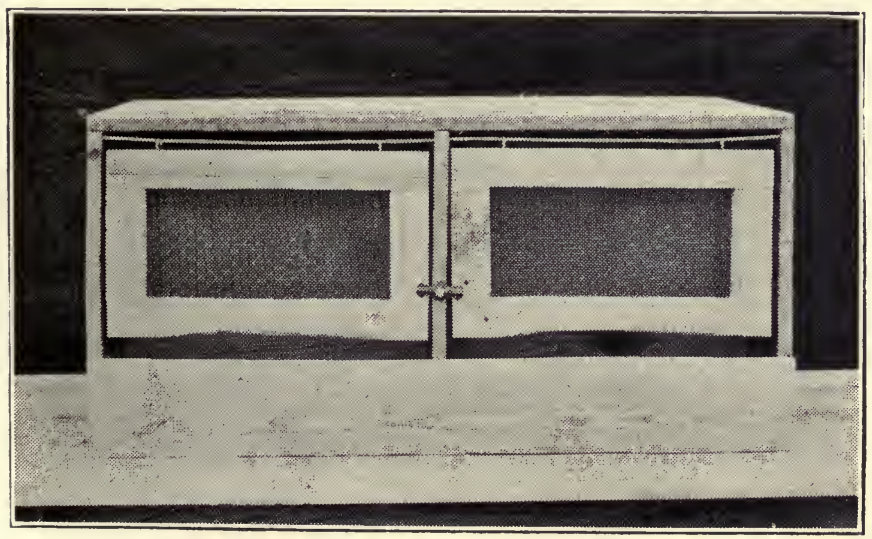

FIG. 38-MISSOURI TRAPNES'T 

a screw eye $1 \frac{1}{2}$ inches from the end and $3 / 4$ inches from the sides. On the upper side tack two rawhide strips using a small staple or nail for each. The end of the strap will be 2 inches from the end and $1 / 2$ inch from the side of the door.

Place the door in front of the trip-board, the

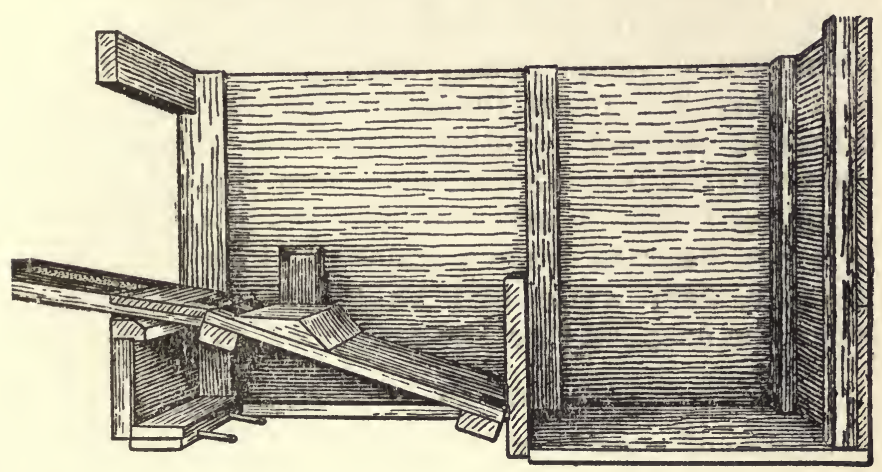

screw eyes down; push the rawhide strips through the holes in the trip-board; turn the boards over and draw the strips up tight then bend the door back over the trip-board until there is full $3 / 4$, inch between the boards when laid flat; the strap should then be tacked to the lower side of the trip-board.

The door and trip-board are put in place by pushing the iron rods through the sides and the screw eyes. Care should be taken in placing the screw eyes in the proper places. The screw eyes may be adjusted in order to make the door balance properly. 


\section{CHAPTER X}

\section{Diseases and Vices}

It is sometimes supposed, because the poultry press has so much to say about diseases of fowls, that they are more liable to disease than other domestic animals. Nothing could be farther from the truth. A hen can bear more neglect and careless handling than any other animal would endure, and it is just because she can endure so long in spite of bad air, foul water and unhygienic feeding that when she does get sick, the case is apt to be hopeless.

\section{CAUSES OF DISEASE}

Causes of disease in fowls may be classified as follows :

1.-INHERENT WEAKNESS.-Fowls which lack constitutional vigor are always the first to contract disease. Run-down stock which, either through inbreeding or lack of selection for vigor, has lost its vitality is the prey of ailments which pass by a vigorous, well cared for flock. In fact, neither prevention nor treatment is of much use with run-down stock. Keep your stock vigorous, and disease will give it a wide berth.

2.-POOR FEeding AND SANitation.-These matters have been fully discussed in the chapter on sanitation. The most vigorous stock will not remain vigorous in filthy quarters or with careless feeding, and a fowl that has once been really sick rarely regains its vigor.

3.-Contagion.-Chicken-pox, cholera and many other diseases are passed from fowl to fowl with ap- 
parently no other reason for their existence, yet even these diseases will be found to attack the weaker stock first. Chicken-pox, particularly, is very infectious, and may be carried in coops or on the hands or clothing, and the germs will remain year after year in a house where it has been. When any contagious disease is prevalent, the greatest care should be observed to avoid carrying the disease in any way. When any sick fowl has been treated, the hands should always be thoroughly cleansed before other fowls or feed troughs or water fountains are handled.

4.-ACCIDENT.-Such diseases as crop bound, rupture of the ovary or egg tube, are in a way accidental, and yet they may very often be traced in the final analysis to a weakened constitution.

Prevention is better than any sort of treatment, but when disease does appear, promptness in dealing with it may effect a cure, when delay means sure death.

\section{SIGNS OF DISEASE}

The poultry keeper should train his eye to discern any lapse from health on the part of a single one of his fowls; the dark or pale comb, the lagging step, the ruffled plumage, the "humped up" attitude, the failure to be on hand at meal time, are all indications that something is wrong. Now is the time to find out what is the trouble. Don't wait till they are past help.

Diseases of fowls, like those of human beings, are acute and chronic. The chronic disease comes on slowly and gradually; the only symptoms at first may be the color of the comb or a disposition to stay on the roost. Acute disease comes on more rapidly. Sometimes the only symptom is a dumpiness or drowsiness that increases till the fowl dies. 
The hen's comb has been called her "certificate of health," so unerring a signal does it display as to her physical condition. An acute disease like roup does not, of course, immediately change the color of the comb, but a bright red comb can usually be counted on as an indication of vigorous health. Sometimes a pale or shrunken comb merely indicates that the hen is not laying, but a hen with such a comb should always be watched. A pale comb, combined with diminishing weight, "going light," suggests tuberculosis and should subject the fowl to careful investigation, followed, in most cases, by speedy elimination. A dark comb means liver trouble, and the case should be taken in hand before further symptoms develop. When warty-looking excrescences appear on the comb and about the head, chicken-pox may be safely diagnosed.

As soon as the first sign of illness is observed it is a good plan to give a dose of castor oil or Epsom salts and put the bird on free range where it can pick at something green if it wishes to eat. Some poultrymen give their flocks Epsom salts in the wet mash once every week or so to cleanse the system and prevent liver trouble. Others give it regularly for a while in the spring.

\section{COMMON DISEASES}

The following descriptions of symptoms and suggestions for treatment are taken mainly from "Poultry Diseases and Their Treatment," by Dr. Raymond Pearl of the Maine Station, which may be had for 25 cents by writing to the Agricultural Experiment Station, Orono, Maine; and from Bulletin 530 of the U. S. Department of Agriculture by Dr. Salmon, which will be sent free. Every keeper of poultry 
should have at hand some such book for immediate reference.

\section{Liver Disease}

Caused by lack of exercise, overfeeding, or feeding too rich foods.

Sanborn mentions as early symptoms: "Rough plumage, watery diarrhea, first brownish then yellow; lack of appetite and indisposition to move. The comb may be purplish at first, becoming dark and then quite black." The disease may be diagnosed positively only by a post mortem examination, when the liver will be found enlarged or congested or marbled or spotted.

TREATMENT.-Make the mash light and bulky; feed green and vegetable food liberally; compel exercise by scratching. Get the fowls out a little every day, or let them out altogether if it is possible; correct any sanitary conditions that are not right. Dandelion tea mixed in the mash is a valuable medicine. Give Epsom salts frequently.

\section{Crop Bound}

The walls of the crop may be over-distended with dry grain, or, as more often happens, the lower portion of the oesophagus becomes clogged by straws, grass, feathers, or other substances. In either case the crop fails to empty itself while the bird continues to eat. The real cause of impacted crop probably lies in low vitality due to improper feeding and indigestion.

TREATMENT.-If the crop-bound condition is caused by swelled grain, the bird may often be treated without an operation. First give the bird a teaspoon of castor oil. After allowing this a little time to work into the crop begin to knead the hard 
mass. After this has been softened hold the bird head downward and try to work the grain out through the mouth. If this does not succeed, or if the impaction is due to straw, it will be necessary to open the crop. The following method for this operation is given by Sanborn, "Farm Poultry Doctor":

"Pluck out a few feathers and then cut through the skin over the crop a line about one inch long. Then make an incision three-fourths of an inch long through the crop. The distention of the crop will cause the opening to gap, and the mass will be in plain sight. With toothpicks, tweezers or similar tools take out the contents of the crop and make sure that there is nothing remaining to obstruct the outlet to the organ. To close, take three or four stitches in the opening in the crop, making each stitch by itself and tying a knot that will not slip. Then do the same thing to the cut in the skin. For the stitches use white silk if possible, if not, No. 60 white cotton will do."

\section{Tuberculosis}

Tuberculosis is caused by a minute germ, the Bacillus tuberculosis of birds. These bacteria gain entrance to certain portions of the body and there multiply in vast numbers, causing the formation of small nodules or tubercles. The disease is highly contagious and is spread through the flock by contact of healthy birds with diseased ones. Avian tuberculosis is not the same as the disease which attacks human beings, and while cases have been known where persons have apparently taken the disease from birds, it is believed that birds rarely if ever take it from human beings.

There are no symptoms by which the disease can be recognized till it reaches an advanced stage. 
Emaciation is the surest symptom. There is pallor of the comb and wattles, general weakness, lameness, ruffling of the feathers, and in many cases, diarrhea. "When combined with the foregoing you notice a bright eye and a ravenous appetite, you may have very strong suspicions." If a post-mortem reveals the liver, spleen, and intestines "studded with white, cheesy nodules of various sizes," your suspicions will be strengthened, but it is only by examination of these nodules under a microscope that the pathologist can be absolutely sure that the bacilli are present.

TREATMENT.-When tuberculosis has reached a stage where it can be diagnosed there is no longer any cure. Sick birds should be killed, and all birds which are suspected removed from the flock. Disinfect houses, runs, feeding troughs and water vessels, using cresol disinfectant or a carbolic solution on houses, troughs and fountains, and lime on the ground. If many birds are affected it may be necessary to move to clean ground. Dr. Salmon says: "When the disease is discovered the effort should be to eradicate it at once by killing off the whole flock and thoroughly disinifecting all the houses and runs."

\section{Aspergillosis}

This is a very common disease and is caused by eating moldy food or scratching in moldy hay or straw. It is often mistaken for tuberculosis and is a frequent cause of the condition known as "going light." The mold spores find lodgment on the membranes of the air passages and grow there, causing inflammation and sometimes abscesses.

Salmon gives this account of the symptoms of the disease: "In the early stages of the disease no symptoms are noticed, and it is only after it has pro- 
gressed considerably that these become apparent. The affected birds do not follow the flock; they are very weak, scarcely able to stand, and consequently remain by themselves and move about very little. They remain in a recumbent position, resting upon the sternum, are sleepy, and, if forced to run, soon fall from exhaustion. The plumage is dull and rough, the wings are pendant, the eyelids partly closed, the head depressed. Respiration is quickened, and accompanied by a rattling or snoring sound, and becomes difficult and labored, the bird opening its beak from time to time to take a long inspiration. There is fever and thirst and little appetite. There is more or less catarrh of the trachea and bronchi, with emaciation and diarrhea leading to death from exhaustion in from one to eight weeks."

TreatMenT.-No cure is known, and it is therefore obviously important that all grain and scratching litter be absolutely clean.

Young chicks are even more susceptible to aspergillosis than adult stock, and no pains should be spared to make sure that their food and litter are free from mold.

\section{Catarrh}

Catarrh is simply a cold in the air passages and is not contagious. It is caused by exposure to cold or storms or by drafts in the roosting house.

SYmptoms.-The birds are dull, they sneeze, and breathing is obstructed. Soon there appears a watery discharge which gradually becomes thicker; the eyes are watery, the eyelids swollen and sometimes stuck together. Catarrh is very like the first stages of roup, and it is impossible in many cases to distinguish between the two. 
TREatment.-Removal of the cause will usually effect a cure. Dr. Salmon recommends this tonic:

Gentian root................ drams.

Ginger ..................... drams

Sulphate of iron..............2 drams

Hyposulphite of sodium...........1 dram

Salicylate of sodium............. dram

Pulverize and mix thoroughly and give three to four grains a day for a medium-sized fowl.

In severe cases the eyes, mouth and nostrils may be washed twice a day with one of the following solutions :

1. Boracic acid, 3 per cent solution.

2. Creolin, 1 per cent solution.

3. Carbolic acid, 2 per cent solution.

Hydrogen peroxide and witch hazel are also good.

\section{Bronchitis}

The symptoms of bronchitis are the symptoms of a hard cold, with rapid breathing and cough. It may be distinguished from simple catarrh by the whistling sounds or rattling made in breathing. When the disease is neglected these symptoms may become chronic. In very severe cases the bird becomes dull, breathing is increasingly difficult and the bird finally dies.

Treatment.-Place in a warm, dry, well-ventilated room, feed bread or middlings moistened with milk, and add to this food two grains of black antimony twice a day. Salmon recommends giving ten drops of turpentine in a teaspoon of castor oil and repeating the dose after five or six hours. In very severe cases give from three to six drops of either the syrup or the wine of ipecac. 


\section{Roup}

Roup occurs in many forms. It may affect the head, the eyes or the throat, but there is in all cases great depression and dullness, with a putrid odor which is characteristic of the disease. Where there are symptoms of a cold with a noticeable odor always look for roup. There is usually a discharge from nostrils or eyes, often the eyelids are stuck together or swollen shut, and in many cases there are abscesses under the eyes or about the head.

Harrison and Streit thus describe the special symptoms of roup: "By the term roup we understand a more or less putrid discharge from the nostrils which lasts for weeks or even months. The disease often follows a common cold, to which fowls, especially young fowls and those of the more delicate breeds, are much predisposed.

"In the first stages of roup the birds often cough or sneeze, and the breathing is noisy, caused by the partial closing of the air passages which become blocked with the discharge from the nostrils. When the air passages are entirely closed, the fowl has to open its beak in order to breathe.

"Sometimes a yellowish cheese-like mass forms in the nostrils, growing quickly and pressing the upper walls of the nose upwards; if this mass is removed, an uneven bleeding surface is left which forms a new cheesy mass in from 24 to 48 hours.

"In more serious cases the face of the roupy bird is swollen, especially between the eyes and nostrils, and this swelling, which is hot and sore, sometimes grows into a tumor as large as a walnut. Sometimes the tumor grows inside the nostril and forces the roof of the mouth downward."

In "roup of the eyes" there is inflammation of the 
eyelids, followed by the secretion of a liquid which is first clear, then gray and slimy. This either dries on the feathers or becomes a yellowish cheesy mass in the eye-socket.

Combined with the above symptoms there are often patches of a grayish yellow exudation firmly adhering to the mouth and throat. These are called false membranes, and when they are seen the disease is called diphtheretic roup, which is the most serious of all.

TREATMENT.-The only effective treatment is prevention. Housing in open-front houses, avoiding drafts by carefully closing all cracks and knot-holes about the roosts, keeping houses sanitary and feed clean and wholesome, taking care to avoid contagion; and above all, breeding only from vigorous birds, and especially from birds which have never had roup, will soon do away with all fear of the disease. I have not seen a case in three years, and I am satisfied that attention to the simple rules of sanitation and hygiene is a sure preventive.

Especially important is it that the ground on which poultry houses stand should be well drained and that houses should be dry and sunny.

For those that feel they must treat roup, the potassium permanganate treatment is as good as any and easier than most: Press the nostrils together between thumb and forefinger two or three times in the direction of the beak, and press upward between nostrils and eyes to loosen the discharge, then plunge the bird's head twenty or thirty seconds in a one to two per cent solution of permanganate of potash. Give this treatment twice a day till all symptoms have disappeared.

"Roup of the eyes" is successfully treated by syringing the nasal cavities with boracic acid and 
camomile, or by washing out the nostril with a two and one-half per cent solution of creolin and glycerine. "If there are solid tumors in the eyelids, they should be opened so that the skin may bleed freely. The cheesy matter should be removed and the surrounding membrane touched with a five per cent carbolic or silver nitrate solution, and then a cotton plug put in to prevent the cavity from healing too quickly."-Harrison \& Streit.

Sanborn "Reliable Poultry Remedies" recommends spraying the nasal passages and the mouth with the following solution:

Extract of witch-hazel, 4 tablespoons.

Liquid carbolic acid, 3 drops.

Water, 2 tablespoons.

\section{Canker}

Canker sores in or about the mouth are caused by some injury to the mucous membrane and are most common in male birds which have been fighting. Apply undiluted creolin with a cotton swab or wash the sores with equal parts of hydrogen peroxide and water.

\section{Chicken Pox}

Chicken pox, or bird pox, originates entirely by contagion. It is generally introduced into the flock by new birds or by exhibition birds which are infected at shows. Sometimes it is carried by pigeons or sparrows.

Salmon says: "The eruption appears as round, oblong or irregularly shaped nodules from the size of a pinhead to that of a pea or hazelnut. They are seen especially about the beak and nostrils and on the comb, eyelids, wattles and ear lobes. In some individuals, and particularly in pigeons, the eruption 
is more generalized, and is found on the skin of other parts of the body.

"The nodules begin as small, red or reddish-gray deposits with a shiny surface and gradually enlarge, while the color changes to a yellowish, brownish or dark brown, and the surface dries and becomes shriveled, uneven and warty in appearance. Owing to the number of nodules and the extension of the inflammation, large patches of skin become thickened and covered with hard, dry crusts, closing the nasal openings or the eyelids and making it difficult even to open the beak.

"In the most severe cases, especially with pigeons, the eruption extends to the mucous membrane of the eyes, nostrils and mouth, causing a diphtheretic inflammation that is generally fatal."

TREATMENT.-The simplest way of treating this disease is to pull off the scabs from the sores and touch the spots with clear creolin on a brush or feather. Salmon recommends softening the scabs first with vaseline or glycerine, then washing with warm, soapy water till they come off easily. Then touch with a two per cent solution of creolin or a saturated solution of boric acid. If there is much inflammation of the eyes, make a solution of one and one-half ounces boric acid and one ounce biborate of soda in a quart of warm water, and drop in the eyes frequently.

In addition to the external treatment, Dr. Sanborn advises calcium sulphide, one grain per day for each fowl, mixed in the wet mash. This, he says, will shorten the time of the disease and prevent birds that do not yet show symptoms from taking it.

\section{"Going Light"}

"Going Light" is a condition rather than a disease. 
Sometimes a fowl, for no apparent reason, and with no other symptoms of disease, loses weight till it is hardly more than a skeleton. Sometimes this condition is a symptom of tuberculosis, and sometimes of aspergillosis; sometimes it is due to intestinal worms and sometimes to lice or mites. It may also be due to lack of sufficient nourishing food or to poor digestion. Whatever the cause, the poultry keeper must find out what it is and remedy it.

\section{Limberneck}

"Limberneck" and "wryneck" are terms which are often confused. In limberneck the muscles of the neck are paralyzed so that the bird cannot raise its head. In wryneck the neck is twisted till the head is sometimes turned almost entirely around. Limberneck is caused by indigestion or the eating of moldy grain or putrid meat, but wryneck is considered a sort of epileptic or nervous disease.

Limberneck can often be relieved by a good dose of physic. Dr. Salmon prescribes fifty or sixty grains of Epsom salts or three or four teaspoons of castor oil for an adult bird. Director Quisenberry in "The Poultryman's Guide" recommends for small chicks a dose of from two to ten drops of oil of turpentine mixed with an equal quantity of sweet oil, followed at intervals of from one to two hours by a teaspoon or less of ginger tea. This tea is made by mixing one teaspoon of ginger with half a cup of hot milk and sweetening a little with sugar. Adult fowls may have from one to two teaspoons at a dose. When the birds begin to improve, let their first meal be a little boiled rice.

\section{Rheumatism}

This disease is an inflammation of the connective 
tissues of the muscles and joints, and is caused by exposure to cold and dampness. The only treatment is prevention by keeping the fowls in dry, wellventilated houses and on well-drained soil.

\section{Scaly Leg}

This disease is caused by a tiny mite which burrows under the scales of the leg, raising the scales and forming a powdery or spongy substance beneath them. It is due to filthy yards and houses, but when once introduced into a flock is passed from bird to bird.

TREATMENT.-A number of ointments and oils have been used successfully. Before using any of them the legs should be well brushed with warm, soapy water. If they can be soaked for a short time the scales will come off more easily. When as many of the scales have been removed as can be taken off without drawing blood, use one of the following:

1. Balsam of Peru.

2. One part oil of caraway mixed with five parts vaseline.

3. One part kerosene and two parts raw linseed oil.

When many fowls are to be treated, an easy method which is recommended by Robinson is: Fill a quart measure with the kerosene and linseed oil mixture, go to the henhouse at night and dip both legs of each infected bird in the liquid, holding them there for a moment, and then allowing them to drip before replacing them on the roost.

If care is taken to keep infected birds out of the flock this disease need never occur.

\section{Depluming Scabies}

The depluming mite is the cause of a sort of skin 
disease in fowls which causes the feathers to break off at the surface of the skin. It usually begins at the rump and spreads to the head and neck, back, thigh and breast. Around the stumps of the lost feathers and at the end of the quills of feathers near the bare spots are masses of epidermal scales. Feather eating and feather pulling are often due to the presence of this parasite. The introduction of one infected bird into a flock will soon cause the whole flock to become infected.

TREATMENTS.-The ointments used for scaly leg may be used for the depluming mite. Salmon also advises the following:

Flowers of sulphur......... 1 dram

Carbonate of potash........20 grains

Lard or vaseline........... 1/2 ounce

The application should be repeated every four or five days till the disease is cured.

\section{White Diarrhea}

It has been the fashion to speak of white diarrhea as a sort of bugaboo which is lying in wait for every chick and which only the most fortunate escape. All this is pure nonsense. The well-hatched, well-bred chick which is kept warm and reasonably well fed has just as many chances of surviving as any other young animal. The trouble is that when large numbers of chicks are artificially hatched and artificially brooded they are often not well hatched and still more often not kept warm. Overheating before hatching or chilling after hatching weakens the constitution, and especially the digestion. A sort of diarrhea ensues, which is not white diarrhea, though it is often erroneously so called, the chick is "pasted up behind," droops for a few days, and usually dies. 
The real white diarrhea is an infectious disease, Bacterium pullorum, and usually comes from an infected egg which was laid by an infected hen. Prevention should therefore begin with the hatching egg. Dr. Salmon says :

"If eggs are purchased they should only be accepted from flocks known to be healthy, and the eggs of which give rise to healthy chicks. If this assurance cannot be obtained, it is better to produce the eggs needed for hatching on the home farm and from hens that are known to be free from infection.

"Having obtained the eggs, they should be kept until ready for incubation in a dry, moderately cool place, so spread out that the air can circulate over them and carry away the moisture which they exhale. Before putting them into the incubator or under the hen they should be wiped with a cloth wet in grain alcohol of seventy to eighty per cent strength to remove any germs that might be on the surface of the shell. The hens used for hatching should be free from all infection and the incubator should be thoroughly cleaned. If there have been any sick chicks in it, it should be disinfected by washing with compound solution of cresol (five per cent solution). The same precautions should be adopted in regard to the brooder."

White diarrhea may usually be diagnosed by the characteristic white or creamy discharge from the vent and by the chick's behavior. Sometimes a chick that has been chilled will "paste up behind" with a brownish discharge, but remains as lively as ever. This is not white diarrhea. In Bulletin 68 of the Connecticut Experiment Station, by Professors Rettger and Stoneburn, the white diarrhea chick is thus described:

"The chicks soon become listless and sleepy, in- 
clined to huddle together and remain under the hover most of the time. They seem to lose appetite and do not eat much. The wings begin to droop or project slightly from the body, with feathers ruffled. Many of the chicks peep or chirp constantly, the sound being shrill or weak, according to the strength of the individual."

Dr. Rettger says it is only during the first fortyeight hours that the chick can be infected, hence the greatest care should be taken during those first two days. Incubators should be disinfected with the greatest care between hatches. Any good disinfectant, such as creolin, Zenoleum, or a carbolic solution, is sufficient. Kerosene, of course, must never be used about an incubator. Brooders also should be disinfected before a new brood is put in. No hen should be used for hatching or brooding that is not perfectly healthy and vigorous or that shows any sign of diarrhea.

Treatment.-When a chick is "pasted up," the excrement should be carefully removed and the vent greased with vaseline. If faulty brooding is the cause, remedy this at once and you may save the chick. Boiled rice with cinnamon and scalded milk with a little grated nutmeg instead of the regular diet are recommended, and sour milk or buttermilk are the best of remedies; but a chick with real white diarrhea will not eat much, so the treatment must be mainly preventive. Rettger and Stoneburn give the following on preventing white diarrhea:

"Since the disease cannot apparently be transmitted through the food supply after the chicks have reached the age of three or four days, every means should be taken to prevent the spread of the infection during this critical period. We suggest: 
"The segregation of chicks in small lots during this interval.

"Perfect disinfection and cleanliness of brooders and brooder coops.

"Food and water supplied in such a manner as to prevent contagion by the droppings.

"The use in the brooder of a liberal amount of fine, absorptive litter which will quickly cover and seal up the droppings.

"Raise and maintain the vigor and vitality of the breeding stock and chicks by every reasonable means known to the poultryman."

\section{Gapes}

Gapes is a disease which frequently attacks young chicks, especially on old ground, and is caused by minute parasitical worms in the trachea or windpipe. The disease is thus described by Woods in "Reliable Poultry Remedies": "The symptoms of gapes are frequent gaping, sneezing, a whistling cough with discharge of mucus and worms, dumpishness, weakness and drooping wings." The only sure cure is to extract the worms from the windpipe with a gape worm extractor or a loop of horsehair or fine wire, though good results have been reported from medicating drinking water with fifteen grains of salicylic acid or three drams of salicylate of soda to the quart of water.

Reliance must be placed chiefly on prevention. Whenever cases of gapes occur in a flock, all chicks should be moved to clean new soil-indeed, young chicks ought always to be upon soil which has had at least a year of purification by some green crop since fowls were last upon it. No soil on which gapes has been known is safe for several years after. Salmon says the eggs of this worm live a long time 
in the soil and are sometimes taken into the digestive tube of earthworms. In badly infested soil the earthworms may, if eaten, cause gapes in the chicks.

As soon as the disease appears all affected birds should be isolated, and those which die should be burned. Feed troughs and water dishes should be scalded and houses and coops disinfected. Use potassium permanganate in the drinking water.

To extract the worms from the trachea, pass the extractor carefully down the trachea for some distance, holding the chick's head well back, and turn it around to loosen the worms. If there are worms, some will be removed with the extractor. If from four to ten worms are extracted a cure may be counted on, though as many as thirty worms have been extracted from one chicken.

\section{Worms}

Worms in small numbers are said to inhabit the digestive organs of all fowls, and when they are not too numerous do no perceptible harm. Under certain conditions they are supposed to develop too rapidly, and then we have the disease known as "worms." This is one theory, and no one seems to have a better one. Without question worms are often found in the intestines of fowls, and without question they affect the health. In recent years a number of poultry plants have been put out of business by epidemics of worms, so it behooves every poultrykeeper to watch for symptoms, to treat cases that occur, and to prevent infection as much as possible.

Three species of worms are known to infect the digestive organs of poultry: Tape worms, round worms and flukes. The tape worm is a long, flat, segmented worm like those which infest man and other animals; the round worm is white and, as the 
name indicates, round, and varies in length from onethird of an inch to five inches; the fluke is small, flat, and usually oval in shape.

For tape worm Salmon recommends a teaspoon of powdered pomegranate root mixed in the mash for every fifty birds. Follow this with a dose of castor oil for individual birds, or Epsom salts in the mash. Powdered areca nut in doses of thirty to forty-five grains, mixed with butter and made into pills; male fern in the form of powder (dose, thirty grains to one dram), or of liquid extract (dose, fifteen to thirty drops), and give morning and evening before feeding; and oil of turpentine (one to three teaspoons) forced through a small, flexible catheter that has been oiled and passed through the mouth and aesophagus to the crop, are all effective remedies for tape worm. A dose of Epsom salts or castor oil should follow each. Areca nut and male fern are said to produce bad effects when given to turkeys.

For round worms Salmon prescribes thymol (one grain made into a pill with bread and butter to each fowl) or santonica (worm seed) in doses of seven or eight grains. A purge should follow each.

Turpentine is a time-honored remedy for worms. When many birds are affected, give a tablespoon to a gallon of drinking water and a teaspoon to a quart of moist mash.

Pumpkin seeds, chopped or ground, and chopped garlic bulbs are both excellent remedies. The birds should fast 12 hours or more before any treatment is given.

\section{Leg Weakness}

This term is sometimes used to indicate lameness due to rheumatism in adult birds, but it more often refers to a disease in young chickens that have been raised in brooders. 
The affected chickens first walk unsteadily, finally they tumble over and seem unable to stand alone. Then they grow weak, fail to feather out properly and are most unhappy objects.

Treatment consists mainly in removing the cause, which is lack of exercise and overfeeding with fatproducing foods. Chickens on range are never troubled in this way. Put the chicks, if possible, where they can have range. If this cannot be done, give them deep litter and make them scratch for their grain. Feed plenty of green food, skim milk, wheat, bran and oatmeal. Cut out corn and corn meal. Sanborn recommends rubbing the legs with tincture of arnica and adding one-half teaspoon of tincture of nux vomica to each quart of drinking water.

\section{Bumblefoot}

Jumping from too high a perch onto a hard floor often produces a bruise on the bottom of the foot, especially of a heavy hen. These bruises sometimes swell and become abscesses, and there is fever, dullness and pain. The cavity should be opened and washed out with carbolized water or some other good disinfectant. Then apply a healing ointment or paint the surface of the cavity with a solution of nitrate of silver, bandaging carefully to keep the dirt out. I have found soaking the foot twice a day in warm witch hazel an effective remedy for these bruises. If care is taken not to make the perches more than two or two and a half feet from the floor for heavy hens, and two or three inches wide, there will be little trouble of this sort.

\section{Diseases of the Oviduct}

Diseases of the oviduct are quite common and more difficult than other diseases to prevent and 
treat, since the causes are not so clearly understood. On the other hand, since they are in many cases local, instead of constitutional, a cure, when effected, is more likely to be permanent.

Dr. Pearl says: "The general symptoms of the commoner diseases of the oviduct are very much like those of constipation. The poultryman watching his birds is indeed rather likely to confuse the two. But if so no harm is done. The thorough cleaning out of the alimentary tract and stimulation of the liver indicated in the treatment of constipation is the very best thing to be done in cases of inflammation and similar disorders of the oviduct."

Four diseases of the oviduct demand consideration:

1. INFLAMMATION OF THE OVIDUCT.-This is one of the most important and common of this class of diseases. It is caused sometimes by irritation due to too frequent laying or too stimulating foods; sometimes by the laying of too large eggs or the breaking of eggs within the oviduct; sometimes by infection of the lining membranes of the oviduct.

Hill "Diseases of Poultry" gives the following symptoms: "A bird affected with inflammation of the egg passage suffers acutely. At first there is a continual and violent straining (sometimes resulting in apoplexy). The wings are drooped and the feathers puffed out. The vent is hot. As the inflammation proceeds the bird becomes more and more mopish and exhausted, but does not strain so violently. Ultimately the temperature becomes lower, the body cold, and with a few convulsive gasps the sufferer dies."

Treatment must be early if it is to be successful. Give a purgative dose of Epsom salts (half a teaspoon for a full-grown fowl) and follow with one- 
half drop of tincture of aconite root or a one-tenth grain aconite root tablet three times a day. All stimulating foods and condiments should be cut out of the diet at once, and a light ration with plenty of green food given.

2. PROLAPSE OF THE OVIDUCT.- "If there is a mass of red or bloody tissue projecting from the vent, one is safe in diagnosing prolapsus." This is caused by straining to lay a very large egg, by straining to lay when there is an obstruction in the oviduct, by constipation, or by a lump of feces lodged in a blind pocket of the cloaca.

Treatment.-There is nothing to be done, when such a condition is noted, but to remove the cause, if this is possible, and to replace the prolapsed tissue. Dr. Pearl gives these directions:

"If the bird is constipated give it a rectal enema of warm, soapy water, followed by one-quarter teaspoon of Epsom salts by the mouth. If there is a lump of feces lodged in the cloaca this should be carefully removed. The protruding mass of tissue should be washed with a warm 1-to-1000 bichloride of mercury solution or a warm one-half per cent cresol solution. After the protruding parts are thoroughly cleansed they should be well greased with vaseline. Then with the fingers well greased an effort should be made to replace the protruding mass in the body. In doing this one should proceed with the greatest gentleness. In most cases, with care and gentleness, it is possible to reduce the prolapsus; that is, to get the extruded tissue back into the body in approximately its normal position."

In order to insure contraction of the walls of the oviduct so as to hold the parts in place, some experts recommend the use of ergot, but Dr. Pearl holds that ergot is too violent a poison, and that a lump of ice 
in the cloaca and renewed as necessary and kept for some hours may yield better results. The bird should be kept in a small coop, partly darkened, so that it will be as quiet as possible for a few days.

3. OBSTRUCTION OF THE OVIDUCT, "EGG-BOUND". - This is the commonest of all abnormal conditions of the oviduct, and is caused by the egg being too large or by exhaustion or paralysis of the muscular walls of the oviduct. A hen that is eggbound goes often to the nest, but is unable to lay. She becomes restless and afterward dull, and by pressure of the finger about the vent the egg can be felt. Treatment should not be hasty, for sometimes the hen will ultimately, though with difficulty, rid herself of the egg. When there is no doubt that she cannot pass it, try:

1. Holding the hen over a vessel of boiling water to help relax the muscles.

2. If this does not work, oil the vent with a feather, after the hen has rested for an hour, and give her a powder composed of one grain of calomel and one-twelfth grain of tartar emetic. This can be given in a bread pill. If this acts properly the hen will improve in a few hours, and a second powder two days later will probably complete the cure.

3. If the egg can be seen or pushed into sight, it may easily be punctured with an awl or a large darning needle, and the contents removed. In such case the shell must be carefully removed, bit by bit. I have performed this operation more than once, and it is very easy.

In all these cases the bird should be kept quiet and fed a light ration without any fat-forming food, but with plenty of green food.

4. RUPTURE OF THE OVIDUCT.-It sometimes happens when the oviduct is obstructed or inflamed that 
its walls break and let the contents escape into the abdominal cavity. These cases can sometimes be cured, but death usually results in a few days, and it is not considered profitable to attempt treatment. It is better to prevent it by selecting medium sized eggs for hatching, for the trouble usually arises from a hen's trying to lay an egg too large for her size. Select breeders that are of good size and wide bodied.

\section{Vent Gleet}

"This is a true venereal disease in poultry," says Dr. Pearl. "It usually begins with a hen, but is transmitted in copulation to the male and by him to other birds in the flock." There is a whitish discharge from the vent and constant effort to void excrement.

Wright outlines this treatment: "Give thirty grains Epsom salts, and twice a day inject first a four per cent solution of cocaine, and immediately afterwards a solution of nitrate of silver, four grains to the ounce. The fifth day commence a small copaiba capsule daily, and inject acetate of lead, one dram to the pint. Feed rather low meanwhile and dust sore places with iodoform or aristol. If not well after two or three weeks, kill the bird, for the disease is not quite free from danger; if the operator should touch his eyes accidentally before he has cleansed his hands, the result might be a most violent inflammation."

Another treatment, recommended by Director Quisenberry, consists in holding the diseased bird in a pan of hot water which contains two per cent of Zenoleum or Creolin. After the inflamed parts are thoroughly cleansed, which will take from ten to twenty minutes, inject a solution of permanganate of potash and dust with iodoform. 


\section{Air Puff}

Air blisters often show themselves in young chicks. The skin puffs out and seems like a bladder of wind. It comes on the abdomen, sides and under the wings and neck. Prick the blisters with a needle to let out the air. Add carbonate of iron, alternated with granulated charcoal, daily in the food. The diet should be oatmeal principally, with plenty of sharp grit within reach.

\section{VICES}

Fowls sometimes contract annoying habits, which, while they are often due to lack of exercise or proper diet, do not affect the health. These are called vices.

\section{Feather Eating}

Feather eating among fowls is due to a lack of animal food, to body lice or other vermin, or to confinement in small quarters where there is no opportunity for hunting and scratching.

See first of all that the birds are free from lice, and that their houses are not infested with mites. Give them more meat, either in the form of green cut bone or in a well-cooked mash, with vegetables, green pepper pods and a little linseed meal. A little sulphur in the mash in summer is good for them. Give a teacup of sulphur once a week in the mash for twenty-five hens. If possible, give free range. Where this is not possible dig grain into the ground for them to scratch out; hang up heads of cabbage or other greens for them to peck at, and give plenty of good, clean scratching litter. An ointment consisting of a teaspoon of extract of aloes to a cup of lard, the two being well mixed, rubbed on the feathers around where the bird has been plucked, will usually put an end to the trouble. 


\section{Egg Eating}

Egg eating is usually the result of faulty nest construction whereby the eggs are allowed to roll in front of the hen. A nest that is too large or perfectly flat, or that for any reason allows the eggs to roll out from under the hen, encourages egg eating. Sometimes an egg is broken in the nest, and the hens, from eating the broken egg, get a liking for the taste of egg and soon find that they can break them for themselves. Usually the darker a nest is, the less danger there is of the hens getting this expensive habit, and it can usually be prevented by gathering the eggs as soon as possible after they are laid.

When the habit is once formed it is difficult to break, and often the only cure is to eat the hen. Filling an egg shell with a mixture of cayenne pepper or other disagreeable but harmless condiments or drugs, and leaving it in the nest for the hen to taste, will sometimes effect a cure. Leaving china eggs in the nest or about the house for the hens to peck at is also discouraging. Director Quisenberry says: "If the hen persists in this bad habit, trim the point of her beak till it bleeds."

\section{Toe Picking}

The habit of picking each others' toes is one which White Leghorn chicks which are closely confined sometimes develop. Sometimes this indicates lack of animal food, and it is well to give extra meat in some form when toe picking is discovered. The use of deep scratching litter is a good preventive, and keeping the chicks busy is another. It is always necessary to remove the injured chicks from the flock, for the taste of blood drives the flock wild, and they will soon kill the chick that has blood about it. 



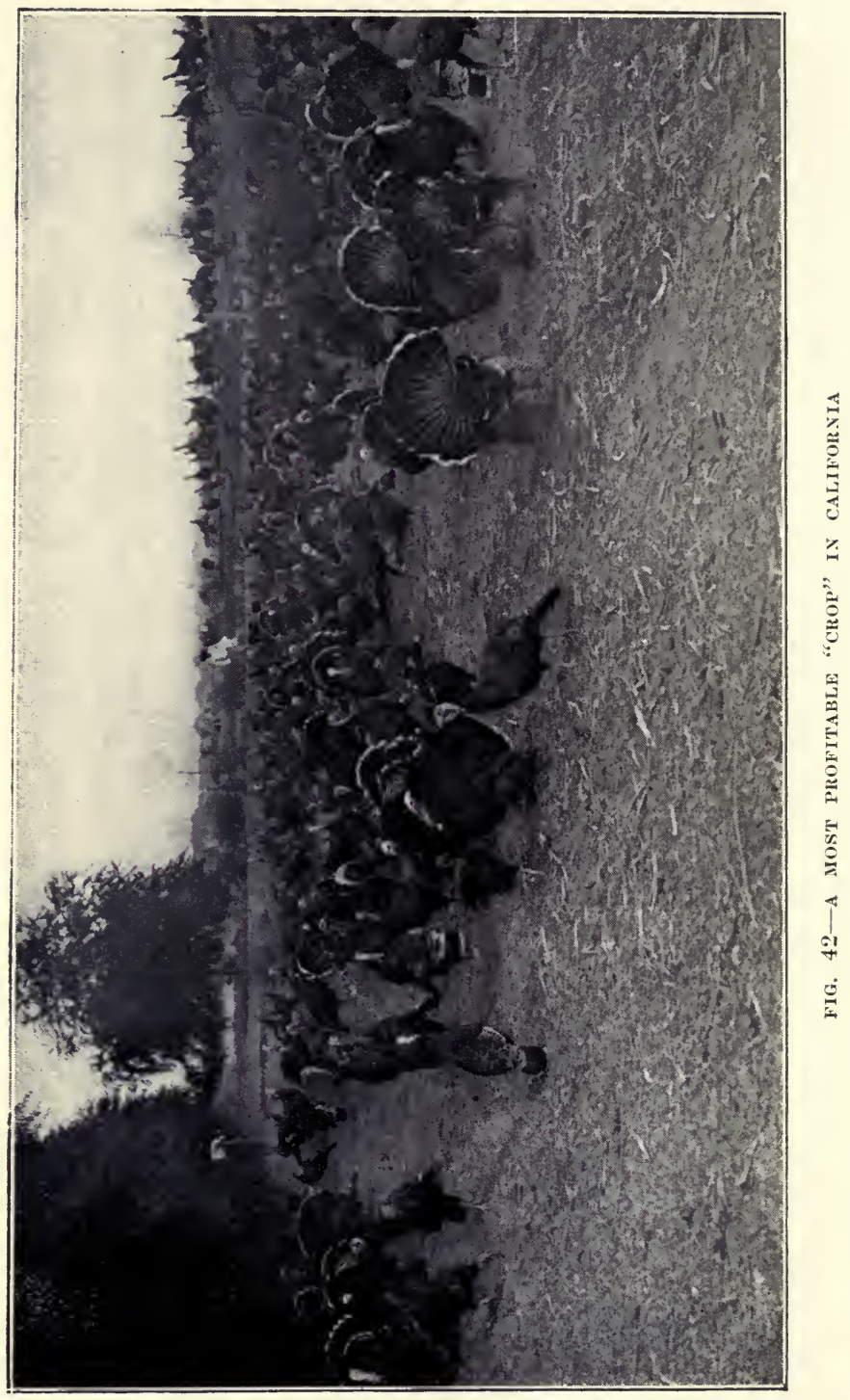




\section{CHAPTER XI}

\section{Turkeys}

The turkey, when it can be raised successfully, is perhaps the most profitable of all kinds of poultry. On range where it can pick up its food it costs much less to feed than a chicken, and prices are always high, for the demand always exceeds the supply.

\section{THE TURKEY A WILD BIRD}

The turkey, it must never be forgotten, is not a domestic bird, accustomed by centuries of artificial feeding and housing to eating what is set before it and being thankful if it happens to be well fed; it is a wild bird with a wild bird's ways. It is its nature to pick up its food, here a bug, there a grasshopper, a weed seed or a nibble of grass-never much at a time, and always plenty of little stones and animal food, and our way of feeding-perhaps I should say stuffing-fowls is absolute destruction to this delicate wild creature. There is no doubt in my mind, after more than one bitter experience, that ninetynine out of every hundred turkeys that come to their death die from overfeeding. The person undertaking to raise turkeys must write this rule on the tablets of memory and never for a moment forget or ignore it- "Keep them hungry." And this means, not merely give them what they will eat up clean, but make the meal so small that they will be always begging for more.

In matters of care and housing, as well as in feeding, this inherent wildness of the turkey must always be considered. The turkey is naturally a forager, 
and this means that it must have range over which to forage. Probably one difficulty most frequently encountered here in California is that most people are unable to give their turkeys the range they need. When we say the turkey cannot bear confinement, we do not mean that it will thrive if it is allowed to run on a lot or two, or that a good-sized flock will have range enough on a few acres. Range for turkeys means land enough to pick up their living on and something there to pick up. Five hundred turkeys to forty acres is the lowest estimate I have seen of the land actually required for raising these birds. That would be about twelve birds to the acre. Is it any wonder people who try to raise a flock of a dozen or so on a town lot do not succeed? I have raised ten fine turkeys this summer on three lots, but they have eaten up the lawn, the alfalfa patch and all my tomatoes.

And even an acre to twelve birds is not always enough, for there is a good deal of land in this state that would not support six birds to the acre. We have the rocky hillsides, to be sure, which make a good ranging place for turkeys, but we lack the shady woods where bugs and worms grow in abundance, and we are not even well supplied with grasshoppers. The best turkey range in California is a field of newly cut wheat or oat stubble.

Again, in the question of shelter the wildness of the turkey asserts itself. Chickens will thrive in a well-ventilated house; turkeys must have the big outdoors for their bedroom, the sky for their roof. It is a question whether turkeys need a roof in any part of the United States. Certainly they need no protection in California except perhaps some shed where they may go in heavy storms. This is adult birds, of course. Poults need to be well pro- 
tected at first, but before they are three months old mine find a roosting place on top of a six-foot fence, and I do not interfere with them. Turkeys that roost out will rarely, if ever, be troubled by colds or roup.

\section{HOW TO BEGIN}

A prominent breeder has said: "The best way to begin with turkeys is to buy a trio of the very best birds you can get. If you cannot afford a trio, buy a pair; if you cannot afford a pair, buy a setting of eggs." This is all right if you already know how to raise turkeys and to care for them. If you do not, buy a setting of eggs from ordinary market stock, hatch them under your own hens and see if you can raise them. You will learn in time, and if you manage to raise only half of what you hatch you will be paid for your trouble.

\section{THE BREEDING STOCK}

The first thing to be looked for in purchasing breeding birds is vigor. If this is important with chickens it is doubly so with turkeys, for if your breeding stock is weak you will be certain to lose a very large per cent of your young stock. Disregard of the rules for selecting and mating to secure vigor is said to be the cause of the dread disease, blackhead, which has destroyed the turkey industry in parts of the east.

Breeding stock should be well matured, strong, healthy and not overfat. Above all the hens and the tom should not be related. Skillful breeders can sometimes line-breed by mating sire to daughter or son to mother for the sake of securing fancy points, but no one but an expert should ever attempt inbreeding. Vigor invariably suffers if this is done. 
It is best to buy a new tom of entirely different blood each season.

The best mating is that of a two-year-old hen with a yearling cock, or vice versa. Some breeders prefer to use an old cock with pullets because the pullets lay more eggs than hens, but two-year-old hens will have larger, stronger poults. A turkey is not fully mature till it is from two to three years old, and a good breeder may be used for breeding for several seasons after it has become mature.

One tom will take care of from eight to twelve hens and sometimes suffices for fifteen or twenty.

Size is of prime importance in breeding stock, for size is what every customer wants and what every judge cuts most severely on, but it is not desirable that breeding birds should be oversize, for a fortypound bird is a drug on the market.

Size does not mean weight; it means frame. In selecting breeders from a flock of young birds, pick the tall, rawboned, rangy ones. They may be little heavier at six months old than the short, chunky ones, but they are the birds that will put on weight later. Fat is never desirable except in a bird that is ready for market.

In breeding for size select a female that is tall and rangy with a deep, long body, broad back and fullrounded breast, and mate her with a male that is fully up to standard weight. Sometimes good results can be secured from a female that is under weight, but it is never safe to use a small tom.

It is poor policy to sell off the early-hatched birds because they are larger at Thanksgiving time and to keep the late-hatched birds for breeders. Earlyhatched birds are almost always more vigorous. Especially unwise is it to use a late-hatched, small- 
boned tom or a poorly marked one, for the tom is half the flock.

Breeding stock should never be allowed to get fat. Infertility is almost sure to result. About a month before the birds begin to lay, which is usually in February or March, some breeders put them on "starvation rations," a diet of oats, meat and vegetables. It is also important that breeding birds have range with plenty of grass. Oats and wheat are the best grains for breeders. Ground bone given once or twice a week mixed with bran is said to help fertility, but as a rule turkey eggs are fertile except when the birds are too fat.

\section{LAYING AND HATCHING}

A turkey hen lays from two to four clutches of eggs, with from twelve to twenty eggs in a clutch. It is customary among breeders not to allow the turkey hen to sit till she has laid two litters. The first eggs laid are hatched by chicken hens, which many prefer to turkeys because of their quieter disposition, but the turkeys are made to mother them in the following way:

The eggs of the first clutch are put under the chicken hens about three weeks before the turkey hen is likely to become broody after laying her second clutch. As it takes turkey eggs four weeks to hatch, the turkey hen will have a week in which to settle down on the nest and get ready for the poults.

As soon as the turkey shows signs of broodiness she is carefully removed at night to a nest that has been prepared for her in a barrel. The barrel may be laid on its side and fastened firmly in place or stood on end, with an opening cut in the side for the bird to go in and out. Whichever way you use it, the main thing is to make the nest dark by covering 
the opening, for a turkey is not trained to sit quite as easily as a hen and must have a dark, quiet place. China eggs are put under the turkey, and after a day or so she is allowed to come off and eat.

When the poults have hatched and are dried off, two or three are put under her at night, or she may be given part of the eggs to hatch. She will usually take all the poults and mother them without further trouble. The turkey hen, as well as the chicken hen, should be thoroughly dusted with lice powder so that there may be no lice when the poults are hatched.

Some breeders allow the turkey to hatch her last clutch of eggs; others prefer to have all incubation done by chicken hens. A turkey can cover from sixteen to eighteen eggs, a hen from eight to ten. Turkey eggs hatch as well in incubators as they do under hens, but raising poults in brooders is rarely a success. When the incubator is used for hatching, either turkey or chicken hens should be used for mothers.

All my hatching and raising of turkeys has been done with chicken hens, and I have found them entirely satisfactory as mothers if they are managed a little. A hen cannot be allowed to run at large with poults, for she will drag them out in the wet grass in the early morning and very likely forget, in her zeal for finding the early worm, that her charges need hovering; neither can she be allowed to feed them, for she will feed them to death; but it is not necessary to permit her to do these things and she is otherwise an excellent and devoted mother. A Buff Orpington hen of mine last spring hatched and raised ten turks from ten eggs; even a turkey mother could have done no better.

In dry weather it is sometimes best to sprinkle the eggs with warm water once or twice the last 
week, but this does not always improve the hatch and should be done with judgment, if at all. It is safer, I think, to use no moisture unless the weather is exceedingly dry or the eggs are slow in pipping; and then, if it seems necessary, to immerse the eggs, two or three at a time, in a pail of water which has been warmed to 100 degrees.

Nests for turkey hens are made about as for chicken hens, except that they are wide and shallow, about the size of a wash-bowl, but not so deep. A piece of grass sod turned upside down and hollowed out is the best nest.

Turkey eggs should be collected daily and kept in a place with a temperature of from 50 to 60 degrees. If they are kept long they should be turned occasionally. When the eggs are removed from the nest china eggs should be left in their place, for turkeys do not like an empty nest.

\section{FEEDING AND CARE OF THE POULTS}

It is in rearing the young that most of the losses in turkey culture occur. After the age of three months a turkey is as easily cared for as a chicken, much more easily if it has proper range, and almost as hardy.

Leave the poults quiet in the nest for 48 hours after they are hatched. If the hen will eat she may be given a little wheat out of the hand, but my experience is that a good mother is rarely willing to eat unless she can feed her babies. At the end of the 48 hours, or sooner if they seem very lively, transfer hen and poults to an open front coop with a wire run. Fasten the hen into the coop by means of slats or wire and let the poults go in and out as they please. If you have a small, clean pen where they are protected from the wind this will be better than 
the coop and run the first week. Let the hen move about with the poults while the sun is warm, but confine her in the coop till the sun is out in the morning and after three in the afternoon.

The brooding of poults differs from that of chicks in but two particulars: The poults must not be confined except for the first day or two, perhaps, and they need rather more hovering than chicks. It is on account of these two peculiarities that artificial brooding of turkeys is so difficult.

The first meal of the baby turkeys consists of grit, charcoal and fresh water. The grit is to furnish grinding material for the second meal; the charcoal to keep the digestion in order.

What is the best "first feed" for baby turks? If one may judge by the published opinion of breeders east and west, there is none. But there is a distinct majority in favor of stale bread soaked in sweet milk and squeezed as dry as possible, with a little black pepper or charcoal, or both, added. Some give cottage cheese mixed with stale bread crumbs and chopped onion tops or dandelion leaves. Others still adhere to the time-honored boiled egg and bread crumb formula, but always with a little green added. One of the most successful breeders gives cottage cheese and onion tops with a sprinkling of black pepper and recommends mixing in a raw egg from the first when it can be had. My own experience is that hard-boiled egg is fatal and cottage cheese absolutely essential the first three weeks, but some condemn both egg and curd and give nothing but fine grains, chick feed in which there is but little corn, and steel cut oats.

I was very successful this year with the following mixture: Chop fine a young onion, a little tender lettuce and a small piece of very stale cracked wheat 
bread. To a teaspoon of this mixture add a teaspoon of cottage cheese, a little black pepper and a sprinkling of fine chick grit. After a day or two I began adding a little steel-cut oats or cracked wheat. I fed only a teaspoon of this at first to ten turkeys and the hen, but the hen got very little for the turkeys were so ravenous. Most breeders say three times a day is often enough to feed, but my poults were so very hungry I felt obliged to feed five times a day, and the meal was soon increased to two teaspoons.

The hen is always a problem in feeding poults, for she will not eat unless she can feed them, but I let her manage the first week on what her starving babies would let her have, and she did not suffer. A good fat hen does not mind fasting while she is caring for her brood.

After ten days I reduced the number of meals to three but gave a head of lettuce once a day between meals. I gradually added more oats, either steelcut or rolled, leaving off the bread, but they had the cottage cheese once a day until they were five weeks old, and always, at least once a day, chopped onion or onion tops. Onion seems to be the one thing which is absolutely necessary to a young turkey's welfare, for its liver is its weak point and must always be considered.

When they were two or three weeks old I began adding a little whole wheat to the ration and I always put grit in the food at least once a day. As they grew older and were able to pick up more of their living I worked them onto a diet of chopped onions with dry bran or shorts for breakfast, whole wheat or wheat and rolled oats for supper and a little green at noon. I think shorts is rather better than bran, for bran is laxative. Occasionally I mixed 
in a little ground bone to help them make frame or gave a meal of chopped liver mixed with rolled oats and chopped onion, but I am not sure that this was any improvement. The main thing in feeding young turkeys, I am satisfied, is, not what you feed them (providing always they get onion), but how much, and next year I shall feed less than I did this year. Turkeys that have ample range need very, very little.

Whatever is or is not fed, it is safest not to feed corn in any form until the poults are at least three months old. In the Middle West many breeders do use it successfully, but in this climate turkeys cannot stand it and it is not so cheap that there is any object to be gained by using it. I feed a little kafir corn just for variety after the poults are three months old, but it seems to be best not to feed Indian corn till about a month before Thanksgiving.

\section{COOPS}

Any open front coop that would be suitable for a hen and her chicks will do for young turkeys, only it must be high enough for the hen to stand up in and move about comfortably. I have found a dry goods box about three feet deep, three feet high and three feet wide a good brood coop for both chicks and turkeys. To the front of this I attach a wire run three feet wide and six feet long. At first the hen is kept in the wooden coop and the young ones are not allowed outside the wire run, but after a few days, depending on the weather, the hen is confined only by the wire run and the turks have their liberty. When the mother is a turkey hen, it seems wise to let her go where she will after three or four weeks, but a chicken hen is a better mother if she is confined.

The coop should be moved to clean ground every 
day, for turkeys are more sensitive to filth than chicks, and the wood coop should be hosed or sprayed with disinfectant, and supplied with clean litter very often. All coops for poults should have board floors, and an oilcloth cover for the wire run should be ready for rainy days or foggy mornings. In really rainy weather it is better to move the coop under a roof, if possible, and keep the poults indoors till the sun shines, for damp weather is very hard on them.

As the poults grow older they can stand more dampness, but they should be kept out of the wet grass till they are several weeks old. If the hen is confined the poults may go far enough to wet their feet a little, but they will always come back to be warmed, and the hen will be ready to warm them.

When the poults are old enough to roost, at five or six weeks, it is a good plan to provide a coop with low roosts. Cover the ground under the roosts with clean straw or leaves and let the poults cuddle on the floor or roost as they please. They will soon learn to roost and then they will look for a higher perch on fence or tree-limb.

\section{GRIT AND CHARCOAL}

Sharp grit and powdered charcoal are both very necessary to a young turkey's diet. Grit should always be within reach, and it is a good plan to add it to the chopped feed the first few weeks to make sure that they get enough. Charcoal is a preventive of diarrhea and indigestion.

\section{LICE}

Next to overfeeding, lice are probably the most potent cause of untimely death in young turkeys. One reason for this is that it is hard to see the lice on turkeys for they hide among the quills of the 
wing feathers. Another is that lice powder is sometimes weak and though the poults may have been well powdered they still have lice.

Any hen that hatches turkeys should be well powdered with a good strong louse powder when the eggs are given her and just before they are due to hatch and once between. For the young poults I prefer buhach insect powder. Dust them till they look yellow all over, and dust regularly once a week whether you think they need it or not. When you look for lice raise the short feathers on the shoulders directly over the large quills, spread the wing and examine carefully the outside of the wing. This is where the lice like to hide. You will rarely find them under the wing.

A little olive oil or vaseline on the lice, if you see them, will kill them instantly. Never use kerosene on turkeys. A little tincture of iodine applied with a feather to head, wing feathers and the fluff about the vent is said to be an absolute preventive of lice.

\section{FATTENING TURKEYS}

It is another evidence of the wild nature of turkeys that they cannot be fattened by confining them as chickens can. When they are shut up they lose their appetite and eat little if anything. When it is time to fatten them, some time in October, put them on a diet of whole corn and they will quickly put on flesh. Old corn should always be used for new corn often causes diarrhea.

Turkeys should always be kept away from chickens, partly because they need a different diet, partly because they are so much more susceptible to filth diseases.

VARIETIES AND STANDARD WEIGHTS

The American Standard of Perfection recognizes 
seven varieties of turkeys: Bronze, Black, White Holland, Narragansett, Buff, Bourbon Red and Slate. Only three of these, the Bronze, White Holland and Bourbon Red, are bred in California to any extent.

The Mammoth Bronze has long been the most popular variety. Standard weights are as follows:

Lbs.

Lbs.

Adult cock ....... 36 Cockerel ....... 25

Yearling cock ..... 33 Hen ..........20

Pullet .......... 16

The White Holland was originally a sport from the Bronze. It is much liked by persons who prefer a smaller bird than the Bronze, and is called "the stay-at-home turkey," because it is less inclined to roam than other varieties. Standard weights are:

Lbs.

Lbs.

Adult cock ....... 28 Hen .......... 18

Cockerel ........ 20 Pullet .......... 14

The White Holland is particularly suitable for a market bird because of its smaller size as compared to the Bronze, but it is being bred larger, cocks weighing 40 pounds being found in many breeding yards.

The Bourbon Red turkey has more wild blood than the other varieties mentioned, being a descendant of the wild yellow turkey. Its friends claim that it is hardier than other varieties, and its smaller size makes it a little more suitable for a market fowl than the Bronze. Standard weights are :

Lbs.

Lbs.

Cock ......... 30 Hen .......... 18

Cockerel ........ 22 Pullet......... 14 


\section{DISEASES}

Turkeys are subject to all diseases that affect chickens, but their weak point is their liver. When a turkey seems dull and sluggish, inclined to stand or sit with drooping wings, and refuses to eat, look first for lice. If none are found, diagnose a disturbed liver. There is usually more or less diarrhea in these cases, so the diarrhea is the thing to remedy first. Boiled rice is said to be an excellent remedy and a diet of chopped onion and lettuce for a few days is very beneficial, if the bird can be induced to eat, but loss of appetite is usually the first symptom of illness so there must be a little doctoring.

Probably there is nothing better than quinine in these cases. I must confess I have not found it much help, but it is generally recommended. Give the sick bird first either a liver pill or a calomel pill containing one-tenth grain, once a day for three days and follow with a quinine pill once a day till the bird is cured.

A simple remedy which is said to be a sure cure for diarrhea is a red pepper pill which is made as follows: One tablespoon of red pepper mixed with two tablespoons of wheat middlings; moisten with water, cut into from four to six parts, roll each part into pill shape and bake hard in the oven. Give one pill three times a day till the droppings are improved, then give castor oil, a tablespoon to an adult bird or one-half tablespoon to a poult.

Another disease to which turkeys are subject is known as pendulous crop. The crop becomes greatly enlarged so that it sometimes interferes with walking, and is filled with a dark liquid. An eastern breeder recommends baking powder, a teaspoon for an adult bird, for this trouble, but I have heard 
of a Southern California man who cured it by bandaging the crop.

In general the diseases of turkeys are the same as those of chickens and are cured by the same remedies, but if turkeys have range and sleep in the open, are kept free from lice and not overfed, they will be little troubled by disease.

\section{THE CRITICAL TIME}

It is often said that a poult a month old is as good as raised, and this is probably true if it has not been overfed during this month, but a turkey that has been overfed will often not show the effect of overfeeding till it is about two months old, when it will droop and die of liver trouble. Just about the time they begin to show the red is another critical time, and the poults should be given plenty of meat and green food till it is passed."

Many breeders pull out or cut off the flight feathers of the wings when the poults are a week old. They are said to be much stronger and to grow much faster when they have not the weight of the wings to carry. Probably it is with poults as with Leghorns and other Mediterraneans, the strength of the body seems to go into the wings and cutting them gives the body a better chance.

\section{RULES FOR TURKEY RAISING}

The essentials for success in raising turkeys may be summed up in these eight rules:

1. Don't overfeed.

2. Keep them free from lice.

3. Avoid dampness.

4. Keep coops on clean ground.

5. Give free range after the first month and plenty of room always. 


\section{2}

6. Use turkey hens for mothers if possible.

7. Feed some green at every meal at first, and onions or onion tops at least once a day.

8. Avoid corn the first three months. 



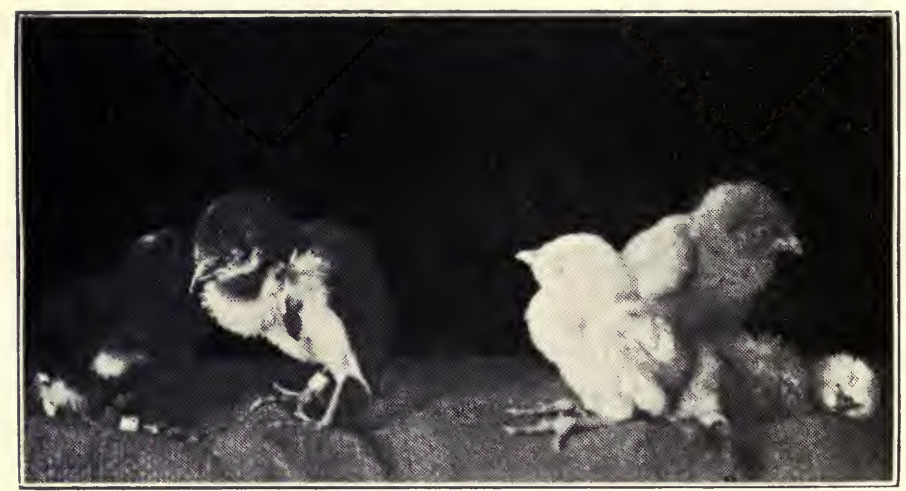

FIG. 40-WHITE DIARRHEA CHICKS. ONE SECH MAY INFECT THE ENTIRE BROOD

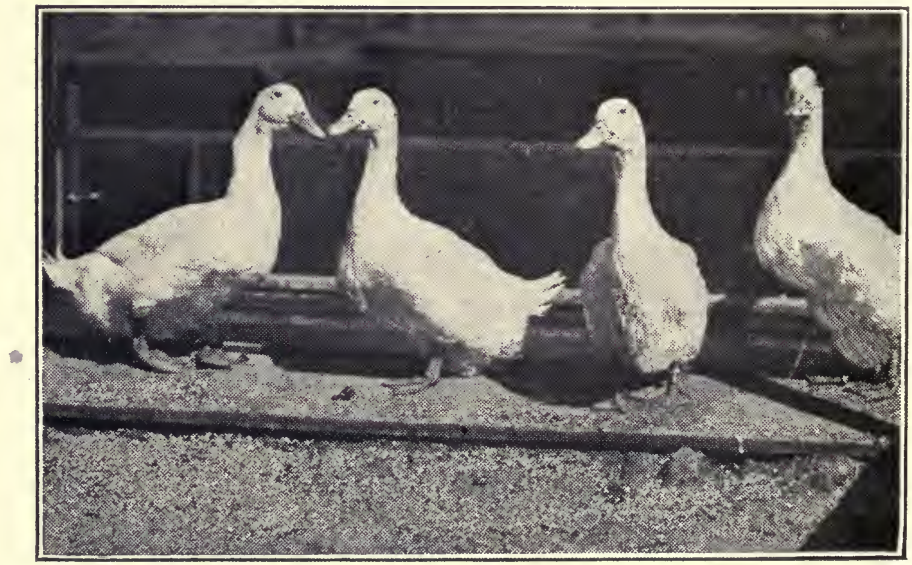

FIG. 41-AYLESBURY DUCKS 


\section{CHAPTER XII}

\section{Ducks and Geese}

\section{DUCKS}

Ducks of the improved races, as they are now found on American farms and poultry plants, are of three general types: the meat type, the laying type and the ornamental type.

To the meat type belong the Rouen, Aylesbury, Cayuga, Blue Swedish, Blue Termonde, Pekin, Muscovy and Buff Orpington; to the laying type, the Indian Runner; to the ornamental, the Crested White duck, Gray and White Call ducks and Black East India ducks. The Mallard, or common wild duck, is the common ancestor of all these except the Muscovy, and is frequently captured and bred in domestication where its size becomes so increased after a few generations that it greatly resembles a small specimen of the Rouen duck.

\section{Meat Types.}

Only four varieties of ducks of the meat type are bred to any extent in California-the Aylesbury, the Muscovy, the Buff Orpington and the Pekin. The Muscovy is kept mainly as a fancy duck and the Buff Orpington, though an excellent market duck, cannot be considered a rival of the Pekin, which is the one duck extensively bred on commercial plants.

The Pekin duck was brought to England from China in 1874 and to America the next year. It is the common duck of China and was from the first 
very large and very hardy. These qualities, together with its rapid growth, have commended it to breeders, and it has grown in popularity till it has come to be known as the one commercial market duck. On the large duck plants of Long Island and Pennsylvania these ducks are grown by the thousand for marketing as "green ducks" at from ten to twelve weeks of age, when they weigh from six to nine pounds apiece.

\section{Rankin Methods.}

James Rankin, a Massachusetts man, has been called the "Father of the Pekin Duck Industry in America," and his methods are still the standard for Pekin duck raising. Mr. Rankin gave his ducks no water except for drinking. The breeding houses were divided into pens, in each of which 25 birds were kept. Early in the season five ducks were allowed to one drake, but later on six or eight ducks to one drake.

When the breeders were selected from among the young ducks at the age of ten weeks, they were turned out to pasture in flocks of 200 each, for range is considered very necessary to the health and development of breeding ducks. Here they were fed twice a day all they would eat of the following mash mixture:

Three parts, by measure, heavy wheat bran; one part low grade flour; one part cornmeal; 5 per cent beef scrap; 3 per cent fine grit; all the green feed they will eat in the shape of corn fodder, clover, alfalfa, oat fodder or green rye, cut fine.

After they are brought into the breeding pens in the fall they are given, morning and night, the following mash:

Equal parts, by measure, wheat bran and corn- 
meal; 10 per cent beef scrap; 20 per cent low grade flour; 10 per cent boiled turnips; mangel beets or potatoes; 15 per cent clover, alfalfa, green rye or refuse cabbage, cut fine; 3 per cent grit. At noon they get a light feed of corn and oats. Clean grit and oyster shell always before the birds in boxes. Mash never cooked, and always mixed with cold water.

The houses are kept clean and well aired and the bedding frequently changed. Lighted lanterns kept in the yards at night to keep the ducklings quiet.

\section{The Indian Runner.}

The Indian Runner duck is the laying duck, and so famous has it become for the number of its eggs that it is often called "the Leghorn of the duck family." It is doubtful whether there is foundation for all the reports of phenomenal laying on the part of Runners, but they are undoubtedly as good layers as the average of hens, and probably better. The eggs usually bring a somewhat higher price, being large and absolutely free from tubercular taint.

There are two colors of Runners, the fawn and white, which is the standard color, and the pure white, which is much less common, but is now a recognized variety. These ducks have been supposed to be natives of India, hence the name, but Robinson says there is little doubt that they were imported from the Netherlands. They are much more erect in carriage than the Pekin and much smaller, standard weights being: drake, four and one-half pounds; duck, four pounds. The body is long and narrow, the breast well developed. The fawn and white or (sometimes) gray and white variety is colored in a peculiar pattern, the dark color occurring in patches on the crown and cheeks and on the back, breast and fore part of the body 
like a jacket. Runner ducklings make very good broilers, dressing very plump and meaty at from two and one-half to three pounds each at six weeks of age.

\section{Raising Baby Ducks.}

Ducklings are far more easily raised than chicks. They require less heat and less hovering, are not troubled by lice nor subject to the diseases which beset chicks, and with just a little attention and heat will raise themselves. Many persons raise them in small numbers with hen mothers, but they are liable to be trampled to death by hens and do so well in fireless brooders that it is not at all necessary to use hens or heated brooders unless the weather is cold.

The ducklings should be left in the nest two days after they are hatched. They will not eat if they are offered food and they require warmth and quiet these two days. When they begin to try to climb out of the nest, about the morning of the third day, they may be taken from the hen and placed in a fireless brooder in a coop similar to that used for hen and chicks, with a wire run in front. When they are two weeks old they may be given range or put in a larger pen.

The first few days they can be let out in the middle of the day, but should be put back in the brooder as it begins to grow cool toward night. A friend of mine who is very successful with Indian Runners gives them at first a "jug-mother." This is a jug of hot water, wrapped in flannel, which stands in their coop or in the run in front of it where the ducklings can easily run to it if they feel chilly, and they soon learn where to go to warm up. At night this is placed in their brooder box 
and covered with a blanket so that they may cuddle about it. After a week or so, depending on the weather, the "jug mother" is dispensed with.

There is no better "first feed" for ducklings than dry bread moistened with fresh milk and squeezed dry, with a small amount of clean sand added. Bread crumbs and rolled oats mixed, half and half, and moistened with milk, is also good. Some breeders use a still more complex ration at first, adding hard-boiled egg to the rolled oats and bread. Whatever feed is used, clean, sharp sand should always be part of it.

Drinking water should be given warm the first ten days. Use a fountain such as is used for chicks, and remove after each meal, for the ducks should not be allowed to play in it or to get themselves wet. Drinking cold water or chilling the body by wetting the down sometimes causes cramps and brings the little life to a speedy end.

If ducklings are to be brought to maturity with the greatest possible speed their rations must be carefully graduated, the mash being made richer as fast as they can bear it. The following is Mr. Rankin's method of feeding young Pekins:

First four days: Four parts wheat bran; one part cornmeal; one part low grade flour; 5 per cent fine grit. Feed four times a day.

Four days to four weeks: Four parts wheat bran (by measure); one part cornmeal; one part low grade flour; 3 per cent fine grit; 5 per cent fine ground beef scrap (soaked first by scalding). Feed four times a day. Finely cut green clover, rye or cabbage fed freely.

Four to six weeks: Three parts, by measure, wheat bran; one part cornmeal; one part low grade flour; 3 per cent fine grit; 5 pèr cent beef scrap; 
one per cent fine oyster shell; a liberal supply of green feed mixed in the mash. Feed four times a day.

Six to eight weeks: The following, three times a day: Equal parts wheat bran, cornmeal and 15 per cent low grade flour; 10 per cent beef scrap, 10 per cent green food and 3 per cent grit. Keep oyster shell before them. Feed three times a day.

Eight weeks till finish: One-half cornmeal; equal parts bran and low grade flour; 10 per cent beef scrap; 3 per cent grit. Oyster shell is kept before them and green feed given less freely till within ten days or two weeks of market time, and then omitted altogether. All mashes are made dry and crumbly, never gummy or pasty.

\section{Moist Mash Best.}

Ducks of all ages thrive best on soft food. Cracked corn and sometimes a little wheat may be fed, but only in limited quantities. When a moist mash is given morning and night cracked corn may be fed at noon.

After ducklings are two or three weeks old any good mash mixture may be given such as the Maine or the Cornell mash, care being taken to watch the amount of beef scrap and regulate it according to the condition of the bowels. Ducklings are rather more easily affected by too laxative food than chicks, and whenever the bowels seem too loose the amount of beef scrap should be cut down.

Runner ducklings do not need as forcing a ration as those given to Pekins. Some breeders give them after the first month a mash composed almost entirely of bran with a little beef scrap added, and cracked corn at noon, with plenty of green food either in the mash or between meals. 
Sand or grit should be part of every meal. The duck has no crop and hence is unable to grind its food without plenty of grinding material.

After ducks are a month old they may have a vessel of water large enough to dip their heads in, but they do not need to swim. Water for their heads keeps their eyes clean and their heads from becoming infested with vermin.

Green feed is a very important part of a duck's ration after the first two weeks. It is easy to see why this should be so, for the duck as found wild, inhabits low, marshy ground where there is a great deal of tender green growth. For the same reason animal food is necessary to take the place of the bugs and grubs a duck would find in its natural habitat. With feed at its present prices it is a question whether there is much profit in raising market ducks in confinement when all feed must be purchased, but when they can be given a moist, marshy range and forage for part of their living they ought to be fairly profitable. Indian Runners, being egg producers and smaller eaters than Pekins, ought to be more profitable.

\section{Hatching Duck Eggs.}

On all the large duck plants the eggs are hatched in incubators, and they hatch very well in this way, only needing a little more moisture than hens' eggs and a little lower temperature.

Mr. Rankin's method of running the incubator is as follows:

"The temperature of the egg chamber is maintained at 102 degrees with a thermometer on a live egg until the animal heat begins to get well established, which is about the fifteenth or sixteenth day, when the heat is allowed to go to 103 degrees, at 
which point the temperature is maintained throughout the balance of the hatch. Readjustment of the regulating device is frequently necessary when running a machine filled with strongly fertile eggs, as there is always a tendency to a rise of temperature, and this is considered a good sign.

"The duck eggs are tested out after they have been incubated about seventy hours and all the clear eggs are sent to market. They are not in the least injured for culinary purposes and will boil perfectly, which is considered one of the best tests of a fresh egg. In keeping qualities these tested out infertile eggs are superior to all others, as they will keep in perfect condition for months if kept in a cold dry place.

"A second test is always made on the tenth or twelfth day and all eggs missed at first test, or those in which the germs have died, are removed. A final test is made on or about the twenty-fourth day. Whenever a dead egg becomes putrid it is smelled out and removed. These can often be detected by color or marbled appearance of the shell.

"The wire cloth of the egg trays is covered with or replaced by burlap, which is less liable to injure eggs and makes turning easier, as the eggs do not roll about on it as they do on wire. Moisture is used in the machines from the eighteenth day and is considered a necessity in incubating duck eggs. The usual method is to sprinkle the burlap and the eggs thoroughly with water at about the temperature of the eggs, the object being to saturate the air of the egg chamber with moisture.

On the twenty-sixth day the eggs and trays are made quite wet with moderately warm water and the machine closed to remain so till the hatch is over. The ducklings are usually all out on the twenty- 
seventh day and are removed to brooders on the twenty-eighth."

When duck eggs are hatched under hens they should be moistened occasionally after the first week by sprinkling them with warm water while the hen is off. Some breeders sprinkle them as often as every other day after the first week, some only occasionally, and a few not at all. Much depends on the weather, but in this dry climate some moisture is a necessity. Twenty-eight days is the time required for incubation of most duck eggs as well as for those of turkeys and geese. Muscovy duck eggs require five weeks.

\section{Diseases.}

The pleasantest thing about duck culture is that the duck is not liable to disease as chickens are. To be sure, a duck that is deprived of its natural ration, sand, green stuff and animal food, will sooner or later suffer from indigestion, and perhaps die, but a duck that receives reasonable care is pretty sure to be a well duck. Roup, colds, tuberculosis and all the long list of chicken ills are practically unknown. When a duck is "off feed," in nine cases out of ten the trouble may be traced directly to improper feeding. Bedding and coops and runs should be kept reasonably clean, but the duck is not so easily affected by lapses in sanitation as other kinds of poultry and will stand a great deal of abuse.

In practically all duck disorders it is safe to prescribe more green feed, more exercise and less hard grain. All green feed except lettuce should be cut fine.

Sometimes a too liberal use of beef scrap causes bowel trouble. This should be guarded against by watching and cutting out part of the beef scrap if it seems necessary. 
Salt is quite poisonous to ducks and should never be put in their feed or left where they can reach it. Severe.cases of poisoning among ducks have been caused by their getting at pickle brine or salt from ice cream freezers which had been carelessly thrown out.

Leg weakness is sometimes caused in young ducks which are being forced for market by heavy feeding and too close confinement. It is better that all ducklings should have some range. When they cannot be given range regularly, let them out often enough to keep their leg muscles strong or give them a pen in which there is room to run. Exercise is absolutely necessary for breeders. Dampness in the sleeping quarters is also a cause of stiffness and weakness in the legs.

Shade is even more necessary to ducks and ducklings than to hens and chicks. Instances are on record where ducks have died of sunstroke when they were carelessly left without shade in hot weather. A burlap sack spread over their coop is sufficient, but some protection from the sun they must have.

\section{GEESE}

There are seven standard varieties of geese: Gray Toulouse, White Embden, Gray African, Brown Chinese, White Chinese, Gray Wild and Colored Egyptian.

Geese are not extensively raised in California, probably because there is too little damp ground and natural pasture to make them profitable. On farms in the river bottoms they might well be raised to a greater extent than they are, for they will forage for most of their living where they have a chance and are very easily raised.

Geese are long-lived birds, some having been 
known to attain the age of forty years, while they frequently reach fifteen and twenty years. On this account it pays to secure good stock at the start. Geese are valuable as breeders as long as they live, but ganders should not be kept for breeding after three years of age.

\section{Mating and Hatching}

Geese are usually mated in trios or pairs. Breeding stock should be two years old and fully matured. The stock should be purchased in the fall so that the birds may become accustomed to their new surroundings before the breeding season begins, and should be turned out to pasture until it is nearly time for the season to begin. If they have plenty of forage they will need no other feed except perhaps a little grain. A little before they are to be bred they may be given the following ration: Equal parts by measure of bran, middlings and corn meal, with five per cent beef scrap added. They should have a ligl.t feed of this ration in the morning, with cracked corn at night. Ten per cent of the bulk of the daily ration should be green feed and cooked vegetables.

The breeding season begins about February 1, though some geese begin laying earlier. They make their own nests and will lay from twelve to twenty eggs before becoming broody. As soon as the goos= shows an inclination to sit, place her in a dark box or small coop and keep her there two or three days with water but no food. She will then begin laying again. The first and second clutches of eggs should be set under hens, but the goose should be permitted to hatch the third clutch. Goose eggs require thirty days for incubation. It is recommended that after the eggs have been sat upon for twenty-five days 
they be taken from the nest and placed for about a minute in water heated to 104 degrees.

\section{Feeding Goslings}

After the goslings hatch they are left under the hen for twenty-four hours and are then moved to a dry, comfortable coop. The following rations for goslings are recommended by prominent breeders:

(1) Two parts corn meal, 1 part shorts, 10 per cent beef scrap. Moisten with water till crumbly and feed what they will eat up clean three times a day for a month. After this grass and water is all they require.

(2) For thirty-six to forty-eight hours give nothing but grass, then feed every two to three hours 1 part corn meal, 2 parts shorts moistened and squeezed almost dry. Avoid sloppy food and feed sparingly. After a week give scalded cracked corn and a grass run.

Goslings should not be allowed to swim till fully feathered.

\section{Feeding Breeders}

The following rations are recommended for breeding stock :

(1) Morning: Shorts and corn meal, equal parts, mixed to crumbly state with 10 per cent beef scrap. Feed only what they will eat up quickly.

Afternoon: Whole grain, oats, barley and corn in small boxes. Plenty of shell and pure water and grass range.

(2) Four parts bran, 2 parts shorts, 1 part corn meal. Ground meat and cooked vegetables frequently added. This ration is dampened with skim milk or water and fed morning and evening with a little whole corn at noon in winter. Grit and shell always before them. 
Geese require but the simplest shelter and do best when given liberty to roam as they please. They are so hardy, however, that they are often raised successfully with chickens, and a few would seem to be a valuable addition to any farm flock:-

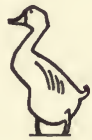





\section{In d e x}

Air Puff................195

Alfalfa ............. 80

Aspergillosis .............. 175

Balanced Ration........... 84

Beginning ............... 10

Breed, choosing........... 18 classification ........... 19

American for farm....... 20 only one.............. 22

Blue Ointment............ 149

Breeding, line............. 122 cross ................124 inbreeding ...........125

Breeding Pen...............114

Breeding Stock, buying....... 13 culling ................114 marks for vigor...........115 care and feeding..........127 exercise ................ 128

Brollers, Orpingtons.........121 ration for..............106 and fryers...............136

Bronchitis ...................

Brooders, fireless........... 71 $\operatorname{lamp} . \ldots \ldots \ldots \ldots \ldots \ldots, 72$ colony house........... 73 heated ............. 75 cold ............... 78 watch for mites............ 153

Brooding ................6. 64 warmth in ...........6. 67 crockery box for.........6. 68 artiflcial $\ldots \ldots \ldots \ldots \ldots \ldots, 71$

Bumblefoot ................

Canker ....................

Cans and Pans................

Capital, how much.......... 17

Capons .....................141

Carbohydrates .............. 82

Catarrh ..................176

Chicken Pox..............

Chicks, buying ............. 12 comfortable quarters....... 12 hatching $. . \ldots \ldots \ldots \ldots \ldots, 23$ mortality ................ hen hatched............ 46 dead in shell............ 59 marking .............62 rearing $\ldots \ldots \ldots \ldots \ldots \ldots 66.64$ warmth essential........6.64 overcrowding ..........6.65 protect from lice.........66 cats and pests.........6. 66 pure air for..........6.67 putting into coop.........6. 69 caring for brooder....... 74 jug for.............75, 166 enemies of ............. 76
Chicks, exercise for....... 79

keep growing. .......... 80

feeding ............... 90

killed by sun............

Cockerel, pens.............118

fattening ............. 137

Comb, indicates health.....172

Contagion ............... 170

Conveniences ................164

Coops, and runs..........66 box for ..............6. 68

clean often............ 70 broody $\ldots \ldots \ldots \ldots \ldots \ldots \ldots 161$

Cresol .................... 152

Crop Bound................173

Depluming Mite.............183

Diarrhea, white............ 184

Digestibility ............83

Diseases, preventing. .........142 and vices...............170 causes .................170

signs of ................... common ..............172

liver .................. of turkeys.............. of ducks............221

Dry Mash................ 104

Dry Picking...............

Ducks .......................

meat types..............

Rankin methods.........214

Indian Runner...........215

raising baby...........216

moist mash for..........218

hatching ..............219

testing eggs...........220

diseases of .............221

Dust Bath................149

Egg-maker ............ 89

Egg Eating.............. 196

Eggs, for hatching.......... 14

color ................22

production .............. 23

broken in nest..........43

composition ............ 45

selecting .............46

care of..............46

fertillty..$\ldots \ldots \ldots \ldots \ldots \ldots 47$

testing .............. 51

throw off heat......... 55

air cells.............6 60

effect of feeds on .........105

cost of dozen...........105

breeding for.............119

fall problem.............

handling ..............132

selling ..................

packing ...............134 
Eggs, improving ..........135 preserving .............135 turkey .............201, 202 hatching duck.........219 testing duck..........220

Exercise, necessity for......31, 156 for chlcks............ 79

Extensive System......... 25

Fancy Stock............ 23

Fats .................. 82

Feather Eating............ 195

Feed Troughs, keep clean.....155

Feeding, continuous........95 laying hens............96 methods of .............103 rules for..............111 regularity ..............111 punctuality .............111 variety ...............112 plenty ................112

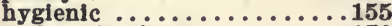
and sanitation..........170

Feeds ............... 82 animal ............8 87 green ............8. 156 condimental ........... 89 rape, best green.........146 don't buy moldy..........155

Females, number to male.....118

Fleas ..................154 stick-tights ............154

Foodstuffs, deflned.........84

Fountain, clean...........155

Fruit and Poultry.........28

Fryers .................. 136

Gapes $\ldots \ldots \ldots \ldots \ldots \ldots \ldots \ldots 187$

Garden Hose. . . . . . . . . . . 144

Geese ...................222

varieties ...............222 mating and hatching......223 feeding goslings.........224 feeding breeders.........224 allow liberty...........225

Germ, weakness..........61

Going Light............175, 181

Goslings, feeding. . . . . . . 225

Grains, list of........... 85

Grit, for chicks.........68 and shell............89

Hatching, when.......... 40 fall and winter........ 41 how $\ldots \ldots \ldots \ldots \ldots \ldots \ldots$. 42 hens $\ldots \ldots \ldots \ldots \ldots$ 44, 47, 50 incubator ............45 rules ............... 48

Health, droppings indicate....156

Hen, setting.............49 feeding .............. 52 bodily requirements of.....99 feeding molting..........109 overfat ................110 size and shape............117

Hen-Incubator ........... 50

Hoppers and Feeders........161

House, requirements. . . . . . . 28
House, colony ............ 32

long ................. 35

farm flock............ 36

Callfornia ............ 37

open front.............. 37

novel breeding.......... 38

tarred paper............. 39

clean, necessary .........143

movable fixtures..........143

clean floor............143

Incubating Coop........... 51

Incubator, operating.......5 53 suggestions for running....54 selecting $\ldots \ldots \ldots \ldots \ldots 55,56$ room ................ 56 use good oll........... 57 floor ............... 57 moisture ........... 58

Insect Pests..............

Intensive System......... 25

Kerosene \& crude carbollc...152 emulsion ..............152

Killing \& Dressing. ........... 139

Lamp, care..............76

Layer, marks.............120 old hens...............128

Leg weakness...............189

Lice .................... ointment ............149 powder ...............150 distillate ...............151 on turkeys..............207

Limberneck .............182

Lowry Powder..............150

Market Poultry..........106, 136

Marketing ...............132

Mating ...................

Meat Production........... 23

Mites ......................

Moisture, in nest......... 53 in incubator.......... 58

Molting, starving..........110 care during. ...........127

Nest, moisture.......... 53 material ...............145 good .................163

Nest Boxes.............. 49

Nutritive Ratio.......... 83 narrow .............8. 84

Oats, sprouting.......... 88

Oviduct, inflammation........191 prolapse ..............192 obstruction ..............193 rupture ..............193

Poultry Farm, locating...... 18 water ............... 14 fertile soli............ 15 transportation .......... 15 proximity to poultrymen.... 16 drainage..$\ldots \ldots \ldots \ldots \ldots 16$ exposure ............... 16 wind protection.......... 16 how much land.......... 17

Poultrymen, flve classes...... 9 Poults, protect.........198, 202 
Poults, in nest.......... 203 brooding .............204 Prepotency ...............119

Producer, rules for..........133 Profit ................. 9

Proteins .............. 82 vegetables containing..... 86

Pullets, separate......... 81 feeding on range..........108

Rations, Californla.......91, 102 Cornell ...........92, 102

Malne ............92, 100

Missouri ..........93, 100

Purdue ...........94, 99

Iowa ............. 95

things to consider.......98

sample $\ldots \ldots \ldots \ldots \ldots \ldots . . \ldots 9$

New Jersey............100

Ontarlo ................101

winter .................101

West Virginia..........102

Southern California........103

fattening ..........106, 107

Rats, protection from....... 30

Rheumatism .............182

Roasters ................139

Rooster, vigorous..........116

gallantry .............117 half the pen ............117

Roosts, movable........... 31 paint with tallow.........153 good ..................

Roup ................178

Scaly Leg...............183

Scratching Litter. . . . . . . . 80

clean .................155

Sex, determining. .........126

Shade .................146 deciduous orchard for......157

Soll, purifying............145

Sticking ...............140

Summer, caring for hens in ...157
Summer Quarters...........144

Temperature, of hen.......76

Thermometer, test........ 58

Ticks ................ 153

Tobacco Powder...........153

Toe Picking.............196

Trap-nest, usıng. .......121, 167

Oregon ..............167

homemade ............168

Trapnesting ..............119

Tuberculosis $\ldots \ldots \ldots \ldots \ldots \ldots 174$

Turkey, wild .............197

breeding stock...........199

hen and tom related......200

breeding size...........200

breeding not fat.........201

laying and hatching......201

broodiness in...........201

nests for.............203

coops for............206

grit and charcoal.......207

fattening ...........208

varieties .........208, 209

diseases $\ldots \ldots \ldots \ldots \ldots \ldots 210$

critical time............211

rules for raising........211

Vent Gleet...............194

Ventilation ..............145

Vigor, necessary...........115

cross breeding..........125

Water, fresh............ 70

clean ................155

vessels for.............160

Water-glass ............. 135

Weakness, inherent. ........170

Weather, protection from..... 29

White Diarrhea...........184

White Leghorns for Eggs..... 19

Whitewash, government......148

and carbolic............154

Worms ...............188

Wryneck ................ 182 


\section{California Cultivator}

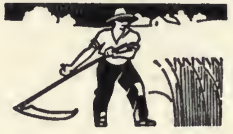

Best Farm Weekly on Pacific Coast

$\$ 1.00$ per Year

Cultivator Publishing Co.

Los Angeles

California 



THIS BOOK IS DUE ON THE LAST DATE STAMPED BELOW

\section{AN INITIAL FINE OF 25 CENTS} WILL BE ASSESSED FOR FAILURE TO RETURN THIS BOOK ON THE DATE DUE. THE PENALTY WILL INCREASE TO 50 CENTS ON THE FOURTH DAY AND TO \$1.00 ON THE SEVENTH DAY OVERDUE.

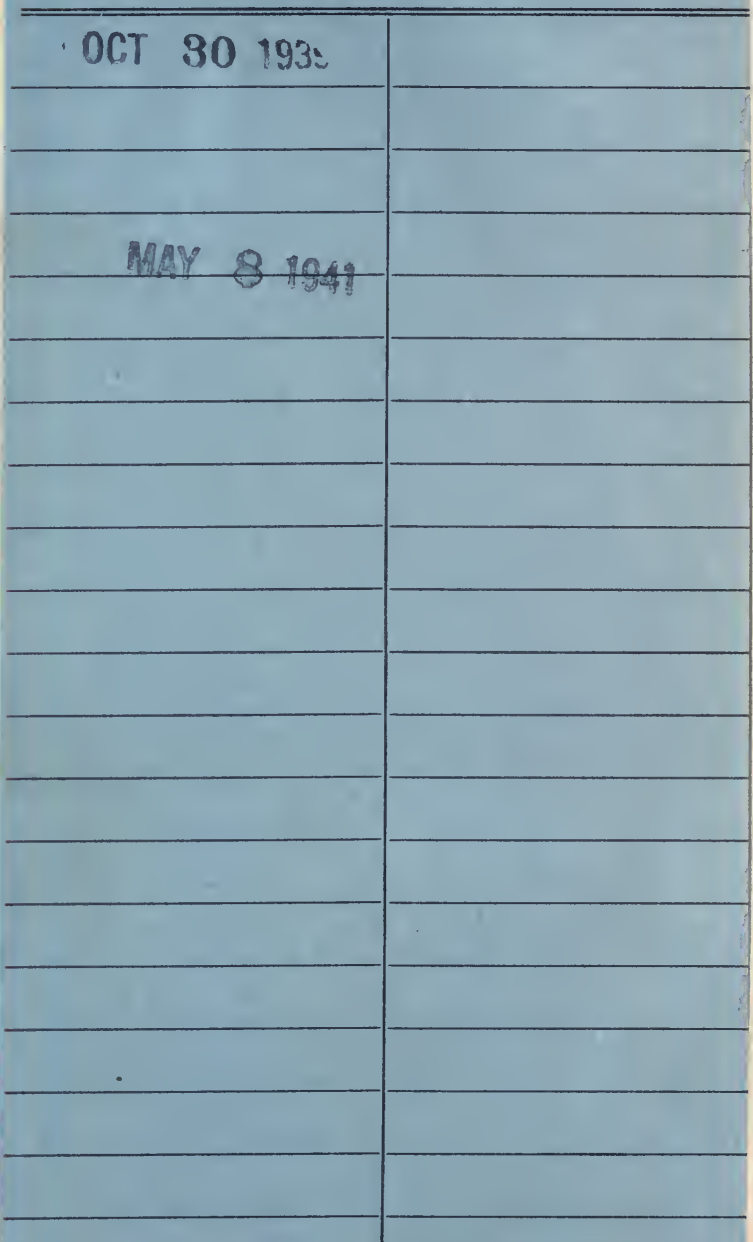

LD 21-100m-7,'39(402s) 


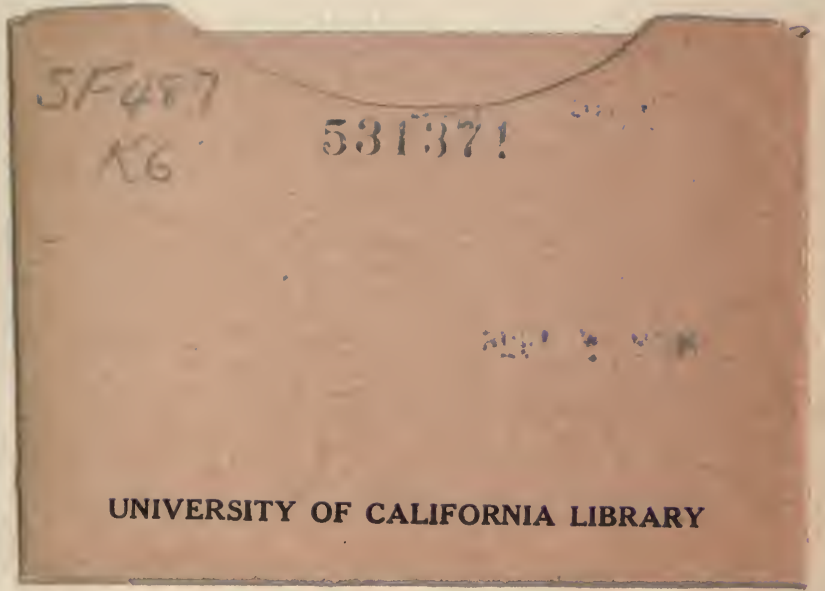


and

intis

8.

20 390

Tis

9

asis

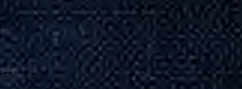

$8 \%$

-

(1)

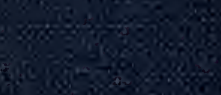

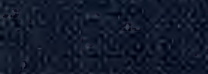

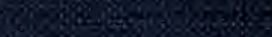

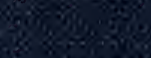

$\log _{3}$

A

cos

3.

\%.5. 